\title{
Impacts of Multiple Stressors on Dryland Vulnerability and Land Conflict Among Border Communities
}

Alvin Maingi Solomon

Follow this and additional works at: https://researchrepository.wvu.edu/etd

\section{Recommended Citation}

Solomon, Alvin Maingi, "Impacts of Multiple Stressors on Dryland Vulnerability and Land Conflict Among Border Communities" (2015). Graduate Theses, Dissertations, and Problem Reports. 6688.

https://researchrepository.wvu.edu/etd/6688

This Dissertation is protected by copyright and/or related rights. It has been brought to you by the The Research Repository @ WVU with permission from the rights-holder(s). You are free to use this Dissertation in any way that is permitted by the copyright and related rights legislation that applies to your use. For other uses you must obtain permission from the rights-holder(s) directly, unless additional rights are indicated by a Creative Commons license in the record and/ or on the work itself. This Dissertation has been accepted for inclusion in WVU Graduate Theses, Dissertations, and Problem Reports collection by an authorized administrator of The Research Repository @ WVU.

For more information, please contact researchrepository@mail.wvu.edu. 


\title{
Impacts of Multiple Stressors on Dryland Vulnerability and Land Conflict
} Among Border Communities

\author{
Alvin Maingi Solomon \\ Dissertation submitted \\ to the Eberly College of Arts and Sciences \\ at West Virginia University \\ in partial fulfillment of the requirements for the degree of \\ Doctor of Philosophy in \\ Geography
}

\author{
Committee Members: \\ Brent McCusker, Ph.D, Chair \\ Bradley Wilson, Ph.D \\ Eungul Lee, Ph.D \\ Robert Maxon, Ph.D \\ Thomas Smucker, Ph.D
}

Department of Geology and Geography

Morgantown, West Virginia

2015

Keywords: Livelihoods, Conflict, Africa, Drylands, Climate Change, Vulnerability Copyright 2015 Alvin Maingi Solomon 


\begin{abstract}
Impacts of Multiple Stressors on Dryland Vulnerability and Land Conflict on the Border Communities of Southeast Kenya
\end{abstract}

Alvin Maingi Solomon

This study examines how individuals and groups respond to prevailing politicoeconomic and biophysical changes and how the adjustments they make influence and are influenced by their social relations and material condition in spatial and temporal terms. This dissertation comprises of three parts: The first part is a critique of the climateconflict relationship debate and the problems associated with studies pushing for a causal relationship between climate variables and conflict. I argue that scholars lack of attention on varying institutional capacities and the focus solely on environmental factors as trigger mechanisms for conflict leads to misleading arguments about conflict distribution and frequency which may ultimately hinder the understanding of why conflicts occur, are exacerbated or resolved, recur or not. I find that as scholars focus on climatic variables in pursuit of narrow causations, they ignore known weaknesses in both theory and methodology. In addition, shifting from a human vulnerability approach to a human security one in climate conflict studies advances a functionalist conservative discourses that pay the most attention to securing the states of the global north and global capital circulation rather than helping vulnerable groups deal with risk and the impacts of climate change. The second part of the dissertation examines how social relations around land allocation and tenure in Africa have changed over time and how the existence of a dual system of tenure in many African countries produces a third system of informal land transfers. I argue that these often-unregulated informal transfers may help circumvent protections provided within law and policy. I find that, in Kenya as in many other parts of 
Sub-Saharan Africa, the existence of many plots of land held as freehold without title coupled with an expensive and deeply bureaucratic process of titling produces and maintains unregulated land transfers that often cement inequalities that are addressed in formal policy and law. The third part of this dissertation utilizes the concept of "ecological gradient" to examine the social benefit of material relations for different livelihood groups living along the Mt Kilimanjaro altitudinal gradient. I find evidence of increased diversification and interdependence between the different livelihoods that occupy the ecological zones along the gradient. Consequently, livelihood groups living within the various ecological gradients along the mountain gradient adjust to changing biophysical and politico-economic factors by extracting social benefits from increased contact with each other. 


\section{ACKNOWLEDGEMENTS}

I would like to extent my appreciation to my adviser, Dr. Brent McCusker, for his unwavering support throughout my doctoral study. His expertise in both the subject of my research and encouragement during times of exhaustion when the road seemed too long has kept me going. To you, Brent, I say thank you. I would also like to extent a special appreciation to my dissertation committee members for all the support during the dissertation process. The contribution of your advise and guidance to the completion of this work cannot be overstated.

This dissertation would not be complete without the people who helped me acquire the data I needed to write it. I would like to thank Dr. Thomas Smucker and the Pare-Kilimanjaro Local Knowledge and Climate Change Adaptation Project (LKCCAP) research team for allowing me access to important data for my dissertation. Special thanks also go to Mr. James Muhindi of the Kenya Meteorological Department for assistance in accessing climate station data for my research sites. I am also thankful to my research participants and guides in the Kilimanjaro region for their cooperation and hospitality. Lastly, I would like to thank everyone else that I could not list here but who nevertheless contributed to the successful completion of my dissertation. 


\section{TABLE OF CONTENTS}

CHAPTER 1: INTRODUCTION ......................................................................................

Summary of the main findings ……………………………….................................................

CHAPTER 2: ON CAUSALITY AND THE UNCERTAIN: A CRITICAL

EXAMINATION OF THE CLIMATE-CONFLICT NEXUS …………………………….......

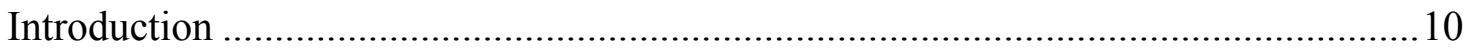

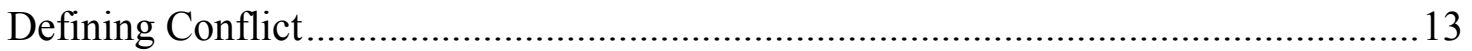

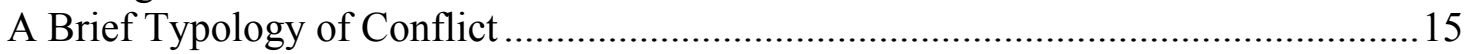

Climate threat? From vulnerability to security ……….............................................18

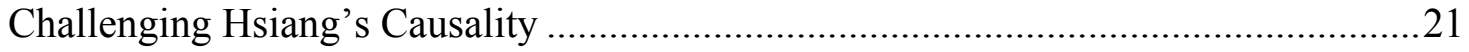

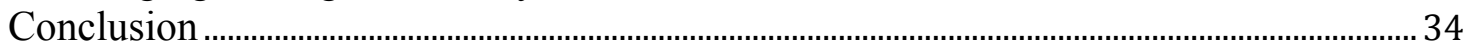

CHAPTER 3: BETWEEN THE LEGAL AND THE CUSTOMARY: INFORMAL

LAND TRANSFERS AND CONTESTED CLAIMS …………………………………….... 37

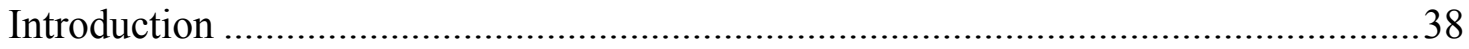

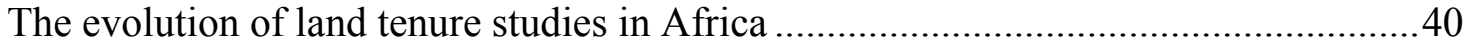

Negotiability, capital formation, and conflict.........................................................42

Informal land transfers: Private property or provisional rights? ....................................46

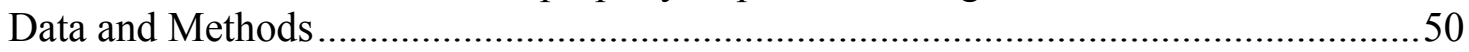

Njukini: A space of land contestation and conflict ................................................53

Locating contested lands and informal transfers ....................................................5

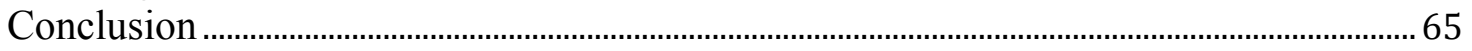

CHAPTER 4: CROSS-BORDER ALTITUDINAL GRADIENTS: DIVERSITY AND

CHANGE AMIDST MULTIPLE STRESSORS ...................................................................... 67

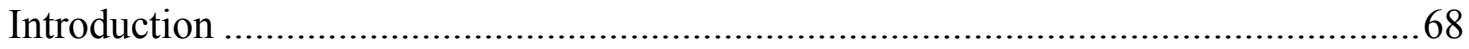

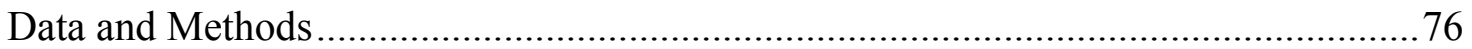

Changing Ecological and Socioeconomic Systems along the Kilimanjaro Gradient....78

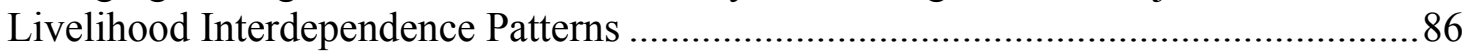

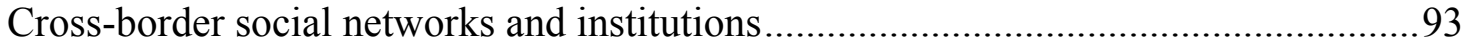

Conclusion .......................................................................................................................

CHAPTER 5: CONCLUSIONS ……………………………………………………... 99

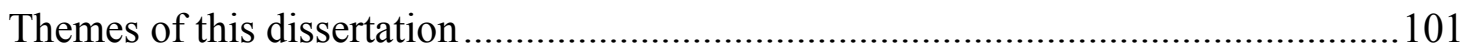

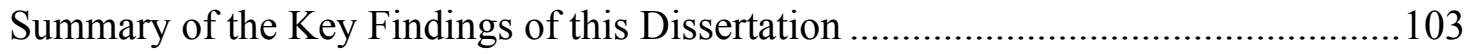

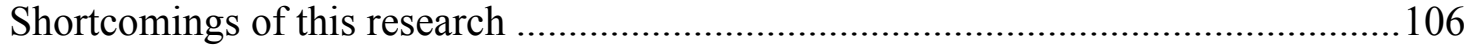

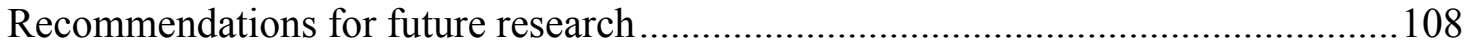

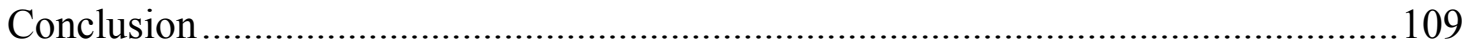

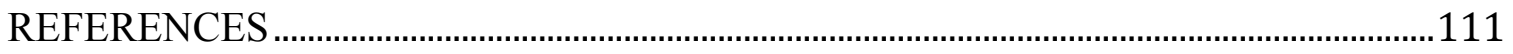




\section{LIST OF FIGURES}

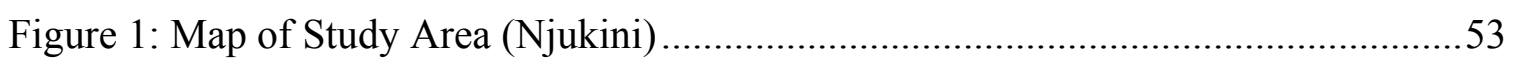

Figure 2: Annual March-May precipitation totals (Station and CRU data comparison), 1980-2009 .78

Figure 3: Study area - From the lowlands of Njukini to the high elevation Mokala.........80

Figure 4: CRU Annual March-May precipitation totals, 1980-2009 .............................82

Figure 5: CRU Annual October-December precipitation totals, 1980-2009..................83

Figure 6: Percent of residents born in village of residence ......................................... 87

Figure 7: Size of primary household plot in acres................................................. 88

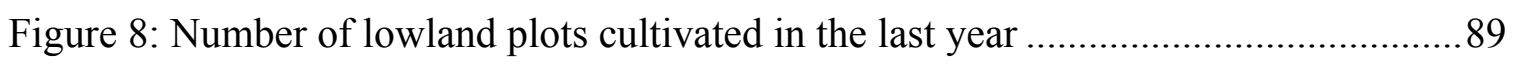

Figure 9: Primary occupation of household head..................................................... 90 


\section{LIST OF TABLES}

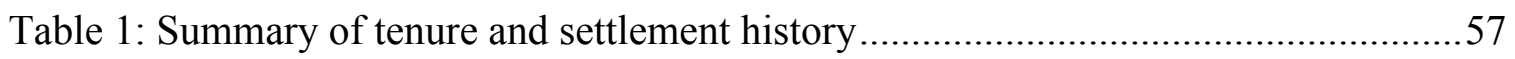

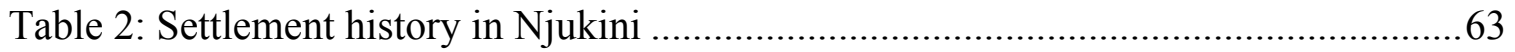

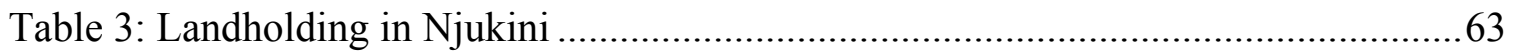

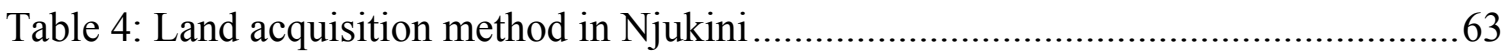




\section{CHAPTER 1: INTRODUCTION}

This dissertation is about shifting the focus from climate variables in the debate on human vulnerability and the impacts of climate variability and/or change to focus on day-to-day social relations among individuals and groups and how they respond to biophysical and economic changes in space and time. I chose to focus on social relations because the human response to climate change is only a part of broader adjustments that individuals and groups have to make in response to positive and negative changes in the environment that affect their livelihood relations in various scalar terms. Social relations encompass the confluences between people's ideas, perceptions, believes, attitudes, and values, and the forces and relations that influence their existence and drive their means of production (Jackson, 1989). A people's social relations are inextricably linked to their material experiences and are continually a space characterized by constant contestation and realignments in line with changes in the prevailing means of production.

Mainstream studies on environmental conflict have produced two bodies of thought. The first suggests a positive link between scarcity and conflict, where competition for increasingly scarce resources such as fresh water and arable land are seen as making participation in conflicts, as a way of expressing grievances, the better opportunity in a cost benefit analysis (Homer-Dixon, 1999; Kahl, 2006; Bergholt and Lujala, 2012; Hsiang et al. 2013; Ban, 2007). According to these scholars, environmental change may undermine resource availability and access patterns thereby exerting pressure on social institutions. Prominent conclusions from this body of research suggest that both delayed onset and early onset precipitation extremes have a direct influence on the level 
of risk of conflict. They also postulate an increasing risk for conflict with environmental degradation. Critics of this approach argue that focusing on the structural factors that precipitate conflict and ignoring the decisions of actors to engage in violence is problematic (Adano et al. 2012; Barnett and Adger, 2007; Peluso and Watts, 2001). Such views have also been criticized for their failure to recognize the role of conflict in creating and escalating new grievances, and the role of conflict as a major agent of poverty and vulnerability (Theisen, 2012; Salehyan, 2008; Bax, 2002). In addition Nordas and Gleditsch argue that the causal mechanisms within this approach operate within multiple pathways and have "[...] failed to account for differing levels of economic and political development on resource consumption and conflict" (2007:704).

The second body of research questions any direct connection between environmental change and natural resource conflict. It is made up of two main groups: quantitative analysis of national and sub-national climate and conflict data (Buhaug, 2010; Kalyvas, 2006; O’Loughlin, et al. 2012; Scheffran, et al. 2012a), and qualitative analysis that focuses mainly on local level power dynamics (Peluso and Watts, 2001; Basset, 1998; Turner, 2004; Theissen, 2012; Adano et al. 2012; Butler, 2012; Peters, 2013). Although these bodies of research recognize that there may be links between environmental change and natural resource conflict, they are critical of any causality or direct relationship due to the presence of many intervening variables. They concur with the argument that the risks of environmental change to social systems may be related to the changes in the environmental system but point out that the importance of the characteristics of the social systems (Barnet and Adger, 2007; Salehyan, 2008; Raleigh and Kniveton, 2012) and the motivations of actors cannot be ignored in assessing risk 
(Adano et al. 2012). For example, Hendrix and Glasser (2007) argued that environmental factors as trend and trigger measures are not associated with the onset of conflict in the absence of socioeconomic control variables while Theisen (2012) and Adano et al. (2012) found that the years of scarcity tended to be more peaceful which is opposite of what much of the literature on the effects of scarcity suggests.

The methodological approaches to environmental conflict have also been influential on the findings. For instance, much of the quantitative work on environmental conflict research relies on state-based conflict data, which has a death threshold and may limit the definition of conflict to those that involve governments (Scheffran et al. 2012b). Although more sophisticated datasets that attempt to cover local level conflicts such as the Armed Conflict Location and Events Database (ACLED) and the Social Conflict in Africa Database (SCAD) are being developed, the extent of their coverage and scope of conflict remains to be seen. In addition, this aggregate notion of covering conflicts as events misses out on the subtleties and complexity of the processes that underlie many conflicts. The nature of environmental variables used in conflict research is also important. For example, long term studies on precipitation and temperature and their impact on resource availability and access may miss proximate factors that may influence conflict (Hendrix and Glasser, 2007; Scheffran et al. 2012a; Theisen, 2012). This is because there may exist other underlying issues surrounding resource tenure and ownership that are exceptionally context dependent and not attributable to one causal mechanism.

On the other hand, qualitative studies are able to examine and disentangle the complex web of factors that underlie conflict, especially the politics of resource access 
and use. However, it has been argued that they may not be generalizable beyond the specific context of their study. Scheffran et al. (2012b:4) assert that both qualitative and quantitative approaches may not independently “[...] be robust against variation of model variables and assumptions, for instance regarding conflict type, involved parties, regional samples, and time periods." A mixed method approach may thus be more analytically sound for this type of study because of the opportunities it may provide in terms of data triangulation and explanation of the complex relationships between variables. A nuanced approach may also involve examining environmental conflict from a conflict angle rather than environmental factors or climate variables.

However, despite the availability of evidence in academic and policy debates and research about the problems associated with simplistic scarcity and causality arguments and methodological issues associated with studies on the climate-conflict relationship, such simplistic arguments continue to permeate government, military, and other policy circles. The most recent simplistic quantitative studies seem to originate from a group of scholars within the broader human security approach (Hsiang and Burke, 2014; Hsiang et al. 2013). I examine the origins of human security debates on climate and conflict and their evolution in chapter two of this dissertation and argue that a human vulnerability approach is more proactive and pro-poor in dealing with the impacts of climate change than a human security one.

In this dissertation, I take away the gaze from climatic variables as key drivers for conflict and focus primarily on conflict itself and the social relations that may or may not produce conflict. Owing to the debates discussed above and also recognizing that the issue of environmental conflict cannot be exhaustively examined in a single dissertation, 
the objectives of this dissertation are threefold: First, critically examine the climateconflict nexus question and recent debates on causality; secondly, examine land and land relations as key factors that may drive local conflicts in places dependent primarily on natural capital; and thirdly, examine the changing social relations among livelihood groups along the Mt Kilimanjaro gradient in response to ecological and politicoeconomic factors and how these changing social relations may strengthen livelihoods but also increase the risk for conflict. These objectives are achieved through three independent papers that deal with each of the objectives but generally speak to the situated nature of social relations that drive local conflicts, which are more prevalent in our world today than broader interstate conflicts. The methods and findings of the three papers are summarized below.

The first paper is a critical review of conflict studies across the disciplines and the recent push towards establishing a causal relationship between climate change and conflict. It starts by defining conflict and explaining why theoretical and methodological conflation of the concepts of violence and conflict may lead to confusion. The article then goes through important considerations in establishing a typology of conflict such as scale, duration, participants, location, and the nature of grievances. This allows me to argue for the situatedness of conflict and against broad generalizations in pursuit for narrow causal arguments. This article also traces the origins of the climate-conflict debates in both policy and academic circles from the 1980s to date. I find that earlier approaches based on human vulnerability were largely disserted for the more recent conservative functionalist human security approaches, which are based on an interpretation of climate change as not just a threat to general human security but more often the security of the 
homeland in the global north and by extension the security of global capital circulation. I then illustrate this through a critique of two prominent articles published in 2013 and 2014 in support of a causal relationship between climate change and conflict.

The second paper examines how the rapid transformation of social relations around land in Africa have led to a system of informal land transfers in some places that helps circumvent protections contained in both formal policy and customary practice. I examine three key discourses around land tenure and conflict in the developing world: the benefits of the negotiability of rights within customary tenure for certain groups, discourse on land tenure formalization and capital formation, and discourse on land conflict. I argue that the existence of dual land tenure systems in many parts of Africa produces and maintains an unregulated third system of informal land transfers that is neither purely customary nor purely in line with formal legal and policy procedures. Consequently, this system of informal land transfers disenfranchise certain groups such as women and the youth that recent policy seeks to protect and may provide avenues for local land conflicts. I utilize qualitative interviews and a quantitative survey to illustrate this situation in a case study from Njukini in Southern Kenya.

The third paper uses both quantitative and qualitative research methods to examine the patterns of livelihood diversification and the intensification of interdependence in the Mt Kilimanjaro altitudinal gradient. I use the ecological gradient as an organizing framework (see: Majule et al. 2009) to understand the social and economic relationships among the different livelihood groups living in the Kilimanjaro gradient and how these patterns have changed over time. I argue that social relations between livelihood groups along the altitudinal gradient have changed in response to 
changes in the ecological and politico-economic systems at various temporal and spatial scales. I find evidence of increased livelihood diversification and the intensification of interdependence among different livelihood groups living in different ecological zones of the gradient. I argue that this intensification of interdependence may strengthen livelihoods against multiple stressors but may also increase the risk for conflict due to increased inter-group and individual contact.

\section{Summary of the main findings}

The overarching argument for this dissertation is that the human response to climate variation and/or change cannot be isolated from people's day-to-day responses to other stressors and general variations in livelihood options. I find that the human response to climate impacts is influenced by the ability of individuals and groups to respond to other stressors and threats to their livelihoods. In addition, local capabilities to respond to multiple stressors, including climate impacts, may be influenced by changing intensity and frequency of stressors and overall changes in the broader political economy of resources access. This may also include their ability to recover from more immediate livelihood stressors such crop failure and drought, which may weaken their overall adaptive capacity. With regards to the climate-conflict relationship, I find that the causal pathways for a climate conflict relationship are too complex to be attributable to a set of climate variables without consideration of varying institutional set ups and other politicoeconomic factors. In addition, I find that negative climate impacts may bring individuals and groups together for mutual benefit from scarce resources, which further complicates the argument for causality. Other research has also shown that socioeconomic 
development may strengthen states and other institutional capacity to provide social welfare for affected groups at varying degrees.

Changing social relations of production and resource access may also influence the capability of a livelihood system to adjust and respond to stress. This is in turn influenced by changes in the prevailing mode of production and biophysical factors that may affect local and broader production systems. The second paper illustrates how changing social relations around land may strengthen access patterns and provide protections for groups that may have been disenfranchised by earlier land tenure regimes. However, I also find that changes in resource access patterns and the institutions that govern them may provide loopholes for disenfranchisement and conflict among individuals and groups. Livelihood systems may also be strengthened by mutual benefits derived from increased contact among individuals and groups living with diverse ecological zones through social relations of exchange and interdependence. In the third paper, I find that increased intergroup and individual contact provides various livelihoods with diversification options but also that increased contact may increase the risk for conflict in the absence of a capable and legitimate institutional framework to govern relations. 


\section{CHAPTER 2: ON CAUSALITY AND THE UNCERTAIN: A CRITICAL EXAMINATION OF THE CLIMATE- CONFLICT NEXUS}

Abstract

Recent critical and empirical human-environment studies indicate that climate change will result in major disruptions to both social and ecological systems. This, recent studies indicate, may increase the vulnerability of livelihoods and increase the risk of conflict. I trace the emergence of simplistic, environmentally deterministic approaches to the climate-conflict nexus to the shift from human vulnerability to human security. I then link human security debates to the security of the homeland in the global North and to global capital circulation, which seem to be facilitating the prevalence these simplistic studies. I argue that the lack of attention on varying institutional capacities while focusing solely on environmental factors as trigger mechanisms for conflict leads to misleading arguments about conflict distribution and frequency which may ultimately hinder the understanding of why conflicts occur, are exacerbated or resolved, recur or not. I rely on two recent articles to illustrate the potential pitfalls of pursuing a causal link between climate and conflict, asserting that conflict is rarely, if ever, a strategic choice in resolving issues related to resource access.

Keywords: Conflict, Security, Climate, Vulnerability, Livelihoods, Institutions.

Solomon, M. On causality and the uncertain: A critical examination of the climate conflict nexus. Human Geography. On review. 


\section{Introduction}

"[...] That spirit of cooperation needs to energize the global effort to combat climate change, a creeping national security crisis that will help shape your time in uniform, as we are called on to respond to refugee flows and natural disasters, and conflicts over water and food." (Obama, 2014)

The above quote appears on a transcript of President Obama's commencement address at West Point in May 2014. Although this statement may appear to be common sense, it represents a growing discourse in security and policy circles that frames climate change as a security issue. President Obama's comments about climate and security were politically strategic as they came a month after the release of the IPCC (2014) report that dedicated a whole chapter on the issue of the impacts of climate change on human security and only days before he launched new rules to cut carbon emissions from power plants. Central to the argument for military intervention on climate impacts is the view that climate change will be a threat multiplier in conflict environments and may be thus threat to the security of the economies and citizens of developed countries. This article is critical of this recent push to securitize climate change and is guided by the following questions: One, why are simplistic, environmentally deterministic approaches to the climate-conflict nexus so pervasive in press, policy, and academic circles? Two, what are the potential pitfalls of some recent quantitative studies that have aided the recent policy push? I argue that this interventionist debates by developed countries has the potential to divert attention from the root causes of vulnerability to climate change and conflict. In addition, the interventionist debate is in furtherance of a national security and economic policy for developed countries and is thus reactionary and paternalistic.

The linkages between climate change and conflict have received unprecedented attention from policymakers, analysts, and academics over the last decade (Nordas and 
Gleditsch, 2007; Hendrix and Glasser, 2007; Salehyan, 2008; Scheffran et al. 2012b; Adano et al. 2012; IPCC, 2014). In academic circles, there has been increased interest in the relationship between the impacts of climate change and conflict with a growing focus on the linkages of the said relationship to local and global security. Some recent studies have undertaken synthesis and re-analysis of earlier studies across broad temporal and spatial scales (Hsiang et al. 2013; Hsiang and Burke, 2014) in an attempt to find causal links between climate and conflict. Security agencies around the world have also identified environmental change and more specifically climate change as a potential threat to human security with bodies such as the United Nations Security Council identifying climate change as a critical issue for global security.

However, recent empirical and critical studies suggest that the relationship between climate and conflict is both ambivalent and inconclusive (Scheffran et al. 2012b; Butzer, 2012; Butler and Gates, 2012; Benjaminsen et al. 2012; Hendrix and Salehyan, 2012; IPCC, 2014). A comprehensive review of the most recent literature shows limited support for viewing environmental factors as key influencers of conflict trends although much of the literature supports the idea that under certain circumstances, they may increase the risk to conflict (Scheffran et al. 2012b; Bernauer et al. 2012; Gleditsch, 2012). In addition, some scholars suggest that local level conflicts are more likely to result from environmental factors than larger conflicts (Scheffran et al. 2012b). Arising from the literature is the importance of the role of institutions in conflict mediation with some pointing out that regions with good institutional conflict resolution mechanisms tend to resolve their issues peacefully (Adano et al. 2012; Butler and Gates, 2012; Theisen, 2012) while those regions where conflict is seen as a normal way of interaction 
are more likely to engage in conflict (Raleigh and Kniveton, 2012; Adano et al. 2012). However, the role of conflict in providing avenues for strengthening communities through sharing collective resources or as a source of new grievances for future conflicts is underrepresented in the literature.

This paper seeks to contribute to this debate by examining the climate conflict debate from the typology and nature of conflict, an examination of why simplistic environmentally deterministic approaches are pervasive, and illustrate that by providing a critique of two high-level journal articles published recently in the journal Science and Climatic Change. I contend that the recent empirical push to establish causality between climate and conflict using datasets of various temporal and spatial scales is simplistic and ignores known weaknesses in both data and methodology. In the next section I define the concepts "conflict" and "violence" and examine the potential theoretical and methodological confusion that may arise by conflating the two. I will follow that by establishing a brief typology of conflict and then briefly trace the evolution of the climate-conflict discourse in the last thirty years. I will then draw upon Hsiang et al. (2013) and Hsiang and Burke (2014) to illustrate the points made in section two, three, and four. I conclude by asserting that the causal structure and the outcomes of conflict are complex and asymmetrical especially in a climate change vulnerability context and they also vary in spatial and temporal terms. Moreover, the causal structure and outcome/s of any conflict are rooted in a particular context. In addition, the focus on environmental factors as trigger mechanisms for conflict leads to misleading arguments about conflict distribution and frequency, allows researchers to shift attention from differing 
institutional capacities, and ultimately hinders the understanding of why conflicts occur, are exacerbated or resolved, recur or not.

\section{Defining Conflict}

"[...] Conflict is both structured and structuring: structured because the idea of violence results from historical events, stored at the memory of past deeds, of past encounters, of past frustrations; and structuring because the idea of violence informs human actions, determines the acceptability, even the banality of violence, if not the ability to erase the scandal of its occurrence." (Dumont, 1992:277).

"Conflict" and "violence" are not synonymous. Theoretical and methodological conflation of the two ideas leads to confusion, at best. Conflict covers a wide range of social relations of real or perceived disagreement that may range from simple relations of interpersonal competition or criminality to larger scale and complex forms of domination or war (Eriksen and Lind, 2009; Fisher et al. 2000; Goodhand, 2001; Ellis and ter Haar, 2004). Violence on the other hand involves actions or structural arrangements that result in physical or nonphysical harm to individuals or groups among actors involved in a specific conflict situation (Harper et al. 2012; Fisher et al. 2000; Das et al. 2000; Riches, 1986). In essence therefore, violence is only a sub-category of the broader conceptualization of conflict. Many conflicts are resolved without turning into violence (Fisher et al. 2000; Salehyan, 2008) while others persist for generations sometimes erupting into violence but most of the time remaining subtle and in many cases only so present to the individuals or groups who experience them. From this basic approach therefore, conflict can be seen as potentially both positive and negative depending on its nature while violence is only negative. For instance, despite the death and destruction that characterized the American civil war, the end of the war saw some positive changes in 
American society such as the reunification of the states, the effective end to slavery, and industrialism boosted by wartime production.

It is important to distinguish between conflict and violence. First, although violence is one of the raw forms of conflict and therefore may be easy to track, using recorded or reported incidences of certain types of violence to show the rates and/or trends of conflict for different regions may be misleading. This is because as mentioned earlier, many conflicts do not turn into violence and the existence of institutions to deal with conflicts in certain places may serve to control the number of conflicts that turn violent. Second, many quantitative studies have relied exclusively on datasets of reported violence to make generalizations about conflict without explaining or at least acknowledging the potential conceptual issues that arise from the definitions they adopt. For instance, in places where institutions have the capacity and capability to resolve conflicts may generally be able to avoid potentially destructive violence or even tap the conflicting forces for constructive change (Fisher et al. 2000).

This paper considers conflict to be context specific and follows Peluso and Watts (2001:5) assertion that violence is a "[...] a site specific phenomenon rooted in the local histories and social relations yet connected to larger processes of material transformation and power relations." Through this approach, I avoid focusing only on violence that more often has given rise to a large discourse on human security such as been adopted by the Working Group II of the Intergovernmental Panel on Climate Change (IPCC, 2014). It also accounts for contexts where conflicts occur but are resolved, exacerbated, and recur or not in order to highlight the importance of institutional capacity in conflict mediation and resolution. This approach helps keep the focus on the critical sociopolitical relations 
that influence conflict and avoids the growing debate that blames climate for conflict (Hsiang et al. 2013; Hsiang and Burke, 2014) although, on its own, climate has no bearing on where, when, and why conflicts occur or not.

\section{A Brief Typology of Conflict}

In their much-publicized articles, Hsiang et al. (2013) and Hsiang and Burke (2014) do not provide a typology of conflict. This is not just convenient but much strategic for two important reasons: One, it allows them to avoid questions around context and combine a wide range of human interactions into one category, conflict. Secondly, it allows them to ignore the root causes of conflict popular within human vulnerability debates (Turner, 2004; Peluso and Watts, 2001; Basset, 1988) in favor of the more recent debates around human security (IPCC, 2014; Barnett and Adger, 2007), which are popular in policy circles. In the next section, I explain the difference between these two approaches to climate and conflict but first I would like to illustrate why a typology of conflict is critical in any analysis of conflict.

The classification of conflicts varies widely across academic disciplines. The Correlates of War (COW) typology, which is widely used in international politics and conflict studies, classifies conflict using the following major variables: the temporal domain, battle-related fatalities, the bulk of fighting, the outcome of fighting, the conflict initiator, conflict duration, and location (Sarkees et al. 2010). Four major types of conflict emerge from this typology: Inter-state conflicts, extra-state conflicts, intra-state conflicts, and non-state conflicts. Inter-state conflicts are defined in this typology as between territorial states, involving armed forces in both sides, and a threshold of one thousand battle-related deaths per year. Extra-systemic wars on the other hand involve a member of 
the state system battling a non-state entity. Intra-state conflicts are divided into civil wars (which involve national governments), regional internal wars (which involve sub-national governments), and communal conflicts, which do not involve any level of national government. Lastly, non-state conflicts are those that do take place within autonomous non-state territories and those that take place within two or more states but among nonstate actors (this type of conflicts may also be classified under extra-systemic conflicts).

Like many other typologies, the COW typology is not uncontroversial. This is generally because conflict is a highly political affair and interventions even more so. For instance, for a conflict to be labeled genocide in the United Nations (UN) system, it has to go through a vote in the UN Security Council (UNSC). This is of course because of the implications of such categorizing the most important being that any state within the UN system can intervene in cases of genocide. Perhaps the most controversial variable for the COW typology is the death threshold, which excludes subtle and sometimes long running conflicts that do not involve at least one thousand battle-related fatalities per year. Also, the definition of battle-related fatalities may exclude deaths related to but not directly resulting from battles between actors in any conflict.

The concept of grievance or the motivation of actors is also important in conflict analysis and especially in establishing a typology of conflict. A grievance is a real or a perceived wrong or other cause for complaint (Murshed and Tadjoeddin, 2009). Grievances cause conflicts and may be originated from one or multiple sides of any particular conflict. The nature and scale of grievances are critical in establishing the type of conflict. For example, the nature of grievances may be related to resource access that would lead to a resource conflict (Turner, 2004; Basset, 1988) while ethnic and racial 
grievances may lead to ethnic and racial conflicts respectively. However, classifying conflict from a grievance perspective is also has many challenges. This is because the grievances of the main participants of a conflict may obscure other forces that may benefit from the conflict but their interests may not necessarily align with those of the actors. For example, the many local actors in the 2007-2008 post-election violence in Kenya may have cited historical injustices around land allocation as the main grievance (CIPEV, 2008) but later studies and government commissions have showed that the violence may have been organized to keep or remove certain groups from power (Brown and Sriram, 2012; Mueller, 2011; Kagwanja, 2009; IREC, 2008) rather than resolve the said "historical injustices".

Scale gives conflict the spatial dimension. Traditional scalar containers of classifying conflict include: local, regional, national, and global. However, studies have shown that scale is much more complicated than these hierarchical and pregiven boundaries suggest (Kaplan et al. 1999; Herod and Wright, 2002; Zimmerer and Basset, 2003; Rangan and Kull, 2009). These scholars see scale as being intertwined and overlapping. According to Herod and Wright (2002), scale is socially produced as part of social praxis and therefore does not pre-exist the social actors and practices that create it. Even when scale is viewed in dual terms, as in global versus local, the two scales being compared or contrasted are seen as producing and to some extent constituting each other. Even more politically important is what gets classified as a global threat in the case of conflict versus what is considered local. This is because, according to Herod and Wright (2002:1-2), a "[...] nexus of power and space" exists behind scale and social actors may attempt "[...] to scale their own activities in ways that allow them to exercise power or 
that facilitate the denial of power to others." The classification of climate as an important global security issue thus puts the climate-conflict nexus in the center of this scalar debate.

The challenge for any analysis of conflict is thus to ensure that the variables used to classify conflict are examined in a way that helps us understand conflict without oversimplifying these same concepts in order to establish narrow conclusions. Hsiang et al. (2013), for example, adopt a broad definition of conflict that ranges from individual level aggression to national instability including civil war in an analysis and reanalysis that argues for causality between conflict and climate variables but does not consider conflict type or context. Such an approach is problematic because it does not tell us what particular role conflict plays in the context of climate change beyond narrow Malthusian assumptions of scarcity and competition. Such assertions have been discredited by recent studies that show that actors are strategic in their choices during times of scarcity and conflict does not necessarily confer any advantage in times of scarcity or even in the pursuit for redistribution (Adano et al. 2012; Theisen, 2012; Salehyan, 2008). However, attempts to establish a causal link between climate and conflict in furtherance of a human security discourse continue in conflict studies and have recently become even more pervasive.

\section{Climate threat? From vulnerability to security}

Two major works in the 1980s shaped the way geographers study the relationship between conflict and environmental change. Watts (1983) and Basset (1988) used a political ecology approach to show how local human-environment relations interacted with the broader political economy to shape resource conflicts in West Africa. These 
studies were a response to earlier Malthusian scarcity approaches that could not explain why conflicts occurred even in spaces and/or times of resource abundance and why certain groups lost rights while others gained. The 1980s was also a period of intensified debate about global warming and specifically the impacts of climate change on the environment. During this period, environmental conflict debates were dominated by studies on human vulnerability, food security, environmental degradation, and disasters.

As the debate about the impacts of climate change almost reached fever pitch in the mid 1990s, Thomas Homer-Dixon published Environmental scarcities and violent conflict (1994) which argued that resource scarcity caused by an increasing population could lead to civil wars and mass migration. In the same year Robert Kaplan published his controversial but much popular article The coming of anarchy, which followed the same line of argument as Homer-Dixon. These two works generated a lot of discussion in government and policy circles about the impacts of resource scarcity caused by climate change on not just conflict but human security. It is during this time that focus shifted from a discourse on human vulnerability to climate change to one of human security against climate change. According to the IPCC (2014:759), human security is " $[\ldots]$ a condition that exists when the vital core of human lives is protected and when people have the freedom and capacity to live with dignity."

The leap from human vulnerability to human security in the late 1990s and early 2000s saw environmental conflict debates become stretched into climate change without the existence of any scientific consensus on the link between climate and conflict (Oels, 2012). The 2000s also saw environmental NGOs, governments, and militaries begin to commission studies on the linkages between climate change and security. For example, 
the US military commissioned the Scenario Planning study by Schwartz and Randall (2003), the UK government commissioned the Stern Review (2007), and the German government commissioned the German Advisory Council on Global Change (WBGU, 2008). Interestingly, while both the UK and the US report present climate change as a threat to human security (national and international), the report from the German government rejects the human security framing and adopts a human vulnerability one that emphasizes the strengthening of livelihoods. In 2007, Political Geography published a special issue on the relationship between climate and conflict and argued that there was limited support for environmental factors as key influencers for conflict (Hendrix and Glasser, 2007; Nordas and Gleditsch, 2007; Barnett and Adger, 2007). This was one of the first attempts to link climate and conflict within academic circles. Since then, many studies have been published on the subject but no consensus has been reached to date on the relationship between climate and conflict. The IPCC also avoided using the language of human security in its 2001 and 2007 climate assessment reports. However, from 2009 the discourse of human security and causality between conflict and climate gained prominence and culminated in the IPCC (2014) report from the working group II allocating human security a whole chapter and the publication of two high level articles claiming a causal relationship between climate and conflict (Hsiang et al. 2013; Hsiang and Burke, 2014).

The concept of human security in a climate-conflict nexus implies in its framing a national security agenda. Consequently, human security debates hare framed not just around individual security but the security of the state. This framing has the implication of creating binaries between the state and a threat that is posed by not just climate change 
itself but also 'aliens' who may not be able to cope with climate impacts. This framing leads to conservative functionalist studies that attempt to model people's behavior vis-àvis their environment, which in turn leads to reactionary policy. According Oels (2012) "[...] since 9/11, human security has more often than not been redefined in terms of homeland security of the global North." By redefining human security into homeland security, governments have therefore been able to legitimize policies aimed at not just securing the state but also global capital circulation for the benefit of states especially in the global North. Oels (2012) argues that when human security is so defined, it leads to policies that are biased towards the strategic interests of the global North. Human vulnerability thus represents a more pro-poor framing than human security in a climateconflict nexus.

\section{Challenging Hsiang's Causality}

In an article published in the journal Science in the summer of 2013, Hsiang et al. (2013) claim to have found that "[...] large deviations from normal precipitation and mild temperatures systematically increase the risk of many types of conflict." These conclusions were made from a synthesis of data from 60 quantitative studies drawn from a variety of disciplines. In another article published in Climatic Change, Hsiang and Burke (2014) use the same approach, this time with 50 studies, and find support for a causal relationship between climate variables and conflict. It should be noted at this point that all these studies are based upon datasets of violence at different scales and for differing time periods and do not include any consideration for qualitative assessments of the causes of violence in these places. This section examines the approach used in these two high profile articles and argues that their theoretical and methodological perspective 
is set up to lead to the conclusions that the articles make. Given the high profile nature of these articles and the recent refocusing of conflict towards arguments relating to security, these conclusions may have substantial impacts on policy and people and thus should not go unquestioned.

Dataset Issues: The datasets and the methodological approaches used to process the data on studies about the climate-conflict nexus are critically important when said studies generate such socio-politically explosive conclusions (Scheffran et al. 2012a; Hendrix and Glasser, 2007). Some of the data variables used by Hsiang et al. (2013) and Hsiang and Burke (2014) include: violent personal crime data, violent inter-group data, rape, political inter-group violence, riots, civil war incidence and onset, political leader exit, paleoclimate reconstructions, and climatological variables such as rainfall and temperature. All these types of data and the specific datasets have weaknesses that are not explained in Hsiang et al. (2013) and Hsiang and Burke (2014) and that may lead to misleading conclusions especially if they are all combined together in one analysis. I therefore examine the potential weaknesses of the analysis of a few data types vis-à-vis climate variables in order to illustrate potential problems with Hsiang's studies.

Much of the quantitative work on the relationship between climate and conflict research relies on state-based conflict data, such as Uppsala Conflict Data Program/Peace Research Institute Oslo (UCDP/PRIO), which has death thresholds in their conflict typology. The UCDP/PRIO typology is similar to that of the COW, which is discussed, and its potential weaknesses pointed out in a different section of this paper. The UCDP/PRIO dataset, which is widely used in conflict studies, is collected mostly from newspaper and other media reports. This means that it may not include unreported 
conflicts and also more subtle and often long-running conflicts that may not be considered newsworthy. Consequently, the editors of such news media have the responsibility of picking which conflicts are newsworthy and which are not. This situation presents two major dataset and methodological issues: one, the selection of which conflicts make it to the news is based upon a market criteria intended on selling news, and two, there are serious problems of coverage because a news media outlet may only be able to report conflicts in places where it has access and therefore may not report conflicts in marginalized regions or in places with long-running conflicts which may not be considered news or newsworthy.

Another major source of data for the studies that Hsiang et al. (2013) and Hsiang and Burke (2014) rely on in their reanalysis is crime data. Crime data in these studies is based upon conflict related police reports and is often presented vis-à-vis rainfall or temperature data. Crime reports may not necessarily be evidence of an actual crime but even if researchers were to rely upon conviction data, this would introduce a much messier problem of having to deal with the process of evidence gathering and legality. Also, crime data is limited to those conflicts that are actually reported and those that qualify as crime in a particular place. This presents its challenges because crime reports depend largely upon a population's perceptions towards law enforcement and whether or not people believe that their cases will be handled fairly or not. In addition, a legalistic approach, which focuses solely on what is considered crime in a legal sense, may miss many other types of conflicts or deviance that may not necessarily be considered illegal. Furthermore, it might be difficult to classify some crimes as property crimes and therefore more related to economic shocks while others may be classified as purely 
violent. Class and spatial dynamics also come into play as certain groups and/or regions may actually exploit economic shocks for their benefit.

Economic data used in studies on the causal relationship between climate and conflict also have major limitations. Finding a direct causal relationship between conflict and climate variables is therefore misleading if it does not address the potential challenges associated with economic data and methodology that led to such a conclusion. For instance, use of economic variables, especially Gross Domestic Product (GDP), may not reflect the day-to-day livelihood dynamics for certain groups and particularly those primarily reliant on natural capital. In addition, according to Bohlken and Sergenti (2010) economic growth may be a consequence rather than a cause of violence. Economic growth may marginalize and disenfranchise certain groups and this may fuel grievances for conflict (Stiglitz et al. 2013). However, economic growth can also be achieved as a result of conflict and marginalization against certain groups and this may also result to conflict. Furthermore, economic growth may not affect the majority of the population or even the people involved in the conflicts in particular places. This raises the question of how good it is as a variable and how it is defined. If it is a matter of a simple change in the GDP, then this may at certain times mean nothing to the groups involved in conflict. Economic growth as a variable in the analysis between climate and conflict must measure the socioeconomic status for the groups involved rather than using a blanket economic measure (GDP) for the entire country or region as in several studies that Hsiang et al. (2013) utilize in their reanalysis.

Disease and epidemiology data from the Global Infectious Disease and Epidemiology Network is also used in Hsiang et al. (2013) reanalysis. This data is 
retrieved from Cervellati et al.'s (2011) article that argues “[...] disease richness is a statistically robust and quantitatively relevant determinant of civil conflicts for the period 1960-2004." However, several issues arise from the use of this dataset. First, diseases and their spread can be a consequence of civil war, social disorder or other climatic shocks such as drought which may lead to economic disruptions causing malnutrition and consequently vulnerability to infectious diseases. Removal/eviction/migration and concentration (in refugee or Internally Displaced People (IDP) camps) due to civil war or shocks related to the environment could also create conditions for spread of infectious diseases. Civil war or general state of social disorder may make it difficult to identify and treat infectious diseases allowing them easy spread. We have to ask ourselves what the direction of the relationship is, how do they influence each other, why the co-occurrence, and whether the relationship has to be causal? In addition, it is important to specify when these epidemics occur. For instance, do they occur before, during, or after the conflicts? Many large-scale conflicts are known to begin with smaller subtle conflicts that may also be potentially destabilizing and may result to the marginalization of certain individuals or groups leading to poor or no access to key medical services and other social welfare resources.

Democratization data such as the Polity IV, Archigos, World Bank Development Indicators, and GDP data from different sources including the Penn World tables is also compared with climate variables such as temperature and rainfall. Some of the studies utilized by Hsiang et al. (2013) include: Dell et al. (2012), Bruckner and Ciccone (2011), and Burke (2012). Interestingly, the findings in some of these studies are contradictory. For instance, Bruckner and Ciccone (2011) find that "[...] negative rainfall shocks are 
followed by significant improvement in democratic institutions" while Burke (2012) finds that faster economic growth may help keep political leaders in power. For Bruckner and Ciccone, negative economic shocks provide a window of opportunity for citizens to contest power leading to more democratic institutions. On the other hand, Burke claims that faster economic growth ensures support for political leaders and therefore the likelihood they will retain their positions. The implication for these two studies is that both economic growth and decline (shocks) may lead to potentially positive social change. Consequently, economic growth or decline, as set up in these studies tells us nothing about political change. Dell et al. (2012) find no relationship between precipitation and growth in both poor and rich countries but find no relationship between temperature and growth in "rich" countries. Several questions thus arise from these data: if the increase in temperature does affect economic output/growth but precipitation has no effect, does increase in temperature presume drought (decrease in precipitation or increase in evaporation)? Assuming we had an increase in both precipitation and temperature for a given period would this lead to economic decline? I also find the use of the Polity IV dataset and Archigos to quantify trends in regime change in "poor countries" while ignoring broader sociopolitical and economic changes such as neoliberal "democratization" efforts and the end of the cold war quite misleading. Hsiang et al.'s (2013) reanalysis of these datasets does not change the fact that other broader changes in global politics may have substantially influenced conflict and democratization tends in the regions in question.

Scale: Hsiang et al. (2013) and Hsiang and Burke (2014) adopt a broad approach to conflict that ranges from individual level conflict to much broader national level civil 
war. The datasets used also range from personal aggression documented in police crime records to datasets of much larger conflicts with death thresholds such as the Uppsala Conflict Data Program/Peace Research Institute Oslo (UCDP/PRIO) Armed Conflict dataset. In the UCDP/PRIO dataset, for example, the definition of a non-state conflict is "[...] the use of armed force between two organized armed groups, neither of which is the government of a state, which results in at least 25 battle-related deaths in a year." Other conflicts that may involve less than 25 battle-related deaths or deaths that may not be considered battle-related are not included in this dataset. Such deaths may include those that result from the effects of conflict on access to medical services, food, and other basic necessities. Also, other acts of violence however rampant that may not meet the requirements of this definition may not be considered non-state conflict. Generalizing conclusions from a dataset such as this and individual crime data from police reports is misleading. Wisner et al. (2004:3) remark that:

Occasionally earthquakes have killed hundreds of thousands, and very occasionally, floods, famines or epidemics have taken millions of lives at a time...many more lives are lost in violent conflict and to the preventable outcome of disease and hunger.

This assertion leads to the question of the difference between the impacts of climate or weather related hazards within a conflict situation and outside of a conflict situation. In other words: what difference does conflict make? Literature from disaster studies and political ecology suggests that conflict may exacerbate the impacts of extreme climate or weather (Wisner et al. 2004; Watts and Bohle, 1993). However, other studies suggest that conflict may be worsened by the impacts of extreme weather (Buckley et al 2010; Card and Darl, 2011; Cervellati et al. 2011). This presents both a temporal and spatial scale issue. At what time scale can we justify a causal relationship and at what scale is this 
justifiable? There is no doubt that Hsiang et al. (2014) and Hsiang and Burke (2014) downplay the issue of scale in their analysis.

Context is extremely important in conflict studies but also seems to have been completely ignored in the two studies. In their argument for the situated nature of conflict, Nordstrom and Robben (1995:4) assert that:

[...] Violence is slippery; it escapes easy definitions and enters the most fundamental features of people's lives. Violence is formative; it shapes peoples perceptions of who they are and what they are fighting for across space and time a continual dynamic that forges as well as affects identities.

Researchers must therefore ask, for example, how robust and rigorous it is to compare a bar fight or fights over the results of a football match in the United States with organized political violence with sets of grievances and demands for different groups such as in Somalia or regional conflicts such as the Arab Spring or even more recently, Ukraine? According to Salehyan (2008), violence is rarely, if ever, spontaneous but arises out of choices made by actors who often perceive available institutions as grievance channels as incapable of resolving their conflicts in a peaceful manner. He argues that conflict is not a strategic choice in dealing with scarcity because of its destructive nature and the fact that it often leaves conflict groups worse off than they begun. Also, and even more importantly, conflict is not the only option at any given time in dealing with issues of resource scarcity and redistribution. This is especially so given that conflict may not redistribute resources rather it may in certain cases form the foundation of a political intervention to redistribute or not. For instance, institutional change may be effected to redistribute resources without necessarily resulting in violence and this may be even more strategic in ensuring broader legitimacy in redistribution therefore ensuring a certain level of protection and right. 
Furthermore, Eriksen and Lind (2009) argue that, for local communities in many parts of Africa, conflict forms part of local adaptive capacity, which is related to claims of reciprocity and social networks in time of increased vulnerability. In such circumstances, conflict is a means of influencing adaptation outcomes, and is related to political, business, and law enforcement institutions in these places. On the other hand, cooperation, even within a context of deep seated conflicts and tensions, during periods of climate stress may threaten local social institutions that depend upon both conflict and conflict resolution. Both conflict and adaptation have uneven outcomes and vary in context. Perhaps researchers need to ask the question: what particular role does conflict play as a climate response strategy? With that, it is difficult to see how larger conflicts such as civil or interstate wars or even smaller interpersonal conflicts may be caused by changes in the climate.

One of the arguments in the studies relied upon in this synthesis is based on the temperature-aggression hypothesis but if indeed people are more aggressive when its too hot or too cold, do they become easier to mobilize for larger political causes or is that the case when the weather is pleasant as some literature (Mares, 2013) suggests? Would it be easier to mobilize individuals and groups towards a conflict whose political basis they do not agree just because of variations in temperature? Recent critical studies (Scheffran et al. 2012b; Hendrix and Salehyan, 2012) suggest that local level conflicts over resource access may be more related to climate impacts than other types of conflict such as civil wars which require a lot more organizing, manipulation, money, and political will. But even though some of these resource-related conflicts may be influenced by factors that may have to do with variations in precipitation and/or temperature, many are rooted in 
historical, territorial, and cultural factors that may not be affected by climate or whose relationship with variations in the weather may not be untangled from sociopolitical factors.

The nature of climate variables used in climate-conflict research and their temporal and spatial scales also need to be evaluated. For example, long term studies on precipitation and temperature and their impact on resource availability and access may miss proximate factors that may influence conflict (Hendrix and Glasser, 2007; Scheffran et al. 2012a; Theisen, 2012). This is because there may exist other underlying issues surrounding resource tenure and ownership that are exceptionally context dependent and not attributable to one causal mechanism. Also the most comprehensive and widely used temperature and precipitation datasets such as the Climatic Research Unit (CRU) (CRU TS 3.1; Mitchell et al., 2004)) and the NCEP/NCAR Reanalysis (Kalnay et al. 1996) dataset are based on observed and numerical models that may not be appropriate for subnational and local scales of analysis especially for regions with a sparse coverage of observation data.

Climate and weather: Climate and the weather are physically and statistically related but imply different temporal and spatial scales. In their synthesis studies, Hsiang et al. (2013) do not define important concepts that constitute the core of their argument. For instance, the authors do not explain what climatologically or meteorologically constitutes weather, climate, or even climate change and to what extent that applies to their study. This would be particularly essential because the datasets they rely on encompass a wide array of spatial and temporal scales. More importantly, there seems to be an assumption in both Hsiang et al. (2013) and Hsiang and Burke (2014) that weather 
and climate can be used interchangeably or constitute the same thing and therefore the temporal and spatial scope of their variables need not be explained. Combining the effects of weather events that are more short-term (minutes, hours to days) with climate events that may constitute weather events averaged over longer time scales (months, seasons, to years, even to millennia) has the potential to exaggerate the relationship between variables. This is even more important when any change in these variables is equated to change in climate.

The findings of these two studies are also inconsistent with both conflict and climate trends observed for different regions over the recent decades. For instance, Buhaug (2010) responding to Burke et al. (2009) notes that general temperature trends in Africa indicate that temperatures have increased in the last 30 years but the occurrence of civil war has declined. He asserts that, "[...] temperature is statistically insignificant when added to standard models of civil war." Also, it may be important to note that recent studies, including some synthesized in Hsiang et al. (2013), on the relationship between climate and conflict variables have tended to return different results for temperature and precipitation with anomalously dry or wet precipitation conditions returning a positive relationship with conflict (Hendrix and Salehyan, 2012; Dell et al. 2012; Fjelde et al. 2012).

The quest for causation: The quest for causality in climate-conflict studies has in the last decade gained prominence especially in the disciplines of political science and economics. Many studies have attempted to disentangle climate from the multiple causal pathways that may characterize a causal mechanism in a climate conflict-relationship (Buhaug, 2010; Kalyvas, 2006; O’Loughlin, et al. 2012). However, many have also 
acknowledged that the relationship between climate and conflict is ambivalent (Scheffran et al. 2012b; Adano et al. 2012; Theisen, 2012; Barnett and Adger, 2007; Peluso and Watts, 2001) while others argue that environmental factors may not be associated with conflict outside of sociopolitical and economic factors (Hendrix and Glasser, 2007; Nordas and Gleditsch, 2007). In the recent studies by Hsiang et al. (2013) and Hsiang and Burke (2014), the failure to differentiate between important scientific concepts such as climate, weather, and climate change and the failure to sufficiently address the issues of scale and context produce an overly exaggerated causation argument.

An important question about quantitative studies in the climate-conflict debate should be whether the quest for causation should be in the interest of explaining relationships between variables or for the mere agenda of proving that a causal link exists. Hsiang and Burke (2013:) claim to use a "standard definition" of causation that allows them "[...] to infer causality through quantitative measurements even if the detailed pathway linking a cause to its effect is not fully understood." In their conclusion, however, they claim to have found strong linkages between conflict, climate, and societal stability, which are of immense policy interest. The implication of this assertion in their conclusion is the creation of a strong narrative of the causal link between climate and conflict in order to influence policy but with a subtle acknowledgement that the link is not fully understood. The broader implication of this is the furtherance of a distorted discourse on the understanding of the relationship between climate and conflict that leads to bad policy.

Ignoring critical theoretical understandings of the relationship between conflict and climate in furtherance of a thin causative argument is misleading and unhelpful. 
Hsiang's empirical studies overlook sixty years of development and anthropology research on the subject and have the potential to take us back to the era of functionalist models of human behavior. What Hsiang misconstrues for a relationship between temperature and conflict is a distribution of institutional capacity to deal with conflict, disease, poverty and other factors that may destabilize society. In other words, their analysis is flawed because it misses an institutional analysis leading to an uncritical and ahistorical pursuance of causation. Their analysis reminded me of a joke my statistics professor used to tell us about pregnancy tests in hospitals. The joke went something like: the high correlation between the female sex and pregnancy should not be misconstrued to mean that being female causes you to get pregnant. Yet Hsiang's studies suggest that increased temperatures cause people to engage in conflict while ignoring all variables that may intervene such a causal relationship, the multiple pathways in which such a causal mechanism operates, and all the theoretical problems that such an approach portends.

Avoiding existing theory on the relationship between climate and conflict, and choosing a purely empirical analysis is convenient for Hsiang and his co-authors in at least two important ways: One, the two studies are able to avoid known epistemological nuances associated with the many datasets that they deal with. By choosing to deal with numbers and avoiding known dataset issues, they are able to evade potential questions that may arise from each dataset they use. For example, one may question the utility of using civil war data in the same study as lab experiments from psychological and/or medical tests. Two, they are able to avoid the inconvenience of dealing with institutional capacity data and therefore to some extent justify the glaring omission of a typology of conflict and the situatedness of any single conflict. This allows them to generalize all 
conflicts (whether violent or non-violent, interstate or personal) into one class that they do not substantively define.

\section{Conclusion}

Critical and empirical human-environment studies indicate that environmental change, and particularly climate change, will result in major disruptions to both social and ecological systems (Satapathy et al. 2014; Sign et al. 2014; Arnell et al. 2013; IPCC, 2014). Such changes, it has been argued, may increase the vulnerability of livelihoods and undermine human security by reducing the availability, access, and quality of key resources that sustain livelihoods (IPCC, 2014; Brown et al 2013; Wangui et al. 2012; Hsiang et al. 2011; Barnett and Adger, 2007). In turn, some have argued, the increased competition for reduced access to natural resources due to environmental change coupled with a changing political economy of resource access may result in an increase in the risk of conflict (IPCC, 2014; Hendrix and Glaser, 2007; Butler and Gates, 2012; Hendrix and Salehyan, 2012). This realization has led to a heightened attention in academic and policy circles on questions relating to the relationship between climate and conflict in recent years.

Recent advances in data collection methods and the availability of large amounts of data have made it possible for researchers to create "rigorous" quantitative models to explain and predict conflict trends without engaging in the time consuming and often expensive qualitative data collection. However, the problems associated with results from these models are many, especially in conflict studies, partly because conflict is situated, it is a lived experience, it is a social relation, and it also defines the identities of people

living in those particular places. Some of these recent quantitative studies that employ 
multiple datasets (Hsiang et al. 2013; Hsiang and Burke, 2014) completely miss an institutional analysis and therefore do not account for the role of institutions in the process and outcome of conflict. Such studies also ignore that conflict has uneven outcomes (Eriksen and Lind; 2009) for different groups in different places and this has an effect on whether conflicts are resolved, exacerbated, recur, or not. An even more important omission is a failure to explain the role of institutions in redistributing resources especially given that these recent climate-conflict debates have been dominated by arguments around resource availability, access, and quality (IPCC, 2014; Hsiang et al. 2013; Barnett and Adger, 2007).

Conflicts rarely, if ever, by themselves redistribute resources. We must thus recognize that whether conflicts turn violent, are exacerbated, or resolved, recur or not is heavily influenced by the capacity of available institutions and the perceptions of conflict groups on the process and outcome of the immediate as well as of past conflicts. By ignoring an institutional and historical analysis in pursuit of a narrow causality between climate variables and conflict, Hsiang's studies tell us little about conflict. In addition, the focus on environmental factors as trigger mechanisms for conflict leads to misleading arguments about conflict distribution and frequency, allows researchers to shift attention from differing institutional capacities, and ultimately hinders the understanding of conflict and mediation. This approach has the potential to lead to militaristic interventionist policies rather than policies aimed at building and strengthening institutions, and supporting mitigation and adaptation strategies that bolster livelihoods so that they are more responsive to the effects of both current and future climate impacts.

The increased focus on the relationship between climate change and conflict has 
refocused both the debates and discourse on conflict from a debate about the causes of conflict and potential avenues for mediation and resolution to one about how climate may affect conflict trends and ultimately to a debate about climatic impacts on human security. The concept of human security as defined by the Working Group II of the IPCC 2014 Report seems to include all livelihood aspects and therefore is too broad to permit the sharpening of any substantive analytical connection between conflict and climate change. Furthermore, there was divided opinion among scientists over the relationship between conflict and climate change. Interestingly, the chapter ended up suggesting that although the relationship was not proven, its impacts are clearly a threat to human security. The challenge for climate-conflict researchers thus remains in establishing what particular role conflict may play as a climate response strategy and what types of conflict may be considered part of adaptation if any. If conflict can indeed be part of adaptation, its negative impacts on adaptation must also be elucidated because it has the potential to generate "losers" and provide grievances that may lead to further conflicts. The role of the state as an institution in providing social safety nets and diversification options (Scoones, 2009) through innovation and economic inclusion as well as conflict mediation and resolution is also a critical area that needs more research. 


\section{CHAPTER 3: BETWEEN THE LEGAL AND THE CUSTOMARY: INFORMAL LAND TRANSFERS AND CONTESTED CLAIMS}

Abstract

The transformation of African economies in the last three decades has led to a rapid change in social relations around land allocation and tenure in varying degrees across the continent. This paper examines the ongoing transition from customary land ownership systems to formal private property regimes in Africa and how that transition has benefitted or disenfranchised certain groups. Using a case study from Njukini in Southern Kenya, I illustrate a system of informal land transfers that do not fit the categories of formal property ownership or customary law that exists in policy and laws on land in Kenya. Transfers or sales that do not involve either immediate formal title change or accepted customary processes characterize these informal land transfers but which are locally accepted as legitimate pre-titling processes. This study also illustrates how the existence of a dual system of land adjudication coupled with an expensive and bureaucratic land titling process in Kenya produces and maintains this unregulated informal transfer system. I argue that these unregulated systems may help circumvent protections provided within law and policy since no mechanism exists to track the chain of exchange until the land is finally formally titled. This study utilizes qualitative methods and a survey to provide a historical basis and an in-depth analysis of land relations and land conflict in Njukini.

Keywords: Land, conflict, property rights, claims, customary, tenure, title

Solomon, M. Between the legal and the customary: Informal land transfers and contested claims. (To be revised and published in Review of African Political Economy - ROAPE) 


\section{Introduction}

Land adjudication in Africa has been an important area of both research and policy since the colonial period. Major areas of focus have changed through time and have differed from country to country and even within countries (Peters, 2013; Berry, 1993; Chanock, 1991; Amir, 1976). This is attributed to the multiplicity of tenure regimes within the continent and the differing approaches to land policy. Recent research has continually placed more emphasis on the negotiability of customary land tenure and context specific analyses in cognizance of recent trends towards increased formalization in Africa (Santos and Fletschner, 2014; Peters, 2013; Colin, 2013). Increased attention has been given to those groups that are likely to be disenfranchised by trends towards more titling especially women and the youth (Colin, 2013; Toulmin, 2008; Joireman, 2008; Mwangi, 2007). However, whether within the context of customary communal ownership or modern private property land tenure arrangements, there appears to be consensus that similar losers and beneficiaries exist. According to Woodhouse (2003), customary tenure is neither a hindrance to economic development nor is it a secure economic safety net for poor households. Consequently, customary tenure and the negotiability debate may fundamentally obscure, even silence, vulnerable groups by masking them within the discourse of the negotiability of rights.

A challenge to researchers is to examine and establish to what extent the ambiguity of rights guarantee any sort of advantage over formal private ownership to disenfranchised groups within customary tenure and in some forms of informal transfer especially given that informal transfers may sometimes lead to conflict and economic loss? I examine this question in both literature and research, and argue that in areas with 
high demand for land and where modern property relations are the norm, community access to private land obscures the power dynamics of ownership and may sometimes hide the fact that the land in question can be fenced off and rights or privileges withdrawn forthwith by owners. Even in cases where land has been transferred or sold informally by way of local recognized institutions, the understanding must always be that it will not revert back to the community unless there is a conflict. Informal transfers, however chaotic, exist largely in places with precedence and recognition for private ownership and may be viewed as a longer route towards titling.

In the following sections, I delve into these perspectives in both discourse and context in an effort to contribute to the continuing debates about land allocation and tenure, conflict, and capital formation in Africa. First, I trace the origins of modern conceptions of land tenure in Africa and examine critically the concept of negotiability and how it relates to recent trends in capital formation and land conflicts in Africa. Secondly, I examine the issue of informal land transfers, the reasons they are pervasive in many areas where land is in high demand, why they might provide an easier ground to marginalization of certain groups as an unregulated pre-titling process. Third, I put the aforementioned issues in context and provide evidence through a case study in Njukini, Taveta, in Southeast Kenya. Through this analysis, I show that negotiability does not necessarily guarantee any advantage over formal tenure to disenfranchised groups since in the absence of policy and a formal legal framework to address these "negotiable" rights, local power relations which disenfranchised certain groups are likely to overwhelmingly prevail in the process of formal titling where land is in high demand. I argue that in the context of rapidly changing social relations around land and especially 
where land is in high demand, formal policies and statutory laws are more effective in addressing problems associated with access rights for disenfranchised groups. In addition, informal land transfers may provide avenues for circumventing the laws and policies that address inequality therefore the process of titling should be simplified and inexpensive.

\section{The evolution of land tenure studies in Africa}

Colonial land tenure policies and research placed emphasis on collective ownership and the role of local authorities and institutions in land allocation. Peters (2009:1317) argues “[...] under the colonial administration, the multiple types of authority and sets of claims over land and its products were glossed as communal tenure, which became incorporated into the developing body of customary law". Extensive research in this field shows that colonial conceptions of communal ownership based on customary law were transmogrifications of pre-colonial modes of land allocation and transfer (Peters, 2013; Bernstein, 2010; Berry, 2002; Chanock, 1991). These conceptions invalidated the existence of individual private ownership in many parts of Africa, which the colonists considered superior to communal forms of landholding. Research has also shown that these positions were largely guided by entrenched Eurocentric conceptions of land allocation and tenure (Peters, 2009; Chanock, 1991). In addition, materialist analyses have also demonstrated that the alteration of pre-colonial land tenure regimes was aimed at transforming labor relations in the colonies to align them with the broader capitalist colonial project (Bernstein, 2010; Mamdani, 1996; Amin, 1976). This was done in order to make colonies to pay for themselves and ease the pressure of the colonial mission from the colonial states. 
Later research and policy during the post-colonial and development era focused on streamlining land tenancy contracts to conform with global capitalist trends to increase productivity while also making sure that land as a commodity could be used as capital, especially in securing credit. One of the most notable researchers associated with the ideas of this period was Hernando De Soto. According to De Soto (2000), the commodification of land and other property is essential for capital formation and poverty reduction. This idea was in line with policy and proposals by development agencies such as the World Bank (WB) and the International Monetary Fund (IMF) towards land reform in developing countries during the 1960s, 1970s, and 1980s. In this school of thought, researchers argue that clearly defined rights of ownership and transfer of property, including land, encourage investment while ambiguity of rights and/or lack of enforcement may hinder investment and stifle economic growth (Fukuyama, 2004; Robinson, Acemoglu, and Johnson, 2004; De Soto, 2000). This thinking led to policies that encouraged the privatization of land and formalization of land transfers in many developing countries, especially in Africa, where such practices were either nonexistent or existed only on a small scale in certain regions (Peters, 2009; Woodhouse, 2003). This policy push by development agencies has slowed down in the last two decades in favor of more context specific policies.

The change from an insistence on privatization of rights to more context specific approaches was largely informed by new research that suggested that universalist approaches towards the formalization of land tenure could potentially disenfranchise certain groups within communities by cementing inequalities and even cause conflicts in some cases (Colin, 2013; Joireman, 2008; Mwangi, 2007; Berry, 2002). In addition, there 
existed little evidence that formalization necessarily led to increased productivity and access to capital (Grimm and Lesorogol, 2012; Sjaastad and Cousins, 2008; Joireman, 2008). Research has demonstrated that although clear and enforced private property rights may lead to less conflicts over ownership and improve people's lives, they do not necessarily guarantee the availability of capital (Peters, 2013; Sjaastad and Cousins, 2008; Woodhouse, 2003). Furthermore, the negotiability of access rights to land resources may provide continued access to certain groups within communities that do not necessarily have the power of ownership (Peters, 2013). Other researchers (Santos and Fletschner, 2014; Colin, 2013; Mainzen-Dick and Mwangi, 2008; Woodhouse, 2003) add that, although the formalization of land tenure seems to be the development trend in many countries in Africa, there should be efforts to address the complex and dynamic 'web of interests' in the land resource before the issuance of formal title of ownership.

\section{Negotiability, capital formation, and conflict}

"[...] Conflict centered on land has increased in incidence and severity as land values rise, patterns of land acquisition become more commercialized, land becomes more concentrated, and disputes and litigation over competing rights proliferate." (Peters, 2013)

In many countries in Africa, land and other property rights may be subject to both customary and statutory law (Sjaastad and Cousins, 2008; Joireman, 2007; Bruce and Mighot-Adholla, 1994). For example, although statutory law takes precedence over any other law in Kenya, customary law and other local institutions may adjudicate on certain matters and especially pertaining communal or family property. The courts are consequently expected to recognize the decisions of these institutions although aggrieved parties may still contest the said decisions in statutory court. Some scholars argue that the existence of multiple sets of law in many African countries can be advantageous to 
communities especially due to the various customs and livelihood systems (Santos and Fletschner, 2014; Joireman, 2008; Mwangi, 2007). They argue that the formalization of tenure will deny ownership and use rights to women and the youth who form the most agriculturally productive groups in developing countries especially in sub-Saharan Africa. For example, Meinzen-Dick and Mwangi (2008) found that the formalization of land ownership curtailed women's use rights and autonomy in decision-making associated with agricultural production while also diminishing social networks and traditional social safety nets among pastoralist communities in Kenya. Research has also shown that the commodification of land has not led to increased agricultural production or even access to credit (Peters, 2009; Joireman, 2008). According to Sjaastad and Cousins (2008), increased formalization has in some cases resulted in land speculation in certain areas.

Yet we have to be careful not to fall into the trap of rural 'peasant essentialism' and the 'agrarian myth' given the glaring evidence of rapid transformation of rural livelihoods and the current trends in favor of privatization. Brass (2001:1) argues that "[...] there has been an analogous shift in development debate about agrarian transformation, from 'peasantness'-as-economic-alienation to 'peasantness'-as-culturalempowerment" which caries the danger of creating a discourse that reinforces practices that were advantageous to traditional peasant societies but are incompatible with the challenges of a modern capitalist economy. According to Brass, " $[\ldots]$ the agrarian myth is a discourse about the desirability/feasibility and 'naturalness' of small-scale economic activity" that supports cultural economic institutions and perceived connections to nature. We therefore have to ask ourselves why these discourses endure even with recognition of 
the dynamic nature of social relations under capitalism. According to Mitchel (2000), a people's believes, attitudes, and values are usually influenced by their prevailing social and material conditions. Mitchel's assertion is a Marxian one,

"[...] It is not the consciousness of men that determines their being, but their social existence that determines their consciousness". (Marx, 1970: 21)

It is thus critical for us to recognize that capitalist continues to influence social relations in rural Africa and has affected the transformation of livelihoods and the economic choices of both governments and rural communities. Woodhouse (2003) argues that increasing commodification of land and individualization of access to land and other natural resources such as watering areas may be considered the prevailing economic and social change in many regions of Africa and especially where the value of land has been growing.

The transition to capitalism and the existence of dual sets of law on land tenure have to a large extent influenced the way land and land-based resources are negotiated (Turner, 2004; Basset, 1988). This has in turn affected the role of local informal (traditional) and formal institutions in resource allocation and mediating conflicts arising from local land issues (Lesorogol et al. 2013; Grimm and Lesorogol, 2012; Peters, 2009; Homewood et al. 2009). Although resource conflicts among different groups in Africa existed even in the pre-colonial period, it is widely accepted in this area of research that the transition to capitalism through privatization of natural resources by colonial and post colonial states continues to provide avenues for grievance thus exacerbating conflicts (Toulmin, 2008; Robot and Peluso, 2003; Schroeder, 1999; Berry, 2002). According to Ribot and Peluso, law, whether customary or statutory, is insufficient in delineating "[...] all the modes and pathways of resource access along complex and overlapping webs of 
power" (2003:156). Consequently, modern property relations are generally not how resource claims are made; rather, what exists is a series of access claims about who gains and maintains access to resources at different times and across multiple scales (Sikor and Lund, 2009; Ribot and Peluso, 2003). In her examination of land acquisitions and conflict in Africa, Peters (2013:544) concludes “[...] while relations around land have long been central to political economy, culture, and society across the continent, their greater salience today in intensifying struggles among actors...has direct consequences for competition over authority at all levels of society, and for competing definitions of property, ownership, and citizenship." Of great importance is therefore an analysis of how these often-competing centers of power at both the local and the national scale and their interfaces affect resource governance and whether the ambiguities created by the dual legal-institutional regime is more advantageous for the poor in the longer term than having clearly defined and enforced property rights.

Recent research on land tenure in Africa has focused on ways of securing land transfers to ensure they are inclusive (Santos and Fletschner, 2014), protect vulnerable groups (Toulmin, 2008; Mwangi, 2007), and prevent conflict (Peters, 2013; Colin, 2013). There seems to be consensus that lack of one coherent law on land allocation in many countries in Africa is a major cause for contested claims to land, which may result to conflict. Other factors that hinder smooth transfers in countries that have already started formalizing land ownership include long bureaucratic processes, high transfer costs, and lack of up to date documentation which in turn result to a movement towards informal transfers. Although these informal transfers are expected to be the first step towards formal tenure, they often lead to conflicts especially if the correct procedures are not 
followed. In the next section, I examine informal transfers and show how these transfers may cement inequalities and create conflict in the absence of clear regulatory mechanisms.

\section{Informal land transfers: Private property or provisional rights?}

Informal land transfers are especially common in areas where some level of land formalization has taken place or in places where land is in high demand (Peters, 2009). The process of land transfer involves a transaction, an exchange between the buyer or leaser and the seller to which the land is either formally registered or is informally recognized as the rightful owner of the said parcel. Land transactions between private owners must therefore assume the existence of a private ownership regime and formal or informal rules that guide such a process. In Kenya, for example, the National Land Policy (NLP) outlines different types of land and addresses critical issues of land administration and transfer in line with the Land Act of 2012. Both the NLP and the Land Act provide guidelines on the process of land transfer from the point of exchange (transaction between willing seller/s and willing buyer/s) until the land is formally transferred to a new owner by the registrar of lands. Even in cases where the seller does not own a formal title, the general process of transfer is similar. Yet it is at this point of transfer where access is won and lost. In this section, I examine the land transaction at the point of exchange and argue that informal transfers (legal or illegal) may facilitate the disempowerment of certain groups of society and especially where land ownership has changed many times without the issuance of formal title.

Peters (2013) asserts that conflicts over land are sites of crises over the meaning

of and access to property, belonging, and the place of past systems in modern struggles 
over resource distribution and governance. As capitalism transforms the livelihoods of rural communities in Africa, so do the social relations that govern property access. In some cases, informal land transfers may be illegal i.e. what Peters (2013) calls 'informal formalization' but in other cases, they may be recognized as part of the process of land acquisition which is expected to eventually culminate in the acquisition of formal title or the transfer of informal rights of private ownership. Research has shown that informal land transfers are rampant in Africa and may be as a result of costs associated with the process of formal title acquisition (Sjaastad and Cousins, 2008) rather than a prevailing preference towards informal or traditional modes of exchange. This may be attributed to high costs like in the case of Kenya (Joireman, 2008), preference to informal less bureaucratic and less expensive forms of transfer (Peters, 2009), or issues associated with relations around land and kinship, identity, place, and belonging (Peters, 2013). Although the relations between parties in this arrangement are complex and vary from place to place, informal transfers in many cases suggest an arrangement that may not go back to communal ownership. The process of informal transfer presupposes a process of exchange, commodity exchange. It can therefore be assumed that the individual or group on the commodity side of the exchange possesses a level of exclusive rights to the land commodity being exchanged. In that case we could argue that informal transfers can only happen where there exist a certain level of private property at the individual or group level.

It is important to distinguish between access and control or ownership in the context of property relations in many parts of Africa. Communal access may be allowed or expected in some contexts in Africa even when land resources are privately owned and 
controlled. Research has shown that in some parts of Africa individual ownership existed in the pre-colonial and during the colonial era but this did not always exclude communal access to resources. Tiffen and Mortimore (1992) examine a case study in Machakos Kenya and illustrate the levels of land ownership to land that existed among members of the Akamba community during the pre-colonial and the colonial period. Through their case study, they argue that land access among traditional Kamba communities included private ownership rights for both cultivated and grazing land but communal access was allowed on privately owned grazing areas and in some cases cultivated land. They also show that informal transfers were prevalent although rights to properly were regulated by traditional customary rules.

In many parts of Africa, privately owned land, including titled land may be open to communal use and access especially for critical resources such as water and grazing land but that does not make it community property. Owners of privately held land may allow their relatives, neighbors or friends to, for example, graze their cattle freely in unused land. However, they maintain the right and sometimes the power to restrict or block access although that may affect the relations between them and those who would want or need access. This may be different from the western concept of property common, in Africa, in places where land is scarce and/or in high demand where rules exist against trespassing and other forms of access. However, Meinzen-Dick and Mwangi (2008) assert that there is evidence of increased conflicts over trespassing in private lands that were formerly Maasai group ranches in Kajiado District, which is an important illustration of the rapid change in social relations around land in rural Africa. It has to be 
understood that social relations around land are just part of larger relations and contracts that bind communities in these places.

Recent research points towards substantial progress in the formulation of policy on land tenure and a movement towards more inclusive land tenure regimes. In addition, the level of success or failure in land reform in Africa seems to vary with context with recent attempts seemingly more successful than older ones (Santos and Fletschner, 2014). For instance, while early attempts on land reform in Kenya and Ivory Coast seem to have largely disenfranchised certain groups and cemented inequalities (Santos and Fletschner, 2014; Colin, 2013), later attempts in Rwanda and Tanzania seem to have been more inclusive and largely successful in addressing inequality (Santos and Fletschner, 2014; Daley, 2008). The relative success in Tanzania and Rwanda may be attributed to the creation of a regulatory framework that recognizes the rights of individuals and groups that may not be included in the title by allocating them powers to secure their interests at the time of sale, exchange, or transfer. These powers may be exercised during land transfer to allow or veto the said transfer. Yet these groups may not be able to effectively exercise their rights in cases where informal transfers happen in the absence of title. Informal transfers continue to happen in places where land has never been titled and customary practices continue to influence who benefits from rights over land. The ambiguity of rights for certain individuals and groups such as the youth, wives, and unmarried women in these cases therefore serve as a stumbling block for them to exercise the rights conferred upon them by formal policy or statutory law. In addition, in situations where private land has changed ownership many times without the issuance of formal 
title, it may be impossible to ascertain whether due diligence as per formal procedures was followed for past transfers thus permanently cementing inequality.

\section{Data and Methods}

In order for me to address the issue of informal transfers and how they may stifle progress in addressing inequality through regulating land transactions, I chose a case study in Kenya that fits three major criteria. First, I chose a case study that has undergone drastic changes in population, economy, and politics from the colonial period up to date. This is important in establishing a historical social and material context that current relations around land allocation and tenure are rooted. Secondly, this case study is in a high-land-demand area but the majority of households living in this area do not have formal title deeds for their land although all the land is formally administered as either private, government, or public. This second criteria allows me to illustrate how informal transfers may, even with the existence of regulatory safeguards for vulnerable groups, cement inequality especially because they are difficult to trace. In addition, informal transfers are often sites of conflicts. Thirdly, this case study is a microcosm of the socioeconomic practices in the region and more broadly in Africa, which allows for broader generalization and comparison. The major socioeconomic activities in this area include: irrigated agriculture, pastoralism, non-irrigated arid mixed farming, casual labor, and large-scale farming among other activities.

This study was conducted in the summer of 2010 and relies on qualitative methods and a household survey for descriptive statistics. Qualitative methods were used to capture local people's perceptions about land access and ownership, land transactions, and the dynamics of land access and local institutional governance. Four primary data 
collection methods were utilized, namely: forty-two key informant interviews, a community workshop comprising twelve elders, and fifty household surveys. The composition of the community workshop was based on the period of time individuals had spent in the area and was well balanced to address gender issues. Key informant interviews comprised of nineteen women and twenty-three men while the surveys were conducted on whoever was home between the husband and the wife although in many cases wives would prefer the husbands to answer the questions if both were present. In cases where both spouses were available, all were encouraged to participate. The purposes of these research methods were to examine local resource governance issues through an examination of patterns of power and right among different groups and institutions. Through the exploration of the social relations of property ownership and access, I was also able to establish the drivers of land conflicts and inequalities in the transfer and access to land and land-based resources. I utilized a qualitative thematic analysis method to explore qualitative data and simple descriptive statistics obtained from the survey to explain research results.

All the textual data derived from the various methods was first coded thematically using descriptive codes. Nvivo software was used to organize the text data into descriptive codes. Examples of descriptive codes included: "kamati" (committees), "viongozi" (leaders), "violence" (mapigano), "population" (idadi ya watu), "land" (shamba), "pasture" (malisho ya mifugo), "water" (maji), "farms" (mashamba), "drought" (kiangazi - although Kiangazi can also mean the dry season), "food" (chakula), "climate" (Hali ya hewa) and "rainfall" (mvua). I then developed analytic codes, which were based on an interpretation of the text and descriptive codes, to reflect 
key themes of the research and dig deeper into the data. I also generated some analytic codes from the literature. Analytic codes included but were not limited to: "usimamizi" (governance), "ethnic divisions" (migawanyiko ya kikabila), "generational issues" (rika), "youth unemployment" (ukosefu wa kazi kwa vijana), "population density" (wingi wa watu), "contested claims" (madai yanayotofautiana), and "perceptions of right" (mitazamo ya haki). After developing satisfactory codes, descriptive and analytic codes were grouped together according to substantive relationships and conceptual links so as to make them easier to manage and analyze.

The result of this data analysis included a list of words and themes, and the number of times each was used. These were then ranked in order to generate a prioritization of factors that undelie of land relations and conflict. The data analysis also developed a matrix of word and theme relationships. For instance, if the words "land" (ardhi/mashamba) and "water" (maji) were voiced together frequently, that would help explain exactly which environmental resources underlie a land conflict. If the words "land conflict" (migogoro inayohusiana na ardhi/mashamba) and "people from outside" (wahamiaji) wee spoken frequently, then that would indicate a socio-political context to land conflict. Through the generation of such a word and thematic matrix, I was able to substantiate my observations and thus ensure that the qualitative data is truly empirical. Survey data was uploaded into the SPSS statistical software where simple statistics and tables were generated to help explain themes developed through the qualitative analysis. 


\section{Njukini: A space of land contestation and conflict}

Study Area Map

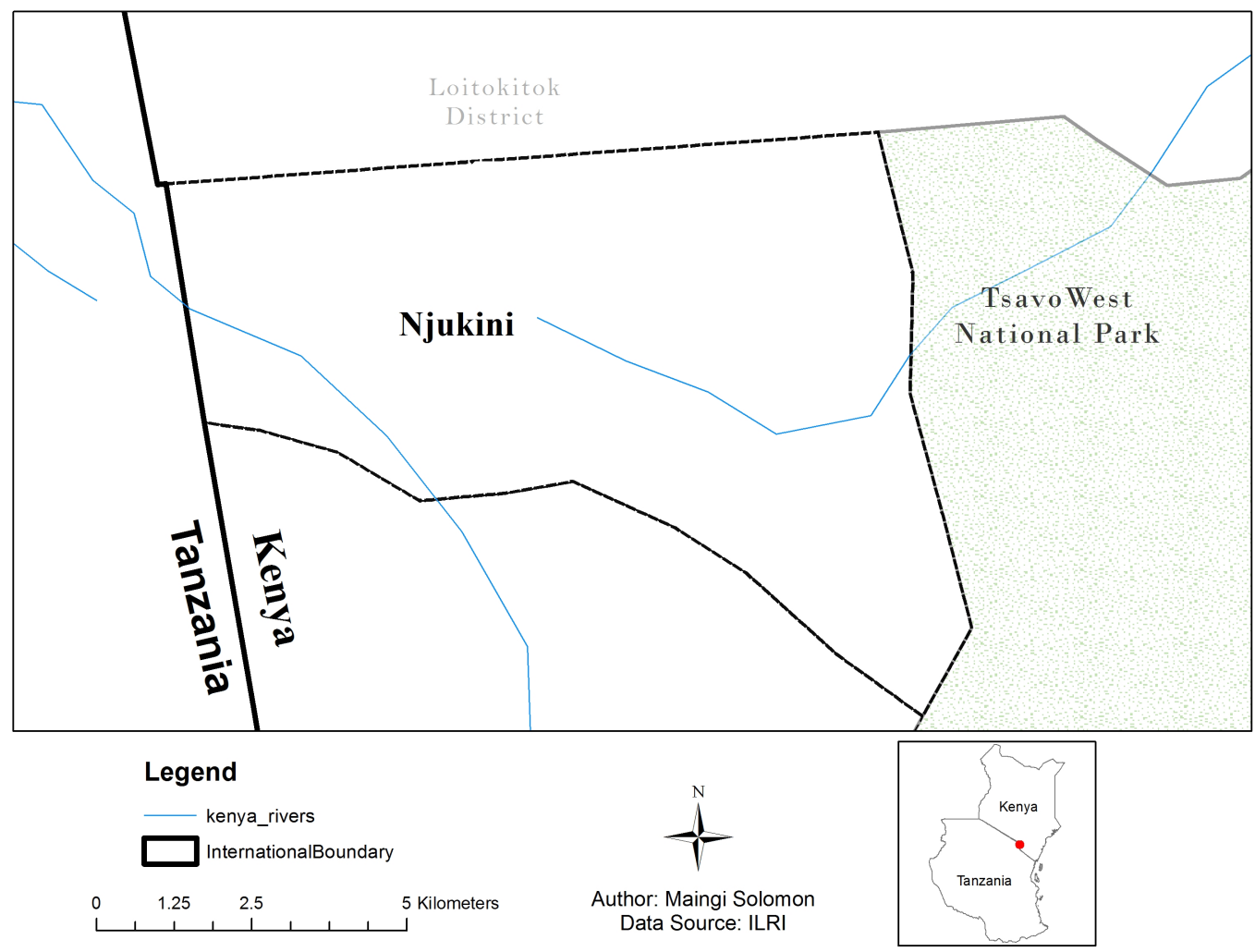

Figure 1: Map of Study Area (Njukini)

Njukini presents a microcosm of dryland areas in East Africa. It encompasses the primary livelihood types and economic activities found in Kenya's arid and semi-arid zones. Njukini also marks a transitional zone between the pastoral areas of Loitoktok to the north, the sisal plantations of Taveta, and the Taita hills and Kilimanjaro gradients, which rise out of the savanna and are host to intensive irrigated smallholder farming systems. It is sandwiched between the Kenya/Tanzania border on the South and the Tsavo West game reserve to the NE. Njukini is located in the leeward side of Mt Kilimanjaro in the lower and drier lowland gradient of the mountain in the Kenyan side. It has a population of 18,025 people according to the 2009 census (KNBS, 2010). The 
area is characterized by erratic unreliable rainfall that varies greatly and has two rainy seasons. The short rains, known as Vuli, in the local languages (Oct-Jan) are more reliable than the long rains known locally as Masika (March-May) (Mutai et al. 2011)

Njukini's history and settlement makes it much ethnically diverse compared to many other rural dryland areas in Kenya. The settlement history represents change and diversity and this has largely shaped resource access patterns in the area. The area that is now Njukini was a protected government water catchment area and was hardly inhabited during the colonial period. Both Taveta and Maasai communities claim historical territorial rights. However, although it was a government protected area where settlement was prohibited; influential people in the post-colonial government acquired large sections of it to practice large-scale sisal and maize farming. This was part of widespread abuse of presidential discretion through land grabbing (Southall, 2005) by powerful people within the postcolonial Kenyan state. However, it is important to mention that the Ndung'u Report, a report of a commission of enquiry appointed by president Mwai Kibaki to look into the issue of land grabbing and land allocation in Kenya concluded that these large farms had been acquired legally, a sentiment that local research participants did not share.

Interviews with local residents and leaders suggest four major waves of migration into Njukini. The areas from which the communities migrated are distinct in time period, area settled within the study area, ethnic composition, perception of rights or power of claim to land and water resources in the area, and in some cases the names of the places they settled. For example, those who migrated from Tanzania in the mid 1970s during the crisis that led to the collapse of the East Africa community (EAC) tended to name their villages after the Ujamaa village from which they migrated. The first group of settlers in 
Njukini was those who migrated into the area after independence in 1963 from the Tanzanian side of the border because they wanted to be part of the new republic of Kenya. Most of these settlers were Akamba and settled just across the border so as to maintain their social networks across the border in Tanzania. The second group comprises of those who moved to Njukini in the late 1960s to work in large-scale sisal estates owned by the family of the first president and a Greek settler. These settlers were of different origins and ethnicities. According to interviews with residents of Irrigation village in Njukini that is adjacent to one of the large-scale farms, most of the current residents of this village were born or lived in the staff quarters of the large-scale farms but later moved out and carved out farms in the 'open land'. Some of these residents are still considered squatters because their farms lie within the boundaries of the large-scale farms but they have not been evicted in more than two decades. These residents claimed to be "more secure" now because evictions have ceased since the late 1980s. None of the participants interviewed in this village had title for their land.

The third group migrated from Ujamaa villages in Tanzania for fear of reprisal in the period preceding and after the collapse of the EAC in the 1970s. Majority of these settlers were also Akamba. Most of the Akamba who moved from Tanzania felt unrepresented politically because they were disconnected from the greater Ukambani region of Makueni, Machakos, and Kitui counties in Kenya. Some of those interviewed suggested they did not feel adequately of Kamba ethnicity due to their history in Tanzania. The last group, which is more recent, is composed of migrants mainly from the larger Taita-Taveta, Kajiado, and Ukambani regions. These are mostly ethnic Akamba, Taita, Taveta, and Maasai although the Maasai and Taveta have strong historical 
territorial claims to this area. Table 1 summarizes the settlement history of Njukini. These settlement patterns have shaped identities and social relations within this area and have often led to forced evictions and conflicts over land since the early 1970s. However, local formal and informal institutions exist that help resolve land and water conflicts and interviews suggest that many conflicts are indeed resolved locally although tensions persist. There are also informal institutions called kamati za ujirani mwema (committees for good neighborliness) that mediate cross-border disputes with their neighbors in Tanzania. 


\begin{tabular}{|c|c|c|}
\hline Period & Tenure status & Land Use/Settlement \\
\hline $\begin{array}{l}\text { Before } 1963 \text { (colonial } \\
\text { period) }\end{array}$ & $\begin{array}{l}\text { Open crown land, } \\
\text { British settler farms, } \\
\text { Access for Taveta } \\
\text { beekeeping, } \\
\text { Access rights for Maasai } \\
\text { pastoralists (grazing land } \\
\text { during climatic stresses) }\end{array}$ & $\begin{array}{l}\text { Seasonal pastoral use, } \\
\text { Beekeeping for Tavetas, } \\
\text { Large-scale } \\
\text { British settler farming }\end{array}$ \\
\hline $\begin{array}{l}1963 \text { to early } 1970 \mathrm{~s} \\
\text { (Period of rapid settlement, } \\
\text { regional integration, and } \\
\text { conflict) }\end{array}$ & $\begin{array}{l}\text { Trust land for the Taveta } \\
\text { "highly contested", } \\
\text { Government protected } \\
\text { water catchment area, } \\
\text { Large-scale privately owned } \\
\text { farms, } \\
\text { Few untitled Taveta and } \\
\text { Kamba settlements, } \\
\text { Access rights for Maasai } \\
\text { pastoralists }\end{array}$ & $\begin{array}{l}\text { Water catchment, } \\
\text { Seasonal pastoral use, } \\
\text { Large-scale farming, } \\
\text { Small-scale subsistence } \\
\text { farming. }\end{array}$ \\
\hline $\begin{array}{l}\text { Early 1970s to date } \\
\text { (Rapid settlement and } \\
\text { population growth, } \\
\text { evictions, and conflict) }\end{array}$ & $\begin{array}{l}\text { Large-scale Kenyan-owned } \\
\text { farms, } \\
\text { Maasai group ranch, } \\
\text { Many untitled settlements } \\
\text { (multiple ethnicities), } \\
\text { 'Settled squatters' from } \\
\text { multiple ethnicities (people } \\
\text { settled in land that the } \\
\text { large-scale farms lay } \\
\text { ownership claims but have } \\
\text { not been recently evicted) }\end{array}$ & $\begin{array}{l}\text { Permanent pastoral use, } \\
\text { Large-scale goat and } \\
\text { cattle farming, } \\
\text { Small-scale irrigated } \\
\text { farming, } \\
\text { Large-scale Irrigation } \\
\text { schemes, } \\
\text { Subsistence non-irrigated } \\
\text { farming }\end{array}$ \\
\hline
\end{tabular}

Table 1: Summary of tenure and settlement history

\section{Locating contested lands and informal transfers}

As mentioned in an earlier section of this paper, Kenya employs a dual legal and institutional system in the administration of land and other property rights. These two systems include formal laws and institutions that govern land allocation and tenure on the one hand and informal institutions and guidelines based on traditional customary laws that may vary from community to community. This dual system has been a key problem in the implementation of laws aimed at private ownership because there was little effort 
to harmonize these two systems after independence and during the development era between the 1960 s and the late 1980s. Studies have shown that this lack of harmony has played a part in cementing inequalities by disenfranchising vulnerable groups (Toulmin, 2008; Mwangi, 2007). However, more recent studies show that there has been progress in trying to address these inequalities and creating a regulatory framework that is more inclusive (Santos and Fletschner, 2014; Meinzen-Dick and Mwangi, 2008) but concerns about inequality in land allocation are still legitimate and widespread. While there are advantages and disadvantages of having a dual system or even of each of the two systems, some policy trends seem to favor harmonization of the two systems so as to promote the security of property rights for individuals and groups while also ensuring that traditional forms of customary ownership are encouraged where they are more suited to local needs.

According to the Land Act of Kenya (2012), there are four forms of tenure allowed in Kenya: freehold, leasehold, partial interests such as easements, and customary rights where consistent with the constitution of Kenya. Freehold, according to the Land Act refers to the right to use and dispose land in perpetuity subject to other laws and government regulations. Leasehold refers to "[...] the grant, with or without consideration, by the proprietor of land of the right to the exclusive possession of his or her land" (Land Act, 2012:11). Partial interests may include but are not limited to nonpossessory interests in another's land that allow for use to a particular extend while customary rights are based on traditional forms of land adjudication and only apply if they are consistent with the constitution and the laws of Kenya. There are three important issues that arise from the way customary tenure is defined in this act. First, its 
applicability is justified only as far as it is consistent with the constitution which may be based on the recognition that it has disenfranchised groups such as women and been used by old men to leverage their interests. Secondly, this justification implies an inherent preference towards formal tenure, which is consistent with the discourse and policy on land allocation in Kenya. Thirdly, there are many known inconsistencies between the different types of customary tenure and the constitution and laws of Kenya. This means that the act is not meant to address the conflicts and inconsistencies between customary tenure and established law but leaves the option to contest customary practices wide open for those who would like to challenge them in court. This is problematic because the legal process in Kenya is expensive and complicated but even more importantly, many disenfranchised individuals and groups may not know that such laws exist that protect their rights.

The line between customary rights and formal titled tenure is not as distinct as policy and law define it. Research on land tenure and rights in Njukini showed that there is a third superstructure of land deals and transactions that is unregulated and thriving. This is precipitated by the fact that there exists a lot of land held as 'freehold' that has never been titled. In addition, many holders of freehold rights to parcels of land have not updated their title deeds even after the land in question has been subdivided and sold. In some cases, land had changed hands many times without title deeds being updated to reflect these changes. What existed was written transactions signed by the buyers and sellers that were assumed to confer full freehold rights to the buyer. In some cases, the land parcels had been surveyed by registered surveyor but in other cases the agreement was for a particular size with a caveat when the land is eventually surveyed. Most of the 
times the caveat was for the buyer to pay for or return for the extra land if it was more than agreed or for the seller to provide more land if the parcel was less than agreed. These practices are widespread in Kenya because of regulatory problems discussed earlier in this paper. I explored land tenure issues in Njukini with a keen interest in how this unregulated superstructure may provide loopholes to circumvent protections for vulnerable groups within policy and the law.

Interestingly, informal land transfers were thriving in Njukini, a place where land holding is highly contested and a history of violent evictions exists. Key informant interviews suggested that many residents were evicted several times from parts of Njukini that were owned by large-scale farmers who had acquired some of the land in Njukini after independence in 1963. A key informant from the Irrigation village of Njukini told me that many workers from the large-scale farms had moved out of the estate and settled in the contested open land from where they were evicted many times. He said, "[...] most of us were born in the staff quarters of the large-scale sisal farms but we were not allowed to live in the quarters after we were older. So, we moved out and constructed houses in the open land." Some of the land they settled was considered part of the largescale estates leading to evictions. However, interviews with locals also suggested that evictions had ceased since the 1990s and households were more settled although still insecure.

"People are not being evicted any more but when anybody settles there, they are not sure how long they will be there." Except from a key informant interview with a resident of Kijiji A Village in Njukini talking about settlement in contested lands close to the large-scale farming estates. 
Formal and informal land transfers require a sale. According to key informant interviews conducted in Njukini, a sale was legitimate if it was signed by at least three members of the seller's family. This rule is meant to protect members of the family whose access rights are not represented in the named owner of the title. These members may include the youth, women, or just members of the family who may be opposed to the sale. However, several female key informants stated that the requirement for a signature from them was more of a formality and that they did not have the power to sale. One female key informant said to me: "[ $[\ldots]$ he will sell the land if he wishes to do so. My signature in that piece of paper does not mean that I fully agreed to the sale." This presents a problem for policy in addressing the unequal gender power relations within many African institutions such as marriage. The husband is still viewed as the household head and wields immense power in terms of control over family resources. Female key informants voiced their concerns about land deals being conducted without their consent only to be informed when the time came for collecting signatures to authorize the sale.

Another important point of contention was in the perception rights over matrimonial property. The threat of gender-based dispossession was a common theme for female-headed households in cases where the husband was deceased. Several key informants reported that matrimonial land dispossession was common in the area when the husband died before the male children were of age to claim the land or resist attempts from their uncles and other relatives. A female key informant told me that she had resisted several attempts to forcefully remove her from her matrimonial property by her husband's brothers after the death of her husband. However, she also informed me that the local authorities, the chief and sub-chief, had resolved the issues after she reported 
being harassed. This is not uncommon in Kenya and although laws and policies exist to protect matrimonial property, many victim for whom the law is meant are either unaware of it, scared of the consequences of taking on the traditional authority, or are just unaware of the existence of such provisions. In addition, the legal process in Kenya is expensive and can be emotionally taxing in cases involving close relations.

Njukini is also site of a clash of interests for different communities living there. The Maasai claim, the Taveta claim, and the claims made by those communities that eventually settled there can be seen as different perceptions of what the landscape was and should be for the different communities. However, these claims are dynamic and constantly evolving with new realities that face the local population. For example, only forty-five percent of respondents surveyed were born in Njukini and the average landholding was only two acres as shown in table two and three. Table four shows land acquisition methods for the local households surveyed. However all the households surveyed had no titles for their land but claimed freehold rights. A major source of conflict therefore arises from the fact that despite the area having a relatively high population density, some communities (Maasai and Taveta) claim traditional territorial rights to land that has already changed hands many times and often among members of other communities. These land transactions are largely informal and unregulated and therefore land ownership in this area cannot be classified as purely fitting any of the four forms of land tenure as per the Land Act of 2012. The challenge therefore is determining what a fair land tenure regime would be for an area such as this? This is not just a problem in Njukini but in many other areas where historically contested land already 
held, as freehold is not titled. This is especially rampant in the coastal and rift valley regions but is also common in other parts of the country especially around wetlands.

\begin{tabular}{|l|l|}
\hline $\begin{array}{l}\text { Was the household head born in this } \\
\text { village }\end{array}$ & Njukini \\
\hline Yes & $55 \%$ \\
\hline No & $45 \%$ \\
\hline
\end{tabular}

Table 2: Settlement history in Njukini

\begin{tabular}{|l|l|}
\hline Size of Primary plot & Njukini \\
\hline None (Landless) & $2.5 \%$ \\
\hline Between 1 and 3 acres & $62.5 \%$ \\
\hline Between 3 and 5 acres & $27.5 \%$ \\
\hline Less than 1 acre & $7.5 \%$ \\
\hline More than 5 acres & 0 \\
\hline
\end{tabular}

Table 3: Landholding in Njukini

\begin{tabular}{|l|l|}
\hline Land Acquisition Method & Njukini \\
\hline Bought & $25 \%$ \\
\hline Government Allocation & $30 \%$ \\
\hline Inheritance & $32.5 \%$ \\
\hline Inheritance-squatter & $10 \%$ \\
\hline Lease & $2.5 \%$ \\
\hline
\end{tabular}

Table 4: Land acquisition method in Njukini

The lack of title deeds for the people of Njukini many years after they have settled a piece of land raises many questions about the politics of the future of the area. The Taveta ethnic community through the Taveta county council went to court in the 1980s to claim that the land in Njukini was trust land held in trust by the Taveta County council for the Taveta ethnic group. However, according to several leaders and other respondents, this case is still pending in court for "political reasons". Key informant interviews suggested the existence of an expectation by the Taveta ethnic group that only Tavetas should hold parliamentary seats although there was evidence of non-Tavetas winning the seat before. This seems to be a strategic expectation by the Tavetas in recognition of their territorial claim and their minority status. It is difficult to ascertain how long this arrangement will last. Several respondents claimed that tensions run high during election 
years when other communities field candidates and this sometimes results to ethnic clashes although most of the times tensions are resolved peacefully. The following quote from interviews illustrates the nature of tensions in Njukini:

"During the election period, we usually have problems here. The Taveta ethnic group has claimed that if people want the farms, they can take them but they should keep away from politics. The political positions in this area belong to the Taveta people. If the other communities stay away from politics, the Tavetas have no problem with the land." Mzee Mwasi (not his real name), an ethnic Taita.

The Maasai, on the other hand, were able in the late 1980s to secure a group ranch in the area in a process that locals defined as highly politicized. Locals claimed that the small group ranch allocated to the Maasai was meant to appease them and satisfy their claim to the land in the area. Several respondents pointed out that the establishment of the group ranch was only possible because of the influence of senior Maasai leaders in the then KANU government at the time headed by president Moi. They further claimed that the allocation was problematic especially because that was the only group-ranch to be established in the then Coast Province although the group ranch is an extension of larger group ranches in the neighboring Kajiado County. However, all the Maasai respondents interviewed claimed that the land allocated was too small to satisfy their claim to the grazing area that they had lost to other communities that had settled there. These conflicting claims have led to tensions among the different groups in Njukini but rarely turn into violence, which may be attributed to the local institutional setup. The most serious conflicts involving the Maasai pastoralists and the local farmers arise during droughts when alternative seasonal livestock watering areas have dried up as the Maasai were said to drive their cattle through the irrigated farms into the main permanent river causing crop destruction. 
Njukini is an extremely complicated case of tenure security but it is a good illustration of the chaos that surrounds the fairness of land allocation and transfer for lands that are held as freehold but are not formally titled. More importantly, it illustrates the complexity of assuring rights to vulnerable groups whose rights of access may be taken away during informal transfers since the lack of title means that these lands only partially fit into the legal definition of freehold tenure. Although the government and other policy makers may recognize these lands as freehold and legitimately privately owned, there exist no policy framework in Kenya to transfer land that is not titled unless it is held under customary ownership. Even in areas where settlement and land tenure is not complicated, many individuals have not kept their transfer records up-to-date due to high registration costs, and long and complex government bureaucracies (see Peters, 2009; Joireman, 2008). This means that if these lands are eventually titled, the verification of consent by those who claim rights may only occur, if at all, on the last transaction. Consequently, that last transaction cements and legitimizes all the previous transfers, however unequal they may have been. Kenyan political leaders are also known to use the allocation of titles as a campaign tool around election time without regard to how such actions may legitimate and cement past disenfranchisement.

\section{Conclusion}

Many countries in Africa have been undergoing land tenure reform since independence in the 1960s. Some countries like Kenya have aggressively pushed for tenure regimes that are guided by private property rights law and a movement towards formal tenure relations since independence. Part of this push was to aid in capital formation and was highly supported by development agencies in the last quarter of the 
twentieth century. As the spread of capitalist property relations continues in Africa, studies have shown a recent trend towards the formalization of land tenure. Recent research has tended to focus not on abolishing customary laws on land allocation and access in light of a movement to formal tenure but more on harmonizing both regimes and encouraging customary tenure where it is suitable to local needs. A substantial amount of research has also been done on land conflict and especially in the advent of climate change and an increasing population that coupled with other politico-economic stressors may undermine the ability of livelihoods that are primarily reliant on natural capital. This paper contributes to the growing discourse on land tenure in Africa and especially in informing a policy framework that does not only provide a protection for disenfranchised groups but also one that provides civic education opportunities to inform these groups about the said protections. In this paper, I explored the ways in which different groups may be disenfranchised even with the existence of laws and policies meant to protect them. I find that informal land transfers offer a mechanism for landowners to circumvent the often expensive and bureaucratic formal land transfer system. However, in so doing, informal land transfers also provide avenues for landowners to avoid or even disregard the protections offered to groups that may possess access rights to the land being transferred. More research therefore needs to be done on these transfers that are not necessarily customary but are not officially formal because they do not involve the issuance of title to guide policy and prevent conflict. In addition, a review of land formalization policies is necessary for Kenya in order to simplify the process and make it affordable so as to guard against the entrenchment of these informal transfers. 


\title{
CHAPTER 4: CROSS-BORDER ALTITUDINAL GRADIENTS: DIVERSITY AND CHANGE AMIDST MULTIPLE STRESSORS
}

\begin{abstract}
This paper examines the patterns of livelihood diversification and change along the altitudinal gradient of Mt Kilimanjaro. The study utilizes four case studies along the altitudinal gradient to show the diversity of land use and livelihood types between the ecological zones and how social relations among these zones are responsive to both ecological and socioeconomic changes. The study finds evidence of intensification of interdependence and increased livelihood diversification. These changes vary across the gradient but are structured to benefit and exploit the ecological diversity of the gradient.
\end{abstract}

Keywords: Livelihoods, social relations, climate change, gradients, conflict, Kilimanjaro Solomon, M. Cross-border altitudinal gradients: Diversity and change amidst multiple stressors. (Intended to be published in Journal of Rural Studies). 


\section{Introduction}

In Africa, changing social and material relations have resulted in the transformation of both livelihood systems and the institutions that govern local resource allocation and access mechanisms (Smucker et al. 2015; Wangui et al. 2012; Toulmin, 2008; Campbell, 1999). Research indicates that this transformation is largely driven by broader changes in socioeconomic relations as well as biophysical factors (IPCC, 2014). Many climate vulnerability studies have also emphasized that the effects of increased vulnerability due to climate shocks and stresses will be differentiated both socioeconomically and geographically (Smucker et al. 2015; Wangui et al. 2012; Scheffran et al. 2012b; Barnett and Adger, 2007). In addition, the effects of climate change will be more devastating in poor countries and mostly among those livelihoods that are dependent primarily on natural capital (Scheffran et al. 2012a; Shongwe et al. 2011; Fussel, 2011; Samson et al. 2011; Barnett and Adger, 2007). Consequently, there will be differential effects depending on the sensitivity of livelihoods to climate change and this will vary in temporal and spatial terms. According to the IPCC (2014), the effects of climate shocks are likely to increase global and country-scale inequality both for current and future generations especially in developing countries. Consequently, these changes are likely to alter the social and material relations that exist between and within affected livelihood groups and potentially strengthen or weaken the adaptive capacity of these livelihood systems.

However, biophysical changes are only a part of the factors that constitute the causal structure of vulnerability and the material conditions of poor rural households. In Africa, global and national economic policies have affected local resource access patterns 
through privatization, government expropriation, and varying degrees of access to nonagrarian employment among other factors (Wangui et al. 2012; Smucker and Wisner, 2008). Availability of non-farm employment opportunities has resulted in mixed outcomes for agriculture-based livelihoods. For example, O'Brien and Leichenko (2003) found that trade liberalization has benefited many rural farmers through access to local and global markets and made it easier to access alternative sources of income in Southern Africa. However, it had also resulted in increased vulnerability for some due to local and global fluctuation of crop prices, competition with cheaper imports, and other problems associated with a neoliberal agricultural sector. This changing vulnerability status has led to a reorganization of rural social relations of production and created new spatial interdependences among livelihood groups.

While a lot of research has been done on the causal structure of vulnerability and broader scale mechanisms of enhancing coping and adaptive capacity for climate impacts, little has been done on the social benefit of material relations among different livelihood groups living within relatively small but diverse regions. Local scale relations of cooperation and other forms of inter-group contact may confer mutual benefits and strengthen the coping and adaptive capacity of different socioeconomic groups. The material realities of different livelihood systems change rapidly in a relatively small area as you move along a mountain gradient in many parts of Africa. This livelihood diversity within a small area may strengthen livelihoods through mutual interdependence networks and trade.

Land use and livelihood systems vary across the landscape in Africa depending on the availability of resources and social relations of production and conflict. Each of these 
land use and livelihood systems are structured to exploit the ecological niches available at their ecological zone. Majule et al. (2009) have explored the concept of the ecological gradient as a framework for understanding the distribution and the relations that exist among livelihood groups living in different ecological zones in Africa. They argue that land use and livelihood systems vary spatially in line with ecological conditions and these changing practices may be represented as ecological gradients. These gradients may be vertical as in the slopes of mountains or horizontal as in across ecological zones within a vast area. Vertical gradients may also be referred to as altitudinal gradients because they exist on mountain slopes with changing temperature and rainfall conditions as you move from the warmer and drier lowlands to the colder and wetter higher elevations on the mountain. Altitudinal gradients form largely because of elevation change and orographic effects. These altitudinal gradients are characterized by differing and sometimes steep changes in physical and biotic composition giving rise to a system of both distinct and transitional ecological zones that provide varying resources exploited by individuals and groups living there for their livelihood needs (Abbott and Brennan, 2014).

In tropical Africa, these ecological changes within the altitudinal gradient also represent changes in livelihood systems as inhabitants of different ecological zones organize themselves and structure their livelihoods around available resources within that zone. This gives rise to a livelihood zonation from the lowland warm and dry savannas through the relatively cool and wet mid-elevations to the cold and wet high altitudes. However, social and economic relations also exist among the different livelihood groups that live within the same altitudinal gradient. These relations are likely to be more intense because altitudinal gradients are usually more spatially condensed compared to horizontal 
ecological gradients (Majule et al. 2009; Smucker and Wisner, 2008). Livelihood systems in altitudinal gradients organize themselves to benefit or protect themselves from surrounding ecological zones thereby forming a web of interdependence and/or conflict across the different ecological zones (Wangui et al. 2012; Smucker et al. 2015). Social relations of exchange, understanding, and conflict thus exist among varying ecological zones with some zones commanding more resources and economic advantage over others. In their study of land use change along the altitudinal gradient in Mt Kilimanjaro, Majule et al. (2009) claim to have found "[...] strong evidence that the areas of higher economic potential remain advantaged compared to areas lower on the gradient."

"[...] Detailed case studies on the gradients of the slopes of Mt Kilimanjaro, Kenya show how land-use change is responsive to the dynamics of both local and external driving forces." (Majule et al. 2009)

The assertion by Majule et al. (2009) that land use change is responsive to local and broader-scale sociopolitical factors is an important consideration in analyzing social and economic relations within altitudinal gradients. This is because socioeconomic relations between individuals and groups are also relations of power. Power is exercised in the negotiations or conflicts over access and control of resources within the gradient and this may create winners and losers. Power relations are also shaped by sociopolitical and economic as well as biophysical changes at different temporal and spatial scales. Consequently, the socioeconomic dominance of any of the livelihood systems within an altitudinal gradient is rarely, if ever, permanent. Broader scale sociopolitical changes may affect the importance of certain livelihood systems within the different ecological zones and alter the perceived economic benefits of certain commodities thus shifting power and material relations across the gradient. For example, studies have shown that lowland 
pastoralists controlled greater power than their highland counterparts during the precolonial times largely because of access to vast grazing and watering areas and the general perception that pastoralism was more economically productive than farming (Majule et al. 2009; Mworia and Kinyamario, 2008; Campbell, 1999; Tiffen and Mortimore, 2008; Ellis and Swift, 1988). However, pastoral dominance greatly declined in the post-colonial period due to sociopolitical and biophysical changes including: government policies in favor of sedentary agriculture, changes in land availability and access for pastoralists, the perception of pastoralism as anti-modern, and increased climate variability (Eriksen and Lind, 2009; IPCC, 2007; Homewood et al. 2001). More recently, fluctuations in local and global prices of important crops grown higher in the gradient, reducing plot sizes due to population pressure coupled with a changing climate have put pressure on production systems in the high elevation areas of the altitudinal gradient. This may suggest an increasing importance of areas lower in the gradient that have access to irrigation water since they have the ability to produce year round and also tend to have relatively larger per capita land holding.

Nevertheless, the transformation of social relations within livelihood systems in ecological gradients does not only happen in the extremities rather they are becoming increasingly common even within less distinct livelihood systems. For instance, as pastoralism continues to decline due to changing tenure regimes and enclosure in the Kilimanjaro region of East Africa, formerly grazing lands have been turned into zones of mixed farming or irrigated agriculture (Homewood et al. 2009; Mwangi, 2007; Woodhouse et al. 2000; Campbell, 1999). This has transformed the altitudinal gradient into rapidly changing ecological zones and altered interdependence patterns. In some 
cases, some formerly distinct ecological zones have merged over time or much less differences exist between livelihoods in formerly distinct areas. This has also led to the existence of diverse livelihood systems within small areas, which may imply an intensification of livelihood interdependence across the gradient.

Recent studies indicate that climate variability in this region will continue to affect the social and material relations of different livelihood groups within altitudinal gradients as they struggle to cope and adapt to changing resource availability and access patterns (Smucker et al. 2015; Wangui et al. 2012; Eriksen and Lind, 2009). Declining rainfall averages and increasing variability has already disrupted agricultural livelihoods and caused differing levels of livelihood transformation in the altitudinal gradient in Mt Kilimanjaro (Wangui et al. 2012; Majule et al. 2009). Increasing population density has put pressure on agricultural production as plot sizes decrease across the gradient. In addition, increased connectedness in the broader economy has availed new opportunities for livelihood diversification and led to increasing prominence of non-farm livelihood options such as casual labor and dependence on remittances. This suggests that old forms of interdependence across the gradient may be changing or even intensifying as new forms of interdependence or take shape. For instance, Wangui et al. (2012), found that major changes have already occurred among the waPare of the Usambara Mountains of Northern Tanzania with up to threefold change in staple food being reported in the last fifty years.

An institutional framework is critical in managing social relations among interdependent groups. Institutions, formal and informal, exist to facilitate the proper management of resources and mitigate conflicts emerging from differing interests among 
individuals and groups. The existing institutions must also be properly constituted and the people they govern have to perceive them as capable of representing the interests they serve in a fair manner. Smucker et al. (2015:42) found that within the Kilimanjaro region of Tanzania, institutions exist in the local level to govern land use whereby land uses are formally zoned into categories such as agriculture, grazing land, and commercial settlement among other uses. They argue that the existence of these institutions has the “[...] potential to rework access to natural resources that influence patterns of climaterelated risk." However, in the neighboring Kenya, such institutions do not exist at a local level and the land that had been originally classified as pastoral land for herding groups has already been sub-divided into group ranches most of which have in turn been divided and converted into private ownership (Mwangi, 2007). Therefore, although the border communities of the Kilimanjaro region in both Kenya and Tanzania are highly interdependent, the formal institutional structure is highly complicated because of the jurisdictional issues and differences presented by the existence of a national boundary. In addition, the prevailing relations between the two countries may sometimes influence cross-border relations, for better or for worse.

This paper examines how biophysical and sociopolitical factors have influenced social and economic relations among the different socioeconomic and cultural groups living along the Northeastern side of the Mt Kilimanjaro gradient. This is particularly interesting because of the existence of a national boundary within the altitudinal gradient, which presents an interesting dynamic in the relations between local groups and the institutions that govern social relations in these areas. I approach the study from the perceptions of communities living on the Kenyan side of the border in the lowland 
gradients but also use responses from the lowland, middle, and higher gradients on the Tanzanian side of the border to examine the nature and level of interdependence and its driving forces. This study is guided by two main questions: 1) what are the interdependence patterns that exist along the altitudinal gradient of Mt Kilimanjaro in Kenya and Tanzania and how have they changed over time? 2) How have institutions adjusted to changing social relations along the altitudinal gradient and across the political boundary?

This study finds that there is increased diversification and intensification of interdependence among the livelihood groups living along the Kilimanjaro gradient to boost adaptive capacity. Population pressure, decreasing farm sizes, and soil depletion coupled with broader economic changes are driving high elevation farmers into the lowlands in search of casual labor and alternative farming land. In addition, there is an increase in the dependence on remittances and other non-farm sources of income from outside of the region, which may signal an increase in vulnerability among local livelihoods. However this increased dependence on off-farm sources of income from outside the region may also signal a greater integration into the broader economy. I also find that local informal institutions worked better in the resolution of cross-border conflicts and in facilitating cross-border economic relations than formal institutions. In the next section I explain the data and methods used in this study and then define the important characteristics of the region under investigation. I then present the study results and conclude with an explanation of key findings. 


\section{Data and Methods}

This study employs both qualitative and quantitative data and methods. A large part of the data for this analysis was collected as part of the Local Knowledge and Climate Change Adaptation Project (LKCCAP), which was implemented in the PareKilimanjaro region of East Africa in the period between 2009 and 2015. This was a National Science Foundation (NSF) funded research involving researchers from Ohio University, Sokoine University of Agriculture in Tanzania, and Michigan State University. Qualitative key informant interviews and household surveys were conducted on low, middle, and high altitudinal gradients on people's experiences and perceptions of change in climate variability and broader socioeconomic trends. Qualitative key informant interviews and quantitative surveys were conducted in four locations on the Mt Kilimanjaro gradient namely: the lowland area of Njukini in Kenya, the middle gradient area of Shimbi Mashariki in Tanzania, and the higher elevation gradients of Ibukoni and Mokala also in Tanzania. A total of thirty-eight key informant interviews were conducted in the four research locations involving community leaders, elders, government officials, and non-governmental organizations (NGO) personnel working in the area on their perceptions of socioeconomic and ecological change in the area. Qualitative key informant interviews were then coded into descriptive and analytic codes to establish themes on the web of relations and interests that exists between individuals and groups along the altitudinal gradient. A total of one hundred and sixty surveys, forty in each of the four villages, were relied upon for the purposes of this paper. The surveys were entered into a spreadsheet and descriptive statistics were uses to further explain patterns 
in the themes generated from the qualitative thematic analysis. Survey data was also used to illustrate the differences in livelihood organization along the gradient.

To augment data collected in the field and answer important questions on the nature of change in climate variables, a climatological analysis was done for three altitudinal gradients areas using data from the Climatic Research Unit (CRU TS 3.1; Mitchell et al., 2004) for the period between 1980 and 2009. This was done to provide evidence on the nature of change or variability in precipitation patterns, which has a large bearing on agricultural production in these areas. The mean precipitation $(\mathrm{mm} / \mathrm{day})$ and daily mean, maximum, and minimum temperatures (degree $\mathrm{C}$ ) derived from the $\mathrm{CRU}$ datasets were used to calculate the time series of monthly and seasonal mean precipitation (Lee et al. 2009). The CRU climate variables are high-resolution gridded data obtained from meteorological stations over the global land surface. Spatial resolutions (longitude by latitude) of the CRU data are $0.5^{\circ}$ by $0.5^{\circ}$ and the data are available from 1901 to 2009. The CRU data was obtained from the data center for the atmospheric sciences at the British Atmospheric Data Center (BADC) in the Natural Environment Research Council (NERC). The regional climate variables for Taita-Taveta in the Kenyan side and the greater lower Rombo region of Tanzania were extracted from the high-resolution precipitation and temperature data using existing CRU grid points from which CRU aggregates rainfall data for the area (Shongwe et al. 2011; Lee et al. 2009) over a longitude and latitude domain including the study sites (Taita plains 38.25 E, 3.25 S; Njukini, 37.75 E, 3.25 S; and Kilimanjaro, 37.25 E, 3.25 S). Note that the area noted as Njukini in the seasonal rainfall variation analysis is a point close to the Kenya Tanzania border that is relatively higher than the villages from where the lowland surveys 
and qualitative interviews were conducted. This data was also compared with station data from the region for accuracy assessment. A correlation comparison between thirty year (1980-2009) March-May (MAM) rain gauge data from the nearest station in Voi, which is lower in elevation (577 m.a.s.l) and drier, was compared to CRU values for Taita and were found to have a significant positive correlation with a Pearson's R of 0.9. Figure 2 shows how the data varied between the two datasets. The temporal and spatial climatological analysis was performed in the Grid Analysis and Display System (GrADS), which is a programmable interface that allows for visualization and statistical analysis of climatological data (Doty, 1995).

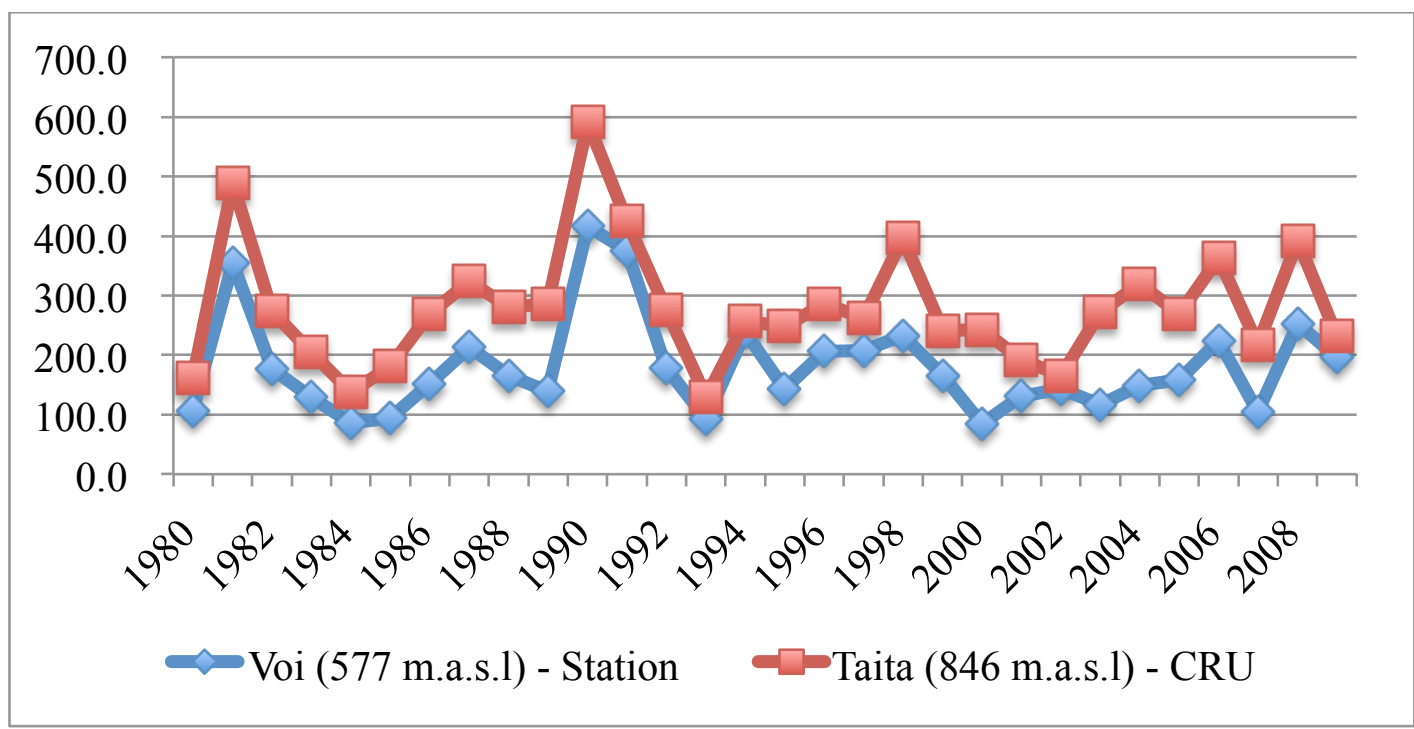

Figure 2: Annual March-May precipitation totals (Station and CRU data comparison), 1980-2009

\section{Changing Ecological and Socioeconomic Systems along the Kilimanjaro Gradient}

The ecological gradients along the Mt Kilimanjaro altitudinal gradient have unique resources that change as you move from the lowlands to the higher altitude zones. 
These agro-ecological zones provide various opportunities for the different livelihood groups found in this area and that influences the land use types found along the gradient. This study covers three agro-ecological zones: the lowland zones $(<1000$ m.a.s.1.) of extensive pastoralist, mixed farming, and irrigated agriculture; the midland belt (1000 1200 m.a.1.s.) which is characterized by intensive crop farming, especially maize and beans; and the highlands (1200 - 2000 m.a.l.s.) which is the coffee-banana growing belt (Majule et al. 2009; Soini, 2005). The rest of the ecological zones in the higher elevations of the mountain include: the Montane forest and the Alpine desert at the summit (Majule et al. 2009; Mbonile et al. 2003). However, it must be noted that these ecological zones are not as distinct as presented because there are transitional zones between each of the ecological zones that may have characteristics similar to each zone on both sides of the elevation gradient. Also similar crops such as maize and beans are grown across the gradient although the varieties may vary with ecological characteristics and resources. Figure 3 shows the locations of study sites along the Kilimanjaro gradient. 
Study Sites Along the Kilimanjaro Gradient

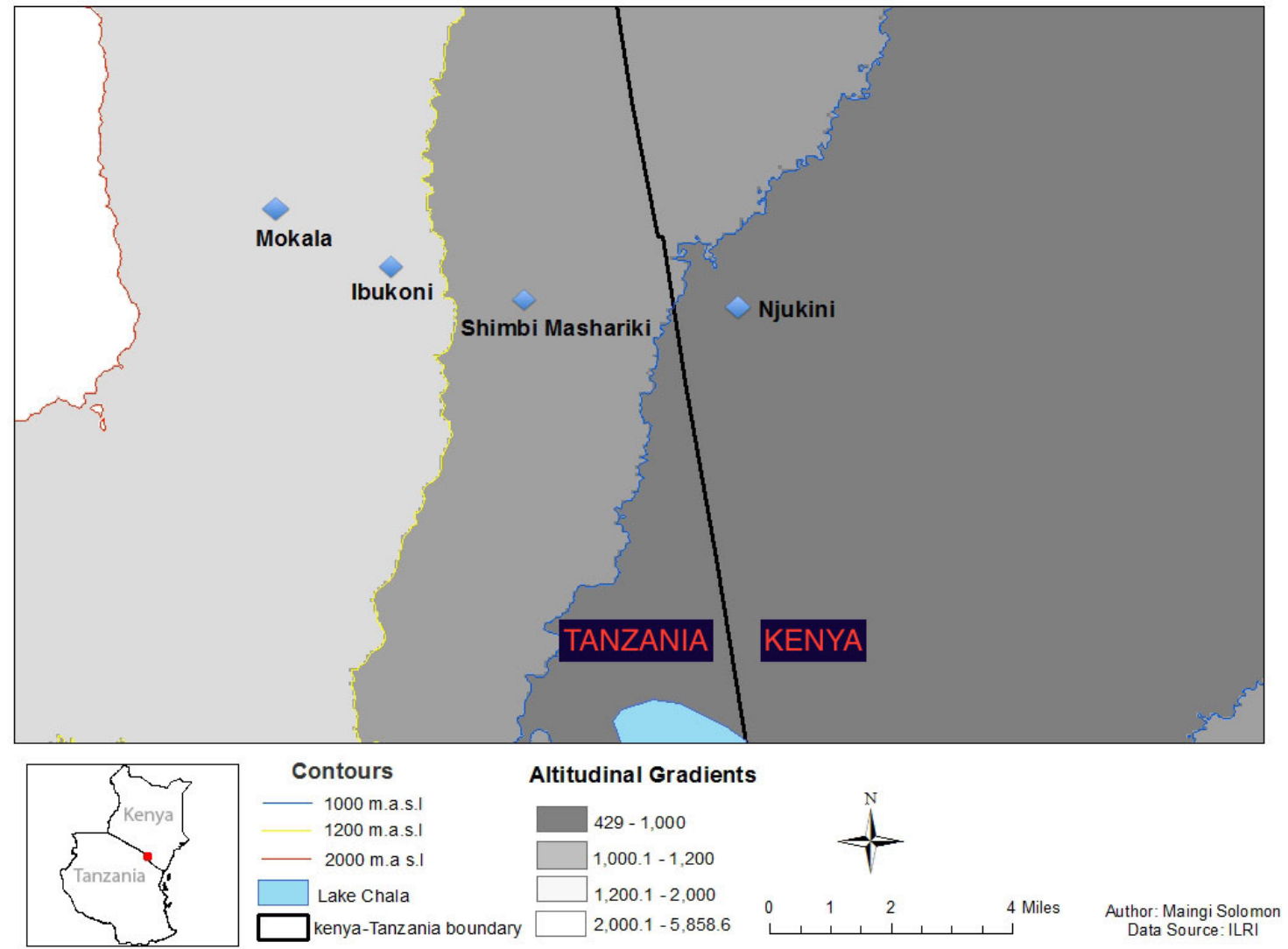

Figure 3: Study area - From the lowlands of Njukini to the high elevation Mokala

Two rainy seasons and two dry seasons associated with the migration of the Intertropical Convergence Zone (ITCZ) characterize the climate of the Kilimanjaro region. The rainy seasons include the long rains (March - May) known as Masika in KiSwahili and the short rains (October - December) known as Vuli in KiSwahili. After each rainy season is a dry season known as Kiangazi in KiSwahili. The intensity of the rainy and dry seasons varies greatly in both temporal and spatial terms along the gradient. According to Soini (2005), annual average rainfall varies between $200 \mathrm{~mm}$ in the lowlands to $2000 \mathrm{~mm}$ in the coffee-banana belt suggesting a great difference between average annual rainfall in the lowland and the annual averages for the higher gradients. It was therefore necessary to conduct a precipitation analysis to illustrate the seasonal precipitation trends for the region. This was particularly important for the lowlands 
because they are more sensitive to rainfall variation because their seasonal averages are relatively low. For example, a majority of respondents in the lowlands observed that the long rains or Masika (March - May) had become almost totally unreliable making it difficult for farmers, as they sometimes had to go for nine months of the year without harvest. In some cases, the duration between rainy days was so variable for this region that even when there was a relatively regular amount of rainfall the crops would not withstand the variability. This quote from a local elder from Njukini sums up the frustration of local farmers in the lowlands:

"[...] The long rains are not reliable. Sometimes it rains heavily for just two weeks and then when you plant and expect it to rain again the rain does not come back so the plants just wither and dry in the farms. By the time the rain comes back the crops are only good for feeding livestock."

An analysis of thirty-year annual mean precipitation shows great variability in precipitation patterns in the entire region. Figures 4 and 5 illustrate rainfall variability for three adjacent grid points derived from CRU precipitation. The selected grid points range from an elevation of 846 m.a.s.l in the Taita region to 1267 m.a.s.1 in the slopes of Mt Kilimanjaro in Tanzania and stretch a ground distance of $111.15 \mathrm{~km}$. March to May (MAM) precipitation totals for both Njukini and Taveta, which are lowland regions, seem to have relatively lower peaks for the last twenty years compared to the previous decade. For the higher elevation Kilimanjaro grid point, the totals are higher than the lowland regions with an unusual high of 1657 during the El Niño period of 1997/1998. All three locations show evidence of high variability for the MAM season with the period between the years 1990 to 2000 being the most variable. The period between 2000 and 2009 has relatively lower MAM totals compared to the previous two decades. Precipitation totals for the October to December (OND) season are relatively lower than the MAM season. 
The OND season also has more year-to-year variability especially for the period between the years 1980 to 2000 after which we see less variability from year to year but also less total annual precipitation for the season. Overall, the three regions registered less precipitation totals for both seasons in the 2000-2009 decade than in the previous two decades. This information is consistent with responses from key informant interviews that suggested precipitation for MAM season is unreliable because of its variability within the season (onset, end, and between rainfall events) rather than its totals. The overall reduction in precipitation totals in the last decade of the study period could spell an increasing vulnerability to agricultural livelihoods in this region.

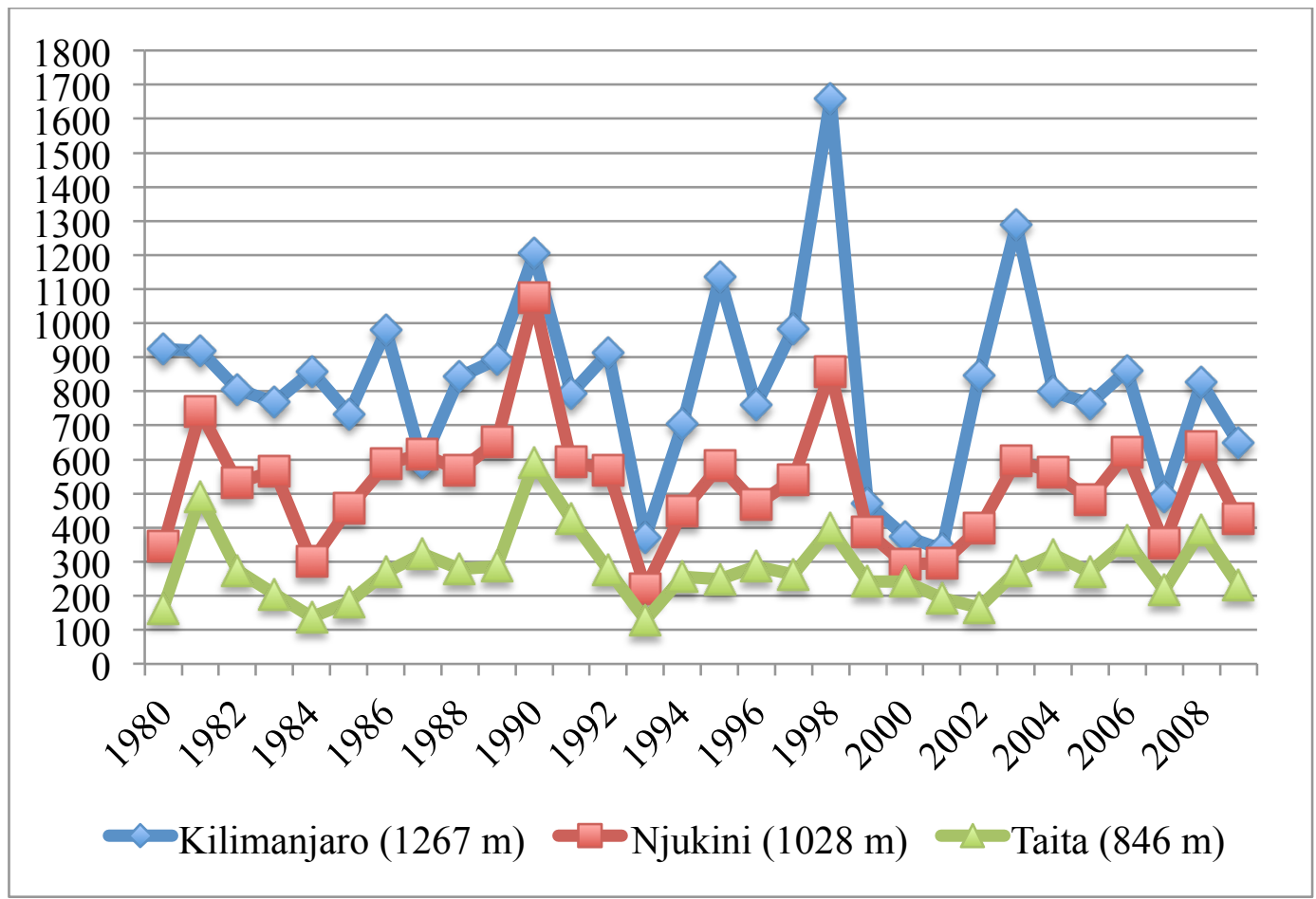

Figure 4: CRU Annual March-May precipitation totals, 1980-2009 


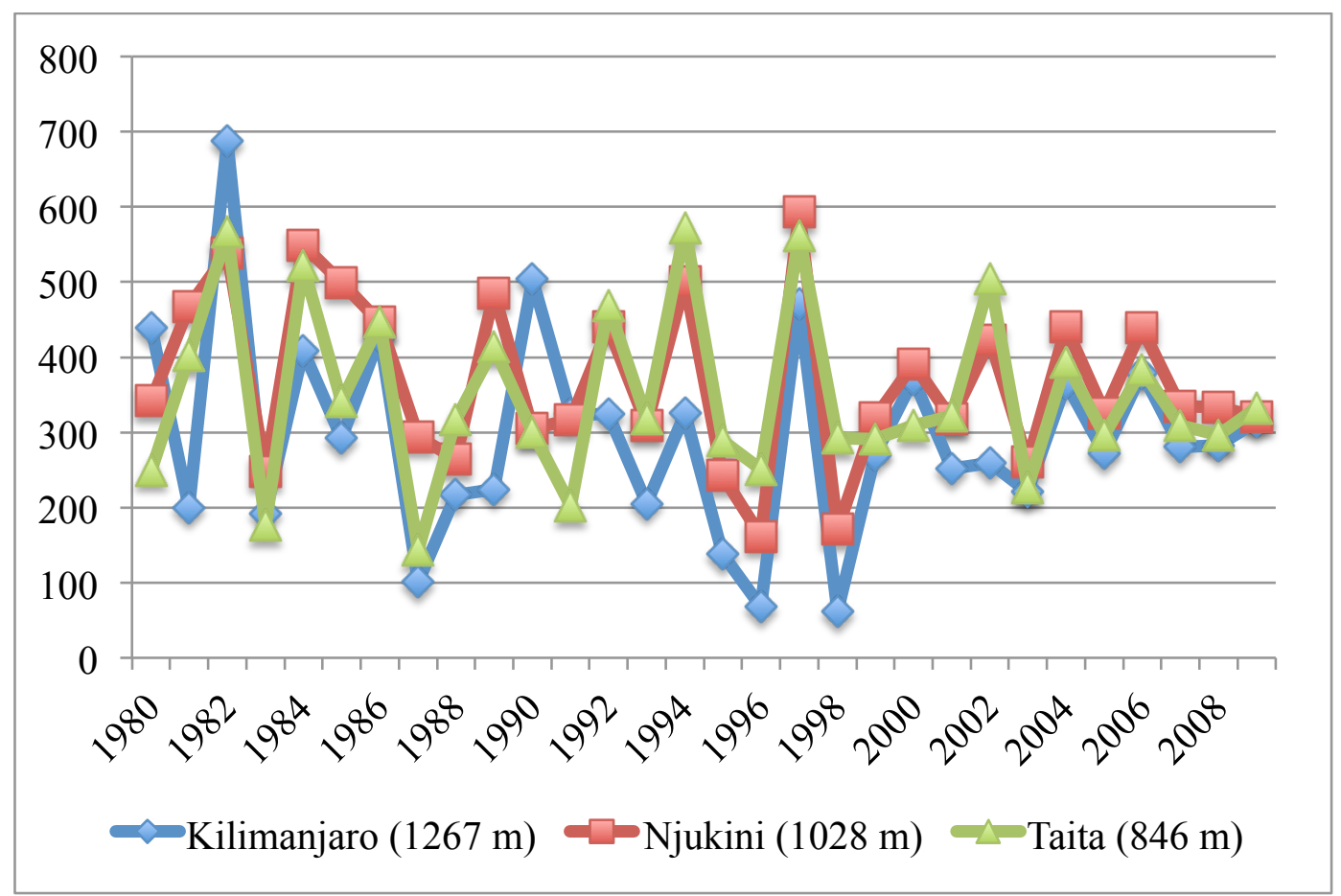

Figure 5: CRU Annual October-December precipitation totals, 1980-2009

This variability is also reflected in the qualitative responses with respondents in the lowlands complaining of inadequate rainfall, decreases in water availability as formerly permanent streams turned seasonal, late and early onset of precipitation as well as early end. This anecdotal evidence shows that annual average rainfall numbers may be important in informing us about year-to-year variations but are deficient in an analysis of the impact of variability on farming systems. In addition, livelihood systems vary greatly in the lowlands, as there are farmers with access to irrigation water and therefore who can produce all year. Those farmers without irrigation water practice mixed farming or pastoralism and they generally reported larger farms than those groups in the high elevations or those in lowlands with access to water for irrigation. Some mixed farmers in the dry lowlands without access to water also lease out their land to pastoralists during the dry seasons for grazing. Livelihoods within the Kilimanjaro gradient are thus 
structured to benefit in some way from each other although these benefits vary in time and space.

Respondents in the lowlands were also more sensitive and aware of the discourse on climate variability and change with many of them saying they have observed changes and variations in climate patterns over the last thirty years. This suggests that climate variability and change are a priority issue in the lowlands as many respondents said they were worried about how sufficient rainfall would affect crop yields and more generally their livelihoods. In the highlands, respondents were concerned about cropland productivity, increased costs, crop and livestock diseases, and decreasing farm sizes. Respondents in these zones also reported increased incidence of malaria but did not directly associate it with climate. Whereas majority of the key informants interviewed in the highland zone said that they had observed changes in climate patterns in the last ten to fifteen years a claim which is evident from the precipitation graphs, majority of those interviewed in the lowlands said that changes had been observed since the late 1970s and early 1980s. However, some of the highland farmers reported variable crop yields because of unpredictable rainfall patterns in their lowland farms that had no access to irrigation water.

Another major change reported was the change in crops produced and their uses. In the lowlands, there was increased intensification of irrigated agriculture. Because of the proximity to Mt Kilimanjaro, the water table for the lowlands is not very low and several rivers and springs flow within these lowland areas. There are also many boreholes within homesteads producing water for both domestic and irrigation uses. However, according to key informant interviews in Njukini, extensive irrigated agriculture only 
started in the late 1980s and early 1990s due to population pressure and decreasing farmland sizes. Before then, irrigated agriculture was practiced mainly in the areas close to the main rivers and many farmers produced for subsistence. During the research in Njukini, I observed that almost all households visited with access to water for irrigation practiced some level of irrigated agriculture. These varied from small backyard vegetable gardens to intensive irrigated farms which grew cucumbers, beans, pepper, tomatoes, and other horticultural crops for export to Mombasa, Nairobi, and overseas. Millet, sorghum, cotton, and other drought resistant crops were also common in the lowland areas without access to irrigation water.

The midlands and the highlands have also undergone substantial changes in terms of crop types and uses. In the midlands, coffee and banana production had almost ceased and farmers reported major decreases in maize and bean crop productivity. A key informant in Mokala reported that within the past twenty to thirty years coffee productivity had fallen from about $240 \mathrm{Kg}$ to between $30 \mathrm{Kg}$ and $50 \mathrm{Kg}$ in his farm. $\mathrm{He}$ also reported the drying of coffee and banana trees in the area. However, these changes were attributed to several factors including drought, crop pests and diseases, decreasing farmlands, and soil nutrient depletion. In the highlands, decreases in coffee and banana production were reported with all key informants reporting at least a reduction in coffee and banana yields. There was also a decrease in the number of livestock kept. Like in the midlands, these decreases were attributed to several factors including ageing of coffee and banana trees, soil nutrient depletion, and high population density leading to a decrease in farming land. A key informant from Mokala reported an increased use of bananas as a source of food rather than as a key ingredient for making alcohol. 


\section{Livelihood Interdependence Patterns}

Livelihood interdependence in the Kilimanjaro gradient is not just a way of coping with extreme variation in climate patterns but it also offers avenues for strengthening livelihoods and adjusting to broader changes in the political economy. This is evidenced by the changes in settlement and social relations of production that occurred through time in this region. While most of the highland and midland gradients have long histories of settlement and land tenure the lowlands were mostly permanently settled in the last quarter of the $21^{\text {st }}$ century. For example, $96 \%$ and $91 \%$ of survey respondents in the highland and midland gradients of Mokala and Ibuloni respectively reported to having born in that village compared to $70 \%$ and $45 \%$ in the lower gradients of Shimbi Mashariki and Njukini respectively as shown in figure 6. Key informant interviews also showed that the lowland gradient of Njukini was mostly settled in the 1970s although it provided an important grazing land for Maasai pastoralists from neighboring Kajiado and Loitoktok and also beekeeping space for the Taveta before the mass settlements of the 1970s and 1980s. These changes in settlement patterns with time point towards an increasing importance of lowland areas for livelihoods living there and also diversification options for those living higher in the gradient. 


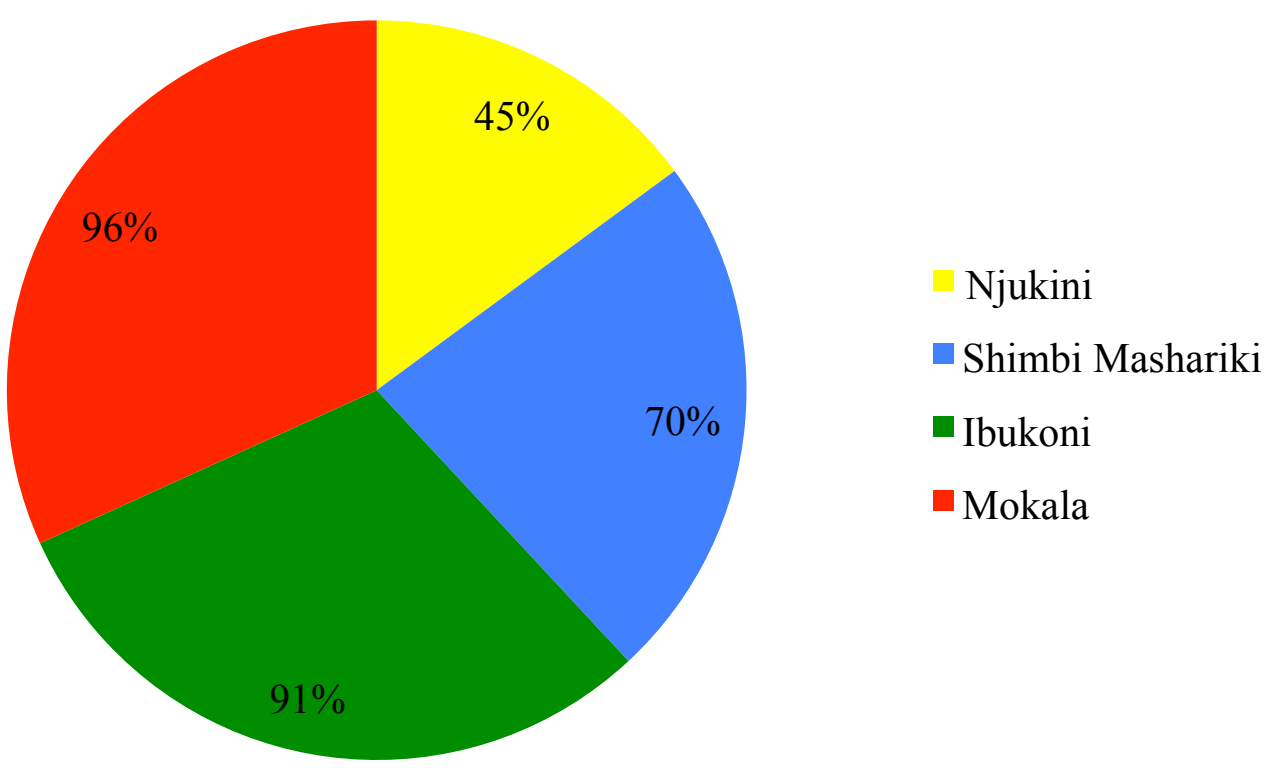

Figure 6: Percent of residents born in village of residence

Land holding is also an important indicator of livelihood interdependence in the Kilimanjaro gradient. In the higher gradients of Mokala and Ibukoni, $60 \%$ and $47 \%$ respectively reported a household landholding of less than one acre with about $4.4 \%$ of household reporting no land at all in both places. In a place where production systems are centered on the land resource, further land fragmentation can only lower the productivity of local agricultural systems exerting even more pressure to a system that is already under threat. This situation raises serious questions about the future of these highland livelihoods and whether it is possible to reverse deteriorating patterns of productivity reported by key informants. In the lower gradients, landholding was much higher with $62.5 \%$ of respondents in Njukini reporting between one and three acres while in Shimbi Mashariki 37\% reported a landholding of between one and three acres. However, 20\% of the highland gradient respondents of Mokala reported to have cultivated an alternative farm in the lowlands in the last year while $84.45 \%$ of respondents in Ibukoni reported to 
have cultivated a lowland plot in the previous year. This high number of alternative plots for respondents in Ibukoni may be attributed to the location of Ibukoni as a transitional zone between the lowlands and highland gradients. Figure 7 and 8 summarize landholding patterns in the study sites. Access to alternative land in the lowlands for highland households was through various methods ranging from private ownership to seasonal, yearly, and several year leases. The size of household land in the highland regions of Mokala suggests that meaningful non-subsistence production has already collapsed. What exists is production of a variety of both cash crops and food crops at a very small scale and with increasing population; these production systems are also under threat. With lowland regions helping absorb the pressures associated with dwindling land and other resources in the highlands, one wonders how long this can continue until it reaches a breaking point.

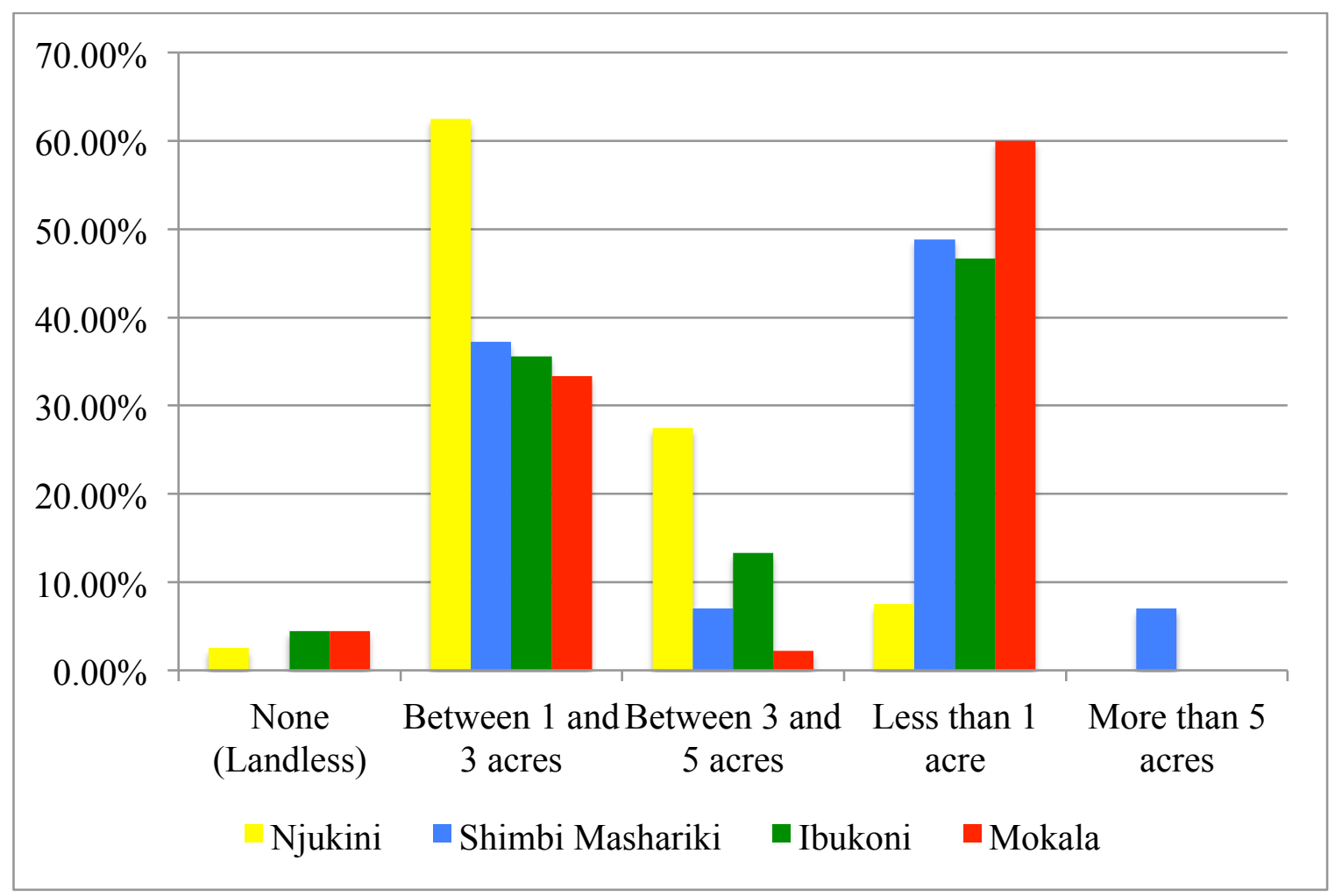

Figure 7: Size of primary household plot in acres 
Figure 7: Size of primary household plot in acres

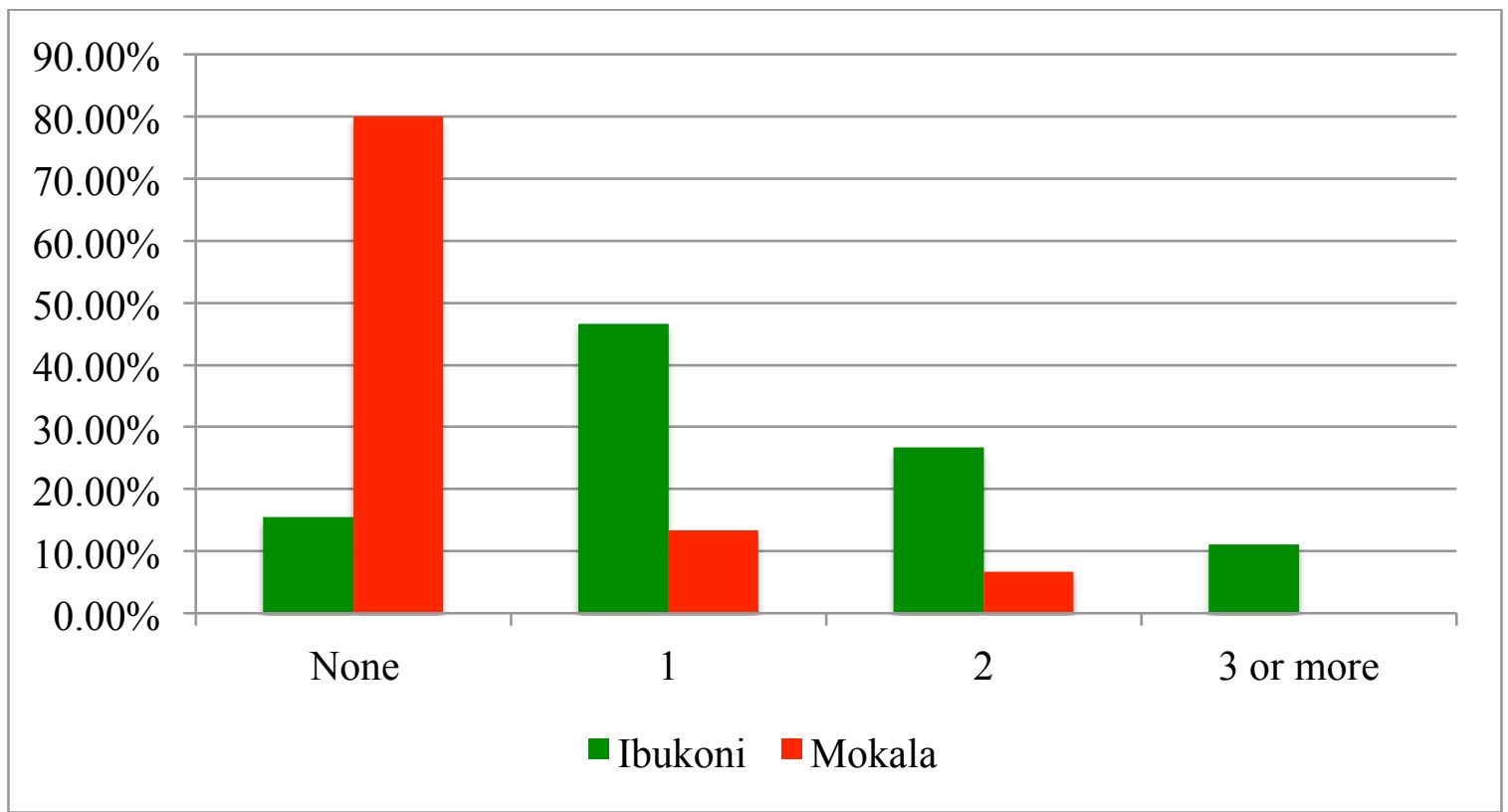

Figure 8: Number of lowland plots cultivated in the last year

Many households across the altitudinal gradient reported farming as their primary source of livelihood although many other households reported a mix of farming and other activities such as casual labor and trade. These responses also varied with the altitudinal gradient. For example, figure 9 shows that $20 \%$ and $31.12 \%$ of respondents in the higher gradients of Mokala and Ibukoni respectively reported a diversified livelihood that included farming, labor, and trade as the primary occupation of the household head while only $11.63 \%$ and $12.5 \%$ of respondents in the lowland gradients of Shimbi Mashariki and Njukini respectively reported similar livelihood practices. Key informant interviews echoed these responses. For instance, several key informants from Njukini's irrigated areas reported large numbers of people seeking casual labor from the higher elevation areas across the border. Several respondents from the non-irrigated areas within Njukini also complained that this movement of people from across the border was driving daily casual wages down in the irrigated areas. An interesting observation from responses 
among the lowland farmers within the irrigated areas of Njukini on the Kenyan side of the border was that extensive irrigation in the area did not start until the late 1980s and early 1990s. One of the key informants asserted, “[...] I remember, it was just the other day when the people here started irrigated farming. We did all the work and did not know where to sell our produce. Now there are so many people from here and across the border (in Tanzania) looking for work."

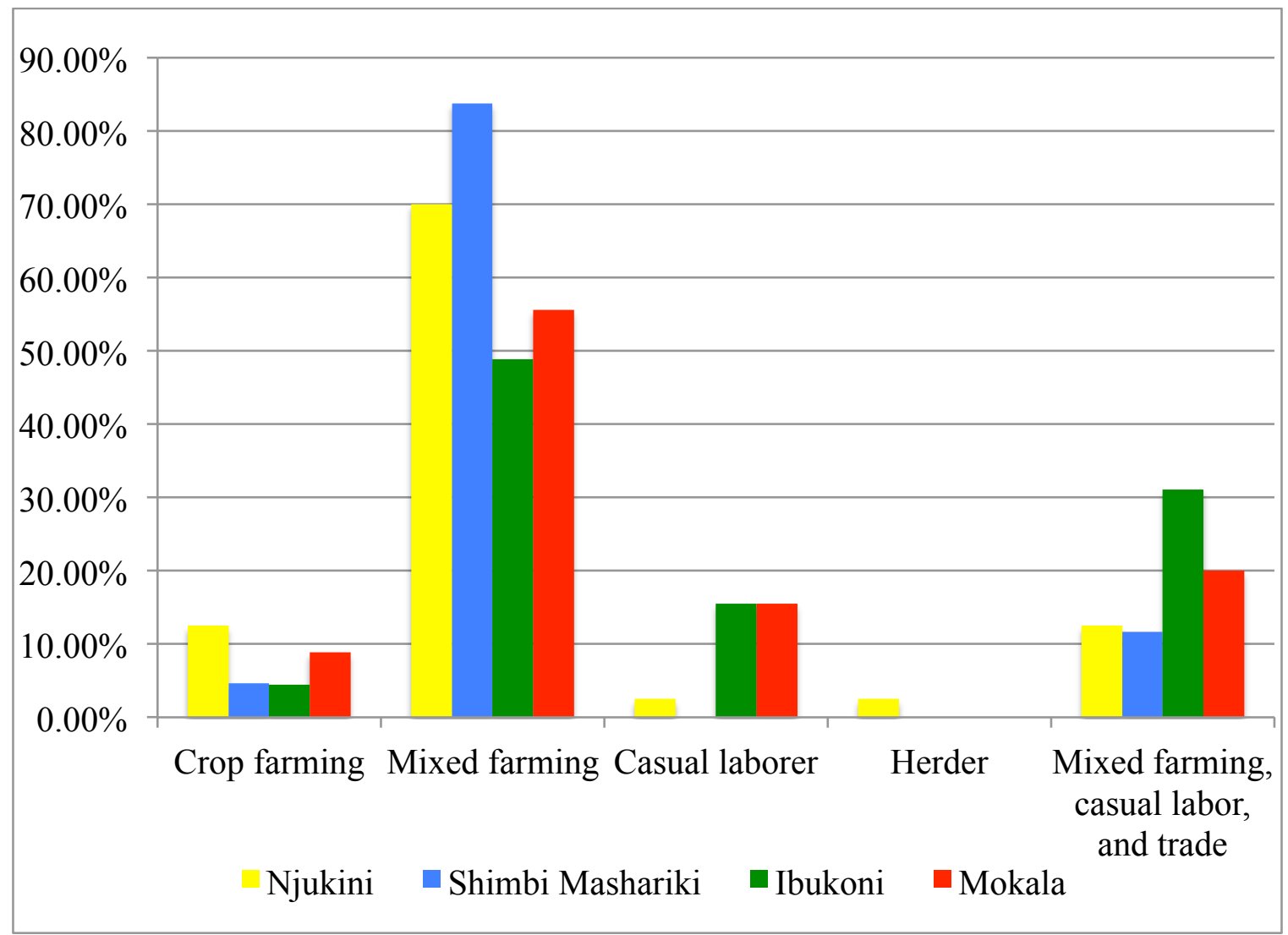

Figure 9: Primary occupation of household head

Access to water for irrigation, domestic use, and for livestock in the lowlands is critical in maintaining livelihoods. The main water access points consist of rivers, boreholes, shallow wells, and springs. The farmers in these regions have the advantage of practicing irrigated agriculture all year round producing horticultural crops for both the local market and exports. Some of the crops produced include tomatoes, cucumbers, 
chilies, brenjols, capsicum, green beans, maize, beans, potatoes, and green grams. However, too much consumption of the water resource during droughts in the irrigated areas results to a significant reduction in water in other areas in the lowlands. For example, key informant interviews suggested that continued exploitation of streams supplying the Tsavo River by farmers upstream, in the villages of Sir Ramson and Town in Njukini, leads to drying up of the streams relied upon by herders who live lower in the gradient, around Lumi. This creates conflicts between farmers and herders because small farms, which are not fenced as farmers try to utilize all the available space for farming, surround the springs in the irrigated areas. Key informant interviews reported that herders are known to drive their cattle through the irrigated farms into the watering areas causing violent clashes with the farm owners.

These interdependence patterns raise important questions about livelihood vulnerability, climate change adaptation, and material change for livelihoods living along the Kilimanjaro gradient. Over time the relations between lowland farmers and their highland counterparts have changed with those with access to irrigated water becoming more and more important in not just providing casual labor but producing cheaper food around the year for locals on both side of the border. However, this intensive irrigated farming only started in the late 1980 s and could be seen as an adaptive response to the impacts of climate variability and change in the lowlands. Irrigated agriculture is also facing similar challenges to those faced by highland farmers. Access to land in the irrigated areas of Njukini is difficult and the plot sizes are relatively smaller compared to other lowland without access to irrigated water. Cases of soil nutrient depletion, run off, new crop diseases, among other challenges were reported in the irrigated areas which 
leads to the question of whether the pressures facing highland livelihoods will be replicated in the irrigated areas in the near future. Currently, lowland irrigated areas and the highlands are able to provide cheap produce, diversification options such as casual labor, and opportunities for trade because the differences in commodities produced along the gradient.

Although highland farmers continue to have relatively higher economic potential compared to others lower in the gradient, the lowlands have recently become more important. This may signal shifting power relations among the different livelihood groups within the Mt Kilimanjaro gradient. As highland farmers chock with high population density, shortage of faming land, new crop diseases and fluctuating coffee prices, the lowlands provide alternatives for diversification, which intensifies social and economic relations among the different livelihood groups living in different ecological zones. The economic advantage conferred by the access to a good climate in the higher gradients is under threat from political economy factors such as access to land, labor, water, and markets for crops which in turn is causing a reorganization of social and economic relations along the Kilimanjaro gradient. The intensification of social and economic relations can be viewed as a positive step towards climate adaptation and especially for those living in the lowlands. In comparison to other livelihood systems along the gradient, farmers in the lowlands without access to irrigation water were more vulnerable to climate variability although they tended to have access to more land. This access to more land allowed them to lease their land to herders and mixed farmers for pasture during dry seasons. 


\section{Cross-border social networks and institutions}

The intensification of social and economic relations among the different livelihood groups living along the Mt Kilimanjaro gradient comes with a heightened risk for conflict and the need to build institutions that promote social cohesion. The social networks among different groups along the gradient are rooted in histories of migration and settlement, ethnicity, kinship, and different types of material relations among other factors. These relations can be a source of unity and cooperation and thus serve to strengthen local cross-border livelihoods. However, these differing relations may also be a source of opposing identities and divisions and conflict. This is further complicated by the existence of a national political boundary, which brings into play jurisdictional issues that may make it more difficult to resolve issues using traditional inter-state mechanisms.

Key informant interviews suggested that the national border is an important asset in livelihood diversification for groups living on both sides of the border. For instance, there was thriving trade on commodities such as farm produce, wholesale industrial goods, livestock, transportation, and small-scale retail goods. This trade is facilitated by availability of uninterrupted motorcycle transport locally known as bodaboda across the border. The border does not have a customs office and therefore all kinds of goods can pass through it with minimal restriction. Many respondents suggested that cross-border trade is beneficial for livelihood diversification and drought coping because commodity prices in Tanzania are more favorable than on the Kenyan side. The lack of a customs office made cross-border trade much easier because movement across the border is almost unregulated and traders did not have to pay customs for their goods as one of the key informants in Njukini stated. 
"The prices are very favorable in Mkuu (referring to one of the main towns across the border in Tanzania). The youth mostly conduct that trade by use of their motorcycle taxis. They use bodaboda to transport goods across the border to the business people in the market. Others use bicycles and they do not pay any custom duty."

There was also a gendered aspect in both the person involved in various trade practices and the types of commodities traded. Most women crossed the border to buy and sell retail items such as tomatoes, onions, sunflower oil, and fruits. On the other hand, a lot of men crossed the border to sell livestock, transport traders and their goods, and also to buy timber for building because higher in the gradients. One of the key informants, a local businessman in Njukini, said that they depended on their Tanzanian neighbors who crossed the border to purchase Kenyan manufactured products and livestock for sale in Tanzania since they were mainly Chaga crop farmers. Participant observations also indicated that many young men work on the border point as businessmen and are mainly engaged in currency exchange and transportation for goods across the border. There were also strong kinship and ethnic ties between groups across each side of the border. Survey responses and key informant interviews shoed that several families stretched across the border while other ties were through intermarriage. For instance, $8 \%$ of survey respondents in Njukini were Chagga women married to men from Kenyan tribes. Kenyan herders, mostly ethnic Maasai, were also able to appeal to ethnic and kinship ties on the Tanzanian border to move their cattle across the border into Tanzania during periods of drought.

However, despite the many economic and social benefits of the intensification of cross-border interdependence and social relations, a history of conflict and illegal activity was reported. Illegal livelihood activities such as trade in illegal drugs, mostly marijuana, 
trade payment disputes, and cross-border livestock thefts were not uncommon. Key informant interviews reported that illegal cross-border activities were prevalent and were mostly facilitated by the existence of the international boundary. This international boundary is largely controlled from the capitals of Nairobi Kenya and Dodoma Tanzania. However, local scale social and economic relations including illegal activities were left to local formal and informal institutions. Apart from the informal agreements and institutions that had been arranged between local communities to resolve conflicts and regulate cross-border relations, the formal structures that exist between the two countries remain different and operate only within the country in which they have jurisdiction. Informal institutions backed by the established government institutions on both sides of the border dealt with local scale cross border conflicts.

Due to the shared historical roots of many communities living in this border region, social ties among them facilitated a general relationship of friendship and cooperation, which allowed for small disputes to be resolved amicably by informal institutions. For instance, local conflict resolution committees known locally as Kamati za ujirani mwema (Swahili for Committees of good neighborliness) that existed on both sides of the border worked together to resolve cross-border conflicts. These are pseudoinformal institutions because some members of the local government such as chiefs were members. An interesting observation was that locals from both sides of the border knew the members of these committees and their authority was acknowledged across the border. There were also other local informal institutions called Nyumba Kumi (Swahili for ten households) in the Kenyan side of the border, which were headed by one of the members of the ten households. The head of Nyumba Kumi worked with the chief to 
resolve conflicts involving his/her members and were only found on the border areas. It should be noted that these institutions exist in many border regions in Kenya and are meant to help the government identify legitimate citizens. They are therefore different from the Nyumba Kumi envisioned by the taskforce that was established by the Kenyan president after the 2013 Westgate attack by Islamic militants associated to Somalia's al Shabaab.

A substantial number of groups that would have otherwise been considered farmers or pastoralists in African drylands are reporting increased reliance on alternative income sources such as casual labor, remittances, and trade as part of or their primary sources of income. This is happening in the Kilimanjaro gradient within a context of changing levels of integration into the broader political economy and climate variation. Opportunities for livelihood diversification offered by the great variation in ecological conditions over a relatively small area within the Kilimanjaro gradient provide local livelihoods with diverse benefits and allow for the intensification of social and economic relations. Different ecological and socioeconomic pressures coupled with a rich history of interaction and cooperation for mutual benefit also serves to strengthen social networks and institutions that govern local patterns of resource access.

\section{Conclusion}

This study shows that there is various land use types within the ecological zones along the Mt Kilimanjaro ecological gradient. These various land use types are change as you move up the gradient from the plains to the highlands. The various land use types within the ecological zones give rise to different livelihood systems, which are set up to exploit the resources that come with the ecological conditions of their location in the 
gradient. This study also shows that there is increasing livelihood diversification within the different livelihood types found in the gradient in response to ecological and other changes associated with political economy. This livelihood diversification varies along the gradient and includes increased dependence on livelihood options such as casual labor, trade, remittances, and cultivation of alternative land in different parts of the gradient. The patterns of change in livelihood diversification vary across the gradient. For instance, the irrigated lowland areas intensifying horticultural production as cash crops while the highland dependence cash crops such as coffee production wanes. Population pressure, soil depletion, decreasing farm plots, and government policies against the mountain forest encroachment are driving highland communities down the gradient to the lowlands in search of casual labor and alternative land for farming.

This study also shows increased interdependence among various livelihood groups along the gradient. The intensification of interdependence can be seen as both a diversification option and a way to transform livelihoods in response to ecological and economic change. The intensification of interdependence not only comes with benefits to foster cooperation and strengthen livelihood but also with challenges as conflicts arise due to increased contact among individuals and groups. The open national boundary is an important part of this intensifying interdependence and diversification as it provides crucial livelihood options through cross-border trade and social networks. Due to the unique location of the study area, institutions exist that govern social relations across the inter-state boundary and are largely able to resolve conflicts despite the existence of complicated jurisdictional issues. Local arrangements between formal and informal 
institutions worked better in resolving cross-border conflicts than purely formal institutions because of broader state politics and local perceptions of representation. 


\section{CHAPTER 5: CONCLUSIONS}

This dissertation was about using social relations to explain the complex relationships between climate impacts, livelihood vulnerability, conflict, and changes in resource access patterns. Livelihood systems in many rural developing countries comprise social relations of both competition and cooperation and these relations may sometimes strengthen livelihoods or even cause conflict. The social relations in these places are also rooted in particular historical and material contexts but change in response to changing ecological and politico-economic trends. Consequently, temporal and spatial dynamics may affect the nature of social relations among individuals and groups living in a particular area and affect the types of livelihood choices that they make. For example, although resource conflicts among different groups in Africa existed even in the precolonial period, it is widely accepted in political economy studies that the transition to capitalism through enclosure of natural resources by colonial and post-colonial governments continues to provide avenues for grievance and conflicts. This is even more important because rapid economic transition in many African rural economies is occurring in the context of changing ecological factors and therefore livelihood groups in these areas find themselves adjusting to multiple stressors at any particular time. However, these changes produce both losers and winners, which in turn may change local and broader power relations that are important in influencing access and control over local resources. For instance, a growing middle class in many African cities and towns has increased the demand for food therefore greatly benefitting some rural farmers with access to these markets. However, this situation coupled with increased wastage by the 
middle class drives up food prices and increases the vulnerability of those who cannot produce or consume at the price for which the middle class is willing to pay.

This dissertation examined how changing social relations as a result of changes in both climate and the political economy may affect rural livelihood systems and conflict trends. Through three articles, I illustrate the complex web of social relations that underlie the interaction of individuals and groups, how these relations change in time and space, and how these changes may alter the power dynamics that affect access and control of resources at any given place. The social relations may involve competition, cooperation, and conflict and these relations may sometimes exist at the same period and in the same place. In addition, the intensification of relations between individuals and groups may serve to strengthen local livelihood systems by providing diversification options from traditional livelihood sources. However, relations of competition and conflict may sometimes turn into violent clashes or undermine the livelihoods and existence of certain groups or individuals especially in the absence of necessary institutions for conflict resolution. Institutions are therefore critical for regulating social relations and maintaining an environment in which different interests can thrive without conflict or violence. This is in recognition that during this time of rapid politicoeconomic and climate change in rural Africa, social relations tend to oscillate between modern private property rights and customary tenure, which is considerably communal with a lot of gray area. Consequently, modern property relations are generally not how resource claims are made; rather, what exists is a series of access claims about who gains and maintains access to resources at different times and across multiple scales. 
These changing power relations in turn lead to a reinvention or transformation of existing institutions or the creation of new ones to respond to the new power structures. As explained throughout the dissertation, institutions are critical in arbitrating conflicts between groups especially in cases where increased contact has become necessary for strengthening livelihoods. Cooperation and harmony between institutions that serve different groups is also important in building capacity and also for enhancing a positive perception across their areas of operation. This is because people's grievances may be influenced by the way they perceive previous conflicts to have played and how different institutions may have handled them. Both local and broader formal and informal institutions must also reinvent themselves in order to be able to handle changes that arise as a result of changing social relations.

\section{Themes of this dissertation}

This dissertation was organized into three papers that answer a set of different but related questions about the way people respond to political economy and ecological changes. The three papers broadly dealt with the following issues: one, the climate conflict nexus and why social relations are important in influencing conflict trends, two, changing social relations around land allocation and tenure in Africa, and three, changing social relations among livelihood groups within the Mt Kilimanjaro ecological gradient. All these social relations were examined within the context of changing material and ecological factors. The general findings were: firstly, local livelihoods change in response to ecological and politico-economic changes. However, these changes are often asymmetrical and happen within a particular historical and material context. Consequently, individuals may respond differently to similar climate or economic 
stresses at different times. For instance, conflict may arise as a result of either positive or negative changes in ecological and/or politico-economic factors. Chapter two illustrated that climatic or even economic variables may not be sufficient in explaining the causes of conflict because of the multiplicity of factors that may underlie any particular conflict and also because these same factors may have the opposite effect of creating peace and more cooperation at different times and in different places. In fact, the same variable may produce conflicting responses in the same place at different times. For instance, economic growth may be both a consequence and a cause for conflict since it may disenfranchise certain groups and fuel grievances for conflict.

Secondly, ecological and politico-economic change is influencing and transforming the way individuals and groups relate to each other in Africa's drylands altering power relations and creating new winners and losers. Chapter three examined changing social relations around land and how that has produced a third system of land deals outside of customary and formal tenure. These changes are largely a response to overly bureaucratic and expensive formal titling regimes and a customary system that is highly variable and unequal. Policies and laws enacted to empower certain groups of society to afford them access and control may therefore be eroded by the existence of this third superstructure that is produced by the lack of harmony between the two accepted systems of land tenure. In Chapter three, I illustrated how the traditional dominance of highland farmers since the mid twentieth century may be slowly eroded by changing ecological factors and changes in the broader political economy. I showed that although highland farmers may still be relatively advantaged over their lowland counterparts, the decline of highland production systems and the increasing exploitation of water sources 
for irrigation in the lowlands where there is relatively more land may be changing power relations in favor of more cooperation for mutual benefit along the ecological gradient of Mt Kilimanjaro.

Thirdly, livelihood groups are exploiting opportunities brought about by changing social relations to strengthen their livelihood systems and renegotiate access and control of available resources. In chapter four, I examined the changes made by different livelihood groups along the Mt Kilimanjaro gradient in response to changing ecological and politico-economic changes. I found evidence of increased diversification across the gradient in terms of farming systems, crops farmed, and access to alternative livelihood sources outside of the primary household farm or farming in general. I also found evidence of the intensification of interdependence and the existence of institutions that regulate these changing patterns of local interactions. In addition, I found that it is becoming increasingly difficult to determine which livelihoods rely primarily on natural capital in rural African drylands because the impacts of increased climate variability and the increased integration into the global capitalist economy has resulted in increasingly diversified livelihoods in these areas over time. Many farmers and herders reported increased reliance on social networks, casual labor, non-farm labor and other sources, and alternative sources such as remittances as primary sources of income. Bellow, I summarize the key findings for each of the three areas investigated in this dissertation.

\section{Summary of the Key Findings of this Dissertation}

On Causality: The first paper (chapter 2) examines the relationship between climate and conflict and is guided by the following questions: one, why are simplistic, environmentally deterministic approaches to the climate-conflict nexus so pervasive in 
press, policy, and academic circles even when critical and empirical research shows that the relationship is much more complex? Two, what are the potential pitfalls of some recent quantitative studies that have aided the recent policy push? For the first question, I find that this discourse is sustained by the national interest of the global north that prioritizes the governing of subjects in the global south so that their responses to climate change do not threaten the security of the citizens and the states in the global north. Consequently, the policies that this discourse produces do not address the root causes of poverty that make individuals and groups in the global south vulnerable to climate change, rather, they address the security concerns of the impacts of climate change for the global north. I therefore find the human security discourse not pro-poor. On the second question, I find the generalization of all types of conflict without the explanation of conflict typology, scale, grievances, and other key factors that influence conflict too convenient in advancing a discourse on the potential causal relationship between conflict and climate change. In addition, the conflation of violence and conflict leads to misleading conclusions about conflict distribution and ignores many subtle conflicts that are resolved peacefully or never turn violent.

On informal land transfers: The second paper (chapter 3) examines changing land relations in Africa with a focus on how informal land transfers may help circumvent protections for disenfranchised groups in formal policy and law. This situation of rampant informal trade in land, I argue, is produced by the existence of a dual, often inconsistent, and sometimes opposing sets of law in many African countries. I ask whether the ambiguity of rights within customary tenure offers any advantage to disenfranchised groups such as women and the youth especially in places where land, 
whether under customary or statutory law, is already held as private property and is in high market demand. I find that the failure of policy and law to recognize that there are many areas where land is held privately without title facilitates the thriving system of land exchanges that may not be governed by customary of statutory law and policy. Even in places where land is titled and is in high demand, informal transfers are prevalent but there exists not policy guidelines to track these exchanges and make sure they do not disempower certain groups. This means that privately held land could change hands many times before it is titled and the last person to acquire title cements all the previous processes as legitimate sales. Without the formal title that legally legitimizes ownership, these informal transfers may continue to cause conflicts over land although most of these conflicts may be of a smaller scale such as between households or individuals.

On livelihood diversification and interdependence: The third paper (chapter 4) investigates the benefits of social and material relations among individuals and groups living along the Mt Kilimanjaro altitudinal gradient. This was done through an examination of livelihood changes over time within the different ecological zones of the mountain and how these changes have affected relations among the livelihood groups living there. I found that highland livelihoods are increasingly exploiting the options provided by the neighboring lowland gradients to bolster their livelihood status while at the same time changing their livelihood systems to adjust to politico-economic and ecological changes. Lowland areas have also undergone major changes in their livelihood system and exploit their highland neighbors for livelihood diversification. In all, I found that contact has increased between different livelihood groups in the last fifteen years. As discussed earlier, this increased contact offers opportunities for livelihood diversification 
and may also result in increased conflict. In addition, the international boundary offers important diversification options such as trade for both highland lowland livelihoods. Due to the difference in production systems in Kenya and Tanzania, many goods are traded across the unregulated border.

\section{Shortcomings of this research}

I have argued and explained my research methods, results, and findings in this dissertation but this was not achieved was not without challenges. The first major challenge was that I was unable to travel to the research site within the period of my dissertation writing due to funding and other personal issues. However, I had access to sufficient data from the Pare-Kilimanjaro Local Knowledge and Climate Change Adaptation project (LKCCAP) in which I participated in data collection in the summer of 2010. LKCCAP was a National Science Foundation (NSF) funded international research project with researchers from the United States and Tanzania, which ran from 2009 to 2015. The research examined human-environment dynamics and local climate adaptation patterns in the Kilimanjaro region. I participated in research workshops and data collection exercises in Tanzania and ran the entire data collection exercise in the Kenyan side of the Kilimanjaro gradient.

The other major challenge was my positionality during the data collection exercise in Kenya in 2010. This was mainly because as a Kamba man, I belong to one of the dominant groups in Njukini whose claim to the land they hold is highly contested by the Maasai and the Taveta community groups. This was complicated by the fact that even within the Akamba speakers in this region, I was still considered an outsider because I come from the larger Ukambani region of Kenya while most Kamba inhabitants of this 
area had migrated from Tanzania in the 1960 and 1970s. The Akamba of Njukini thus consider themselves of a different identity from other Akamba people from the larger Ukambani region. I therefore had to explain myself to each community group because of the suspicion of bias towards the Akamba and also the perception by the Akamba of this region that I was different from them although we spoke the same ethnic language. I overcame this by first hiring two research assistants from the Taveta and the Taita ethnic groups, spent three weeks in the research site familiarizing myself with the people, the issues, and the place, and explained myself during every interview I went.

A third challenge was that as a scholar from Kenya studying in America about local issues that were of immediate concern to my research participants, I was perceived to have some level influence on future government policy. Many research participants therefore requested me to speak to government officials about their plight while others confronted me to explain why the government was not addressing their concerns especially about land allocation and titling. I responded to this challenge by explaining to my research participants and audiences that the research I was conducting was purely academic and although I could publish it to journals and the Internet where government and other officials could access it, I could not guarantee that they actually read or act on it. More importantly I empathized with their problems and sought to create friendships, which helped me build trust. This relationship of trust made the process of data collection much easier. These were just a few of many challenges during my research. Other challenges included my gender as a man seeking information from women about issues with their access to local resources and different research participants interpreted that differently. In all, this was a learning opportunity for me. 


\section{Recommendations for future research}

Land conflicts have been a major focus for research on livelihoods and resource allocation in Africa and other parts of the developing world for many decades. However, little attention has been given to the process and outcome of conflict in shaping grievances and influencing whether conflicts recur or not. In my post-graduation career either as an assistant professor or researcher, I would like to conduct research that critically examines the role of local institutions in mediating land conflicts, the positive and negative outcomes of local land conflicts for conflict groups and mediating institutions, and how ecological and sociopolitical changes may affect future trends in land and natural resource conflicts in particular areas. My interest in studying land conflict is driven by my findings in this dissertation of the importance of institutions in mediating or even sanctioning conflict. I would like to understand why and how some groups are able to form functional institutions to prevent conflict while other groups don't. I would also like to understand why conflicts occur or recur in some places with mediating institutions and not in others. Qualitative evidence such as data on social organization and resource governance, local perceptions of identity, local perceptions on the processes and outcomes of past and current conflicts, and anecdotes on sociopolitical and ecological changes will be utilized. More flexibility in terms of funding sources will allow me to travel more and spent more time in field in order to collect data and learn local practices that drive local social relations. My studies will document the process and outcomes of conflict and seek to identify any evidence as to: a) what locally specific conditions underlie conflict in the study area, b) what processes influence whether 
conflicts escalate to broad violence and c) the positive and negative outcome of local institutional mediation of conflict.

\section{Conclusion}

In conclusion, the process of research and writing this dissertation has helped me learn invaluable lessons about the relationships that exist between climate impacts, conflict, and local resource access dynamics. As stated elsewhere in this dissertation, these relationships are complex and sometimes contradictory and therefore the pursuit of narrow causations in order to prove a causal relationship among them may oversimplify and distort our understanding of the relationship. More importantly, I have a clearer understanding of how the complex web of interests and power dynamics that characterize social relations in different places at different times influence who gains benefits and who loses out from certain resources. In places where climate impacts will be felt the most and in which conflicts are common, it is important for researchers to investigate which types of conflict may be more related to changes in climate and which ones are more related to local historical and sociopolitical factors.

Recent research on the relationship between climate and conflict indicate that local resource conflicts are likely to be associated with variations in resource access due to both biophysical and economic changes (Scheffran et al. 2012a). In my study area, I found that local conflicts may be influenced by intensification of contact necessitated by the need for diversification in response to both climatic and socioeconomic change. As local communities diversify their livelihoods, new alliances are developed, and new groupings based on interests form. However, these new relations reflect a historical pattern of relations among the groups that live here suggesting that the historical context 
cannot be overlooked in investigating contemporary social relations. A challenge therefore for many quantitative studies is to make sure that they consider qualitative factors such as changing power dynamics among individuals and groups, and the historical context of any particular context. 


\section{REFERENCES}

Abbott, R. J., Brennan, A. C. 2014. Altitudinal Gradients, plant hybrid zones and evolutionary novelty. Philosophical Transactions of the Royal Society of London, 369(1648).

Adano, W. R., Dietz, T., Witsenburg, K., Zaal, F. 2012. Climate change, violent conflict and local institutions in Kenya's drylands. Journal of Peace Research, 49: 65-80.

Amir, S. 1976. Unequal development: An essay on the social formations of peripheral capitalism. Hassocks: Harvester Press.

Arnell, N. W., Lowe, J. A., Brown, S., Gosling, S. N., Gottschalk, P., Hinkel, J., Warren, R. F. 2013. A global assessment of the effects of climate policy on the impacts of climate change. Nature Climate Change, 3(5): 512-519.

Barnett, J., Adger, N. 2007. Climate change, human security and violent conflict. Political Geography, 26:639-655.

Basset, T. 1988. The political ecology of peasant-herder conflicts in the Northern Ivory Coast. Annals of Association of American Geographers, 78:651-660.

Benjaminsen, T. A., Alinon, K., Buhaug, H., Buseth, J. T. 2012. Does climate change drive land-use conflicts in the Sahel? Journal of Peace Research, 49: 97-111.

Bernauer, T., Böhmelt, T., Koubi, V. 2012. Environmental changes and violent conflict. Environmental Research Letters, 7.

Bernstein, H. 2010. Class Dynamics of Agrarian Change. Fernwood, Pluto.

Berry, S. 1993. No condition is permanent: The social dynamics of agrarian change in Sub-Saharan Africa. Ann Arbor: University of Wisconsin Press.

Berry, S. 2002. Debating the land question in Africa. Comparative Studies in Society and History, 44(4): 638-668.

Bohlken, A. T., Sergenti, E. J. 2010. Economic growth and ethnic violence: An empirical investigation of Hindu-Muslim riots in India. Journal of peace, 45(5): 1-12.

Brass, T. 2001. Class, culture, and the agrarian myth. Leiden: Brill Academic Publishers.

Bruce, J. W., Mogot-Adhola, S. E. 1994. Searching for land tenure security in Africa. Debuque: Kendall/Hunt Publishing Company.

Brown, H. C. P., Smit, B., Somorin, O. A., Sonwa, D. J., Ngana, F. 2013. Institutional perceptions, adaptive capacity and climate change response in a post- 
conflict country: A case study from central african republic. Climate and Development, 5(3), 206-216.

Brown, S., Sriram, C. 2012. The big fish won't fry themselves: Criminal accountability for post-election violencein Kenya. African Affairs, 00/00, 1-17.

Bruckner, M., Ciccone, A. 2011. Rain and the democratic window of opportunity. Econometrica, 79(3): 923-947.

Buckley, B., Anchukaitis, K., Penny, D., Fletcher, R., Cook, E., Sano, M., Nam, L., Wichienkeeo, A., Minh, T., Hong, T. 2010. Climate as a contributing factor in the demise of Angkor, Cambodia. Proceedings in the National Academy of Science, 107(15): 6748-6752.

Buhaug, H. 2010. Climate not to blame for Africa's civil wars. Proceedings of the National Academy of Science, 107(38): 16477-16482.

Burke, P. 2012. Economic growth and political survival. The B.E. Journal of microeconomics, 12(1): 1-41.

Burke, P., Miguel, E., Satyanath, S., Dykema, J., Lobel, D. 2009. Warming increases the risk of civil war in Africa. Proceedings in the National Academy of Science, 106(49): 20670-20674.

Butler, C. K., Gates, S. 2012. African range wars: Climate, conflict, and property rights. Journal of Peace Research, 49(1): 23-34.

Butzer, K.W. 2012. Collapse, environment, and society. Proceedings in the National Academy of Science, 109(10): 3632-3639.

Campbell, D. 2009. Response to drought among farmers and herders in Southern Kajiado District, Kenya. Human Ecology, 12(1): 35-64.

Card, D., Dahl, G. 2011. Family violence and football: The effect of unexpected emotional cues on violent behavior. The quarterly journal of economics, 126: 103143.

Cervellati, M., Sunde, U., VAlmori, S. 2011. Disease environment and civil conflicts. IZA Discussion Paper No. 5614.

Chanock, M. 1991. "Paradigms, Policies and Property: A Review of the Customary Law of Land Tenure," K. Mann and R. Roberts (eds.), Law in Colonial Africa. Portsmouth, NH: Heinemann, 61-84.

CIPEV, 2008. Commission of Inquiry into the Post-Election Violence report. https://www.ictj.org/sites/default/files/ICTJ-Kenya-Dialogue-Inquiry-2008- 
English.pdf. Accessed: 04/15/2015.

Colin, J.P. 2013. Securing rural land transactions in Africa: an Ivorian perspective. Land Use Policy, 31: 430-440.

Daley, E. and Hobley, M. 2005. Land: Changing contexts, changing relationships, changing rights. Urban rural change, DFID, 1:1-58.

Das, V., Keinman, A., Ramphele, M., Raynolds, P. 2000. Violence as subjectivity. Los Angeles: University of California Press.

Dell, M., Jones, B., Olken, B. 2012. Temperature shocks and economic growth: Evidence from the last half century. American Economic Journal: Macroeconomics, 4(3): 66-95.

De Soto, H. 2000. The Mystery of capital: why capitalism triumphs in the West and fails everywhere else. New York: Basic Books.

Doty, B. 1995. The grid analysis and display system. GRADS Manual 10:148.

Dumont, J. 1992. Ideas on Philippine violence: Assertions, Negations, and Narrations. In The paths to domination, resistance and terror, edited by $\mathrm{C}$. Nordstrom and J. Martin. Berkeley: University of California Press.

Elis, E., Swift, D. 1988. Stability for African pastoral ecosystems: alternate paradigms and implications for development. Journal of Range Management, 41(6): 450-459.

Ellis S, ter Haar G. 2004. Worlds of power: religious thought and political practice in Africa. London: Hurst \& Co..

Eriksen, S., Lind, J. 2009. Adaptation as a political process: Adjusting to drought and conflict in Kenya's drylands. Environmental Management, 43(5): 817-835.

Fisher, S., Ludin, J., Abdi, D. I., Smith, R., Williams, S., Williams, S. 2000. Working with conflict: Skills \& strategies for action. London: Zed Books.

Fjelde, H. Uexkul, N. 2012. Climate triggers: Rainfall anomalies, vulnerability and communal conflict in Sub-Saharan. Political geography, 31: 444-453.

Fukuyama, F. 2004. The imperative of state-building. Journal of Democracy, 15(2): 1731.

Füssel, H. M. 2011. How inequitable is the global distribution of responsibility, capability, and vulnerability to climate change: A comprehensive indicator-based assessment. Global Environmental Change, 20: 597-611. 
Gleditsch, N. P. 2012. Whither the weather? Climate change and conflict. Journal of Peace Research, 49: 3-9.

Goodhand, J. 2001. Violent conflict, poverty and chronic poverty. CPRC Working Paper 6. Chronic Poverty Research Centre, Manchester, UK.

Grimm, E. and Lesorogol C. (2012) The Impact of Land Privatization on Cooperation in Communal Farm Labor in Kenya. Human Ecology, 40:69-79.

Harper, D. W. 2012. Violence: Do we know it when we see it? Durham: Carolina Academic Press.

Hendrix, C., Glasser, S. 2007. Trends and triggers: Climate, climate change and civil conflict in Sub-Saharan Africa. Political Geography, 26: 695-715.

Hendrix, C. S., Salehyan, I. 2012. Climate change, rainfall, and social conflict in Africa. Journal of Peace Research, 49: 35-50.

Herod, A., Wright, M. 2002. Geographies of power: Placing scale. Malden: Blackwell Publishing Company.

Homer-Dixon, T. 1994. Environmental scarcities and violent conflict: Evidence from cases. International security, 19(1): 5-40.

Homewood, K. 2009. In Staying Maasai? Livelihoods, Conservation and Development in East African Rangelands, ed. Homewood K, Kristjanson P, Chenevix Trench P, 335-368. New York: Springer.

Homewood, K, Kristjanson, P, and Trench, P (2009) Staying Maasai? Livelihoods, conservation and development in East African rangelands. New York: Springer.

Kenya National Beural of Statistics (KNBS). 2010.

http://www.knbs.or.ke/index.php?option=com_phocadownload\&view=category\&id $=100 \&$ Itemid $=1176$ Date accessed: 07/09/2015.

Homewood, K., Lambin, E., Coast, E., Kariuki, A., Kikula, I., Kivelia, J., Said, M., Serneels, S., Thompson, M. 2001. Long-term changes in Serengeti-Mara wildebeest and land cover: pastoralism, population, or policies? Proceedings in the National Academy of Science, 98(22): 12544-12549.

Hsiang, S. M., Meng, K. C., Cane, M. A. 2011. Civil conflicts are associated with the global climate. Nature, 476: 438-441.

Hsiang, S., and Burke, M. 2014. Climate, conflict, and social stability: what does the evidence say? Climatic change, 123: 39-55. 
Hsiang, S. M., Burke, M., Miguel, E. 2013. Quantifying the influence of climate on human conflict. Science, 341(6151).

IPCC, 2014: Climate Change 2014: Impacts, Adaptation, and Vulnerability. Contribution of Working Group II to the Fifth Assessment Report of the Intergovernmental Panel on Climate Change. Cambridge: Cambridge University Press.

IPCC (Intergovernmental Panel on Climate Change) (2007) Climate change 2007: Synthesis report. A Contribution of working groups I, II, and III of the Intergovernmental Panel on Climate Change. Cambridge: Cambridge University Press.

IREC (The Independent Review Commission). 2008. The 2007 elections in Kenya: Independent review commission (IREC) report. http://reliefweb.int/sites/reliefweb.int/files/resources/BDC847C443DC8528852574 F100699936-Full Report.pdf. Accessed: 04/18/2015.

Jackson, P. 1989. Maps of meaning: an introduction to cultural geography. London: Unwin Hyman.

Joireman, S. F. 2008. The mystery of capital formation in Sub-Saharan Africa: Women, property rights and customary law. World Development, 36(7): 1233-1246.

Kagwanja, P. 2009. Courting genocide: Populism, ethno-nationalism and the informalisation of violence in Kenya's 2008 post-election crisis. Journal of Contemporary African Studies, 27(3):365-387.

Kalnay, E., Kanamitsu, M., Kistler, R., Collins, W., Deaven, D., Gandin, L., Iredell, M., Saha, S., White, G., Woollen, J., Zhu, Y., Leetmaa, A., Reynolds, R., Chelliah, M., Ebisuzaki, W., Higgins, W., Janowiak, J., Mo, K. C., Ropelewski, C., Wang, J., Roy, J., and Joseph, D., 1996. The NCEP/NCAR 40-Year Reanalysis Project. Bull. Amer. Meteor. Soc., 77, 437-471.

Kalyvas, S. 2006. The logic of violence in civil war. New York: Cambridge University Press.

Kaplan, C., Alarcon, N., and Moallem, M. 1999. Between woman and nation: Nationalisms transnational feminisms, and the state. Duke University Press, Durham.

Kaplan, R. 1994. The coming of anarchy: How scarcity, crime, overpopulation, tribalism, and disease are rapidly destroying the social fabric of our society. The Atlantic Monthly, 273(2): 44-76. 
Kenya National Beural of Statistics (KNBS). 2010.

http://www.knbs.or.ke/index.php?option=com phocadownload\&view=category\&id $=100 \&$ Itemid=1176 Date Accessed: 07/02/2015.

Lee, E., Chase, T., Rajagopalan, B., Biggs, T., Barry, R., and Lawrence, P. 2009. Effects of irrigation and vegetation activity on early Indian summer monsoon variability. International Journal of Climatology, 29:573-581.

Lesorogol, C., Chowa, G., and Ansong, D. 2013. The roles of livestock inheritance and formal education in intergenerational wealth transmission among pastoralists in Samburu District, Kenya. Journal of Developing Societies, 29(2): 215-234.

Lesorogol, C. 2008. Contesting the Commons: Privatizing Pastoral Lands in Kenya. Ann Arbor: University of Michigan Press.

Lesorogol, C. 2005. Privatizing pastoral lands: Economic and normative outcomes in Kenya. World Development, 33(11):1959-1978.

Majule, A., Mbonile, M., Campbell, D. 2009. Ecological gradients as a framework for analysis of land-use change in East Africa. African Journal of Ecology, 47(1): 5661.

Mamdani, M. 1996. Citizen and subject: Contemporary Africa and the legacy of late colonialism. Princeton: Princeton University Press.

Mares, D. 2013. Climate and levels of violence in socially disadvantaged neighborhood groups. Journal of urban health: Bulletin of the New York academy of medicine, 90(4): 768-783.

Marx, K. 1977. A contribution to the critique of political economy. Moscow: Progress Publishers.

Mbonile, J. 2003. Land use change pattern and root causes on the slope of mount Kilimanjaro, Tanzania. LUCID Working Paper 25, International Livestock Research Institute, Nairobi.

Menzen-Dick, R. and Mwangi, E. 2008. Cutting the web of interests: Pitfalls of formalizing property rights. Land Use Policy, 26: 36-43.

Mitchell, D. 2000. Cultural geography: A critical introduction. Oxford: Blackwell Publishers Ltd.

Mitchell, T.D., R.C. Timothy, D.J. Philip, H. Mike, and N. Mark, 2004. A comprehensive set of climate scenarios for Europe and the globe. Tyndall Centre Working Paper, 55 . 
Mueller, s. 2012. Dying to win: Elections, political violence, and institutional decay in Kenya. Journal of Contemporary African Studies, 29(1): 99-117.

Murshed, S. M., Tadjoeddin, M. Z. 2009. Revisiting the greed and grievance explanations for violent internal conflict. Journal of International Development, 21: 87-111.

Mutai, C., Hastenrath, N. and Polzin, D. 2011. Circulation mechanisms of Kenya rainfall anomalies. Journal of Climate, 24:404-412.

Mwangi, E. 2007. Subdividing the commons: Distributional conflict in the transition from collective to individual property rights in Kenya's Maasailand. World Development, 35(5): 815-834.

Mworia, K., Kinyamario, J. 2008. Traditional strategies used by pastoralists to cope with la nina induced drought in Kajiado, Kenya. African Journal of Environmental Science and Technology, 2(10): 10-14.

Nordas, R., Gleditsch, N. 2007. Climate change and conflict. Political Geography, 26:627-638.

Nordstrom, C., Robben, C. G. M. 1995. Fieldwork under fire: Contemporary studies of violence and survival. Berkeley: University of California Press.

Obama, B. 2014. Remarks by the President at the United States military academy commencement ceremony. Office of the Press Secretary, The White house. Date accessed: 01/14/2015.

O’Loughlin, J., Witmer, F., Linke, A., Laing, A., Gettelman, A., Dudhia, J. 2012. Climate variability and conflict risk in East Africa, 1990-2009. Proceedings of the National Academy of Sciences, 109(45): 18344-18349.

Oels, A. 2012. From 'securitization' of climate change to 'climatization ' of the security field: Comparing three theoretical perspectives. In J. Scheffran et al. (eds.), Climate Change, Human Security and Violent Conflict, Hexagon Series on Human and Environmental Security and Peace 8: 185- 205.

O’Brien, K. and Leichenko, R. 2003. Winners and losers in the context of global change. Annals of the Association of American Geographers, 93(1): 89-103.

Peluso, N., Watts, M. 2001. Violent Environments. Ithaca: Cornel University Press.

Peters, P. 2013. Conflicts over land and threats to customary tenure in Africa. African Affairs, 1: 1-20. 
Peters, P. 2009. Challenges in land tenure and reform in Africa: Anthropological contributions. World Development, Special Issue on The Limits of State-Led Land Reform, 37(8): 1317-1325.

Raleigh, C. and Kniveton, D. 2012. Come rain or shine: An analysis of conflict and climate variability in East Africa. Journal of Peace Research, 49: 51-64.

Rangan, H. and Kull, C. 2009. What makes ecology 'political'?: rethinking 'scale' in political ecology. Progress in Human Geography, 33(1):28-45.

Riches, D. 1986. The anthropology of violence. Malden: Blackwell Publishers.

Ribot, J. and Peluso, N. 2003. A theory of Access. Rural Sociology, 68(2): 153-181.

Robinson, James A, Daron Acemoglu, and Simon Johnson. 2005. Institutions as a Fundamental Cause of Long-Run Growth. Handbook of Economic Growth 1A: $386-472$.

Salehyan, I. 2008. From climate change to conflict? No consensus yet. Journal of Peace Research, 45: 315-326.

Samson, J., Berteaux, D., Mcgill, B. J., \& Humphries, M. M. 2011. Geographic disparities and moral hazards in the predicted impacts of climate change on human populations. Global Ecology and Biogeography, 20, 532-544.

Santos, F., \& Fletschner, D. 2014. Enhancing Inclusiveness of Rwanda's Land Tenure Regularization Program: Insights from Early Stages of its Implementation. World Development, 62, 30-41.

Sarkees, M. R., and Wayman, F. W. 2010. Resort to war: a data guide to inter-state, extra-state, intra-state, and non-state wars, 1816-2007. Washington, D.C.: CQ Press.

Satapathy, S. S., Swain, D. K., Herath, S. 2014. Field experiments and simulation to evaluate rice cultivar adaptation to elevated carbon dioxide and temperature in subtropical India. European Journal of Agronomy, 54: 21-33.

Scheffran, J., Brzoska, M., Kominek, J., Link, M., Schilling, J. 2012a. Climate change and violent conflict. Science, 336: 869-871.

Scheffran, J., Brzoska, M., Kominek, J., Link, P.M., Schilling, J. 2012b. Dissentangling the climate-conflict nexus: Empirical and theoretical assessment of vulnerabilities and pathways. Review of European Studies, 4(5): 1-13.

Schroeder, R. 1999. Shady Practices: Agroforestry and Gender Politics in The Gambia. Berkeley: University of California Press. 
Scoones, I. 2009. Livelihoods perspectives and rural development. The Journal of Peasant Studies, 36(1): 171-196.

Shongwe, M., van Oldenborg, G., Hurk, B., van Aalst, M. 2011. Projected changes in mean and extreme precipitation in Africa under global warming. Part II: East Africa. Journal of Climate, 24: 3718-3733.

Schwartz, P., Randal, D. 2003. An abrupt climate change scenario and its implications for United States national security. Washington D.C.: Environmental media services.

Sjaastad, E. and Cousins, B. 2008. Formalization of rights in the South: An overview. Land Use Policy, 26: 1-9.

Sikor, T., Lund, C. 2009. Access and property: A question of power and authority. Development and Change, 40(1): 1-22.

Singh, P., Nedumaran, S., Boote, K. J., Gaur, P. M., Srinivas, K., Bantilan, M. C. S. 2014. Climate change impacts and potential benefits of drought and heat tolerance in chickpea in south Asia and East Africa. European Journal of Agronomy, 52: 123-137.

Sletto, B. 2011. Conservation planning, boundary-making and border terrains: The desire for forest and order in the Gran Sabana, Venezuela. Geoforum, 42 (2) (March): 197-210.

Smucker, T., Wisner, B., Mascarenhas, A., Munishi, P., Wangui, E., Sinha, G., Weiner, D., Bwege, C., Lovell, E. 2015. Differentiated livelihoods, local institutions, and the adaptation imperative: Assessing climate change adaptation policy in Tanzania. Geoforum, 59:39-50.

Smucker, T. and Wisner, B. 2008. "Changing Household Responses to Drought in Tharaka, Kenya: Vulnerability, Persistence, and Challenge”. Disasters, 32(2): 190-215.

Soini E. 2005. Land use change patterns and livelihood dynamics on the slopes of Mt. Kilimanjaro, Tanzania Agricultural Systems, 85:306-323.

Southall, R. 2005. The Ndung'u report: land and graft in Kenya. Review of African Political Economy 103:142-151.

Stern, N. 2007. The economics of climate change: The Stern review. Cambridge University Press, Cambridge. 
Stiglitz, J., Sen, A., and Fitoussi, J. 2013. Measuring our lives: Why GDP doesn't add up. New York: The New Press.

Theisen, O. M. 2012. Climate clashes? Weather variability, land pressure, and organized violence in Kenya, 1989-2004. Journal of Peace Research, 49: 81-96.

The Land Act 2012

http://www.cickenya.org/index.php/legislation/acts/item/233-the-land-act2012\#.VZWZnecqUV8 Date Accessed: 07/02/2015.

Tiffen, M., Mortimore, M. 2008. Environment, population growth and productivity in Kenya: A case study of Machos District. Development policy Review, 10(4): 359-387.

Toulmin, C. 2008. Securing land and property rights in sub-Saharan Africa: The role of local institutions. Land Use Policy, 26: 10-19.

Turner, M. 2004. Political ecology and the moral dimensions of "resource conflicts": The case of farmer-herder conflicts in the Sahel. Political Geography, 23: 863-889.

Wangui, E. E., Smucker, T., Wisner, B., Lovell, E., Mascarenhas, A., Solomon, M., Weiner, D., Munna, A., Sinha, G., Bwenge, C., Meena, H., and Munishi, P. 2012. Integrated Development, Risk Management and Community-Based Climate Change Adaptation in a Mountain-Plains System in Northern Tanzania. Journal of Alpine Research, 100(1).

Watts, M., Bohle, G. 1993. The space of vulnerability: the causal structure of hunger and famine. Progress in Human Geography, 17: 43-67.

Watts, M. 1983. Silent Violence: Food, Famine and Peasantry in Northern Nigeria. Berkeley: University of California Press.

WBGU (German Advisory Council on Global Change). 2008. World in Transition: climate change as security risk. London: Earthscan.

Wisner, B. 2004. At risk: Natural hazards, people's vulnerability and disasters, $2^{\text {nd }}$ edition. New York: Routledge.

Woodhouse, P. 2003. African enclosures: a default mode of development. World Development, 31(10): 1705-1720.

Woodhouse, P., Bernstein, H., and Hulme, D. 2000. African enclosures? The social dynamics of wetlands in drylands. Oxford: James Currey.

Zimmerer, K. and Basset, T. 2003. Political ecology: An intergrative approach to geography and environment-development studies. New York: Guilford. 